\title{
DIE ATLI-LIEDER DER EDDA.
}

Die vorliegende abhandlung soll zur lösung einiger fragen beitragen, die sich an die Atli-lieder der Edda knüpfen. Diese fragen zerlegen sich in zwei gruppen: die eine behandelt die lieder als literarische producte, die andere als sagengeschichtliche denkmäler. Demnach wird sich diese arbeit aus einem literarischen und einem sagengeschichtlichen teil zusammensetzen.

\section{Literarischer teil.}

1. Vorfrage.

Ehe wir an irgend eine vergleichung der lieder gehen können, ist eine vorfrage zu erledigen: ist jedes der lieder ein einheitliches ganze, oder finden sich spuren von überarbeitung, zusammensetzung oder dergleichen?

\$1. Bei den Atlamól (Am.) ist kein grund vorhanden, an der einheitlichkeit des gedichtes zu zweifeln: metrisch, stilistisch, inhaltlich ist dasselbe geschlossen, von wenigen kleinen interpolationen abgesehen, die auf den charakter des ganzen keinen einfluss geübt haben.

Als solche sind wegen ihres störenden charakters sicher anzusehen Am. 48,5.6 (die zählung der strophen ist die von Symons' ausgabe) und 49,3.4. 48,5.6 (svá 7cvópbo Niflunga, mepan sjalfer litbo) ist schon von Grundtvig für unecht erklärt worden, ebenso von Symons, der den ersten halbvers für metrisch auffallend erklärt (ausgabe s. 449); die zeile stört inhaltlich nach Gering (übersetzung s. 274, n.2), da die beiden Niflunge nicht im kampf fallen; ausserdem ist die ausdrucksweise svá $k v \not \not b o$... mitten in der lebhaften schilderung ganz störend. - Durch die ebenfalls von Grundtvig und Symons für unecht Beiträge zur geschichte der deutschen sprache. $\mathrm{XXXIJI.}$ 
erklärte zeile 49,3.4 (ótto alla ok gndurpan dag) wird die chronologie des ganzen gestört: wir müssen einen sprung von mipjan dag (vorhergehende zeile) zu ótto, morgendämmerung, und ondurpan dag, anfang des folgenden tags, machen, und da nach Am. 63. 64 widerum am morgen Atli über den tod der helden triumphiert, so geraten wir bis in den anfang des dritten tages, während. zur ausfüllung dieser zeiträume die ereignisse viel $\mathrm{zu}$ schnell folgen (vgl. Grundtvig, citiert bei Bugge, Fornkvaedti 435). Dagegen ist nach streichung der zeile die zeitfolge einfach, indem der kampf bis zur mitte des tages dauert, am nachmittag die helden gefangen genommen werden und am nächsten morgen tot sind. - Bei den übrigen von Grundtvig, F.Jónsson, Symons beanstandeten versen möchte ich die frage nach der echtheit offen lassen.

Abgesehen von solchen kleinen interpolationen ist das gedicht durchaus als einheitliches werk eines dichters anzusehen.

$\$$ 2. Schwieriger ist die frage bei der Atlakvipa (Akv.) zu beantworten, da sich hier neben dem herschenden málaháttrversmass eine menge viersilbiger halbverse findet. ${ }^{1}$ ) Hier stehen sich vor allem zwei ansichten gegenüber. Bugge (Arkiv 1, 12, ähnlich Zs. fdph. 7, 386) hat vermutet, dass ältere liedzeilen teils unverändert, teils umgearbeitet von einem jüngeren verfasser in seine dichtung herübergenommen seien; er sieht dabei die viersilbigen teile in der regel als die älteren an. Symons (ausgabe s. 422) siebt dagegen die málaháttrpartien für das ältere an und weist den fornyroislag-text in Akv. einem überarbeiter zu.

Fassen wir zunächst die viersilbigen verse näher ins auge. Während manche vereinzelt auftreten, stehen sie an einigen stellen dicht gedrängt, sodass es scheint, als könnten wir ganze strophenteile oder gar strophen im fornyrðislag erkennen.

1) In Symons' text, der im allgemeinen dieser arbeit zu grunde gelegt ist, finden sich unter den 348 halbversen der Akv. 66 viersilbler $=19$ proc. Symons' abweichungen von $R$ sind in diesen füllen gering; sechsmal beziehen sie sich rein auf die schreibung; dazu kommt 19, 3 vin Borgunda statt vinir R, 20,5 svá skal frékn verjask statt svá skal frékn $\mathrm{R}$; auf der andern seite hat $R$ im gegensatz zu Symons 3 viersilbler: 29, 1 Rin skal rába, 29, 3 svinn áskunna, 40,4 olreifa tvá. 


$$
\begin{aligned}
& \text { str. } 21 \text { frógo fróknan, ef fjọr vilde } \\
& \text { Gotna pjópann golle kaupa. } \\
& \text { str. } 24 \text { hér hefk hjarta Hjalla ens blaupa, } \\
& \text { óglíkt hjarta Hogna ens frókna. } \\
& \text { es mjqk bifask - - } \\
& \text { str. } 26 \text { hér hefk hjarta HQ̣na ens frókna } \\
& \text { óglikt hjarta Hjalla ens blaupa } \\
& \text { es litt bifask - - }
\end{aligned}
$$

Str. 33 und 34, beide mit ausnahme ihrer schlüsse ebenfalls streng viersilbig, mögen später behandelt werden. Hier kommt noch in betracht die schlussstrophe, 46:

$$
\begin{aligned}
& \text { brúpr i brynjo brǿpra at hefna, } \\
& \text { hón hefr priggja pjópkonunga } \\
& \text { banorp boret bjort, ápr sylte. }
\end{aligned}
$$

Schon das dasein dieser strophenteile und strophen legt den gedanken nahe, dass ein teil des vorliegenden textes der Akv. nicht vom verfasser der hauptmasse des gedichts herrührt. Das auftreten einzelner eingestreuter viersilbler im málaháttr hat nichts auffälliges; sie kommen sogar in Am. gelegentlich vor $(61,5.84,7.8)$ : aber es ist doch unwahrscheinlich, dass ein dichter, der sonst in málaháttr-strophen dichtete, ganze strophen im fornyroislag dazwischen gesetzt hätte.

Ich habe vorhin nur solche teile zusammengestellt, die die strenge technik des viersilblers zeigen (bez. durch elision gewinnen). Da aber das fornyrðislag in der älteren zeit keineswegs immer streng viersilbig auftritt, so wird noch anderes hierher zu rechnen sein. Zunächst str. 19 und 20,1.2:

$$
\begin{aligned}
& \text { fengo peir Gunnar ok i fjotor setto, } \\
& \text { vin Borgunda, ok bundo fastla. - } \\
& \text { Sjau hjó HQgne sverpe hrQsso. }
\end{aligned}
$$

Beachtenswert ist hier, dass Sievers, Beitr. 6, 352 in str. 19, 1 beir und 19,4 ok streicht, also die verse als viersilbig fasst. Wegen der gleichheit im metrum ist es wahrscheinlich, dass $19,1-4$ und $21,2-5$ einmal zusammen eine strophe gebildet haben, wie das Grundtvig annahm (ausgabe s. 152). - Ferner 23 und 25, 5. 6; str. 23:

\section{skóro peir hjarta Hjalla ór brjóste}

[blópogt] ok á bjóp lqgpo, [ok] bọ́ro [pat] fyr Gunnar.

25, 5. 6 [blópogt] pat á bjóp lqgpo, ok bọ́ro fyr Gumnar. 
Die durch die klammern bezeichneten vereinfachungen rühren ebenfalls von Sievers (a.a.o.) her; Symons und Gering sind ihm darin gefolgt, Gering streicht sogar das ok in 25,6.

Auch str. 27 und 28 müssen mit Sievers (a.a.o.) als fornyrdislag aufgefasst werden:

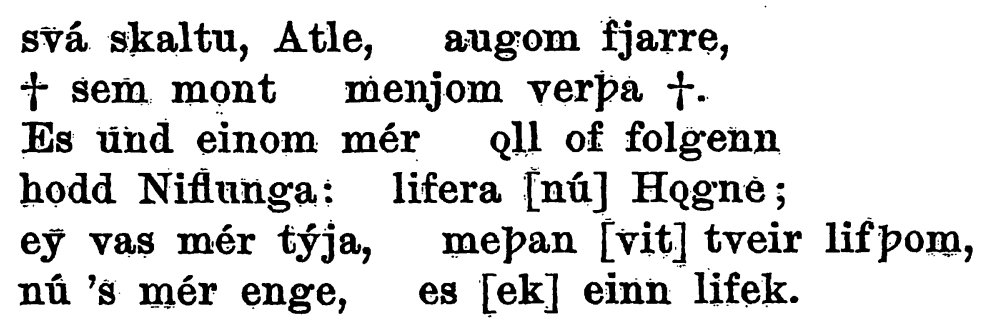

In 28, 4 ist mit Sievers nú, in 6 vit und in 8 mit Symons ek zu streichen.

$\mathrm{Zu}$ beachten ist ferner, dass str. 27 schon von F. Jónsson und Symons als unecht angesehen worden ist, und dass str. 28 von Symons als eine variante zưr málaháttr-strophe 29 angesehen wird.

Endlich gehört hierher str. 40, die auch schon von Sievers als fornyrðislăg aufgefasst worden ist:

kallara [pú] sípan til knea pínna
Erp né Eitel, olreifa traa;
séra [pú] sípan i sete mipjo
golz miplendr geira skepta,
manar meita né mara keyra.

Die in klammern geschlossenen pronomina sind von Symons gestrichen worden. - Die strophe ist von Finnur Jónsson teilweise $(40,7-10)$, von Symons ganz als unecht bezeichnet worden. Ebenso ist die vorher als fornyroislag angeführte schlussstrophe 46 von beiden gelehrten als interpolation bezeichnet worden.

Im gegensatz $z u$ der prunkvollen, oft fast überladenen sprache der málaháttr-strophen, wovon unten zu reden sein wird, zeichnen sich die fornyroislag-teile durch einfachheit im ausdruck aus. Man vergleiche einmal die inhaltlich ziemlich parallelen strophen 28 und 29 daraufhin. 28 sagt ganz schlicht: 'Bei mir ganz allein ist verborgen der Niflunge schatz: Hogni ist tot. Ich zweifelte immer, solang wir zwei lebten; nun nicht mehr, da ich allein lebe.' In 29 dagegen entfaltet der dichter die ganze pracht der skaldischen ausdrucksweise: 'Der Rhein soll walten über das kampferz der helden, der schnelle strom 
über das asenentstammte erbe der Niflunge; in rollender flut glänzen die todesringe besser als an den händen der Hunnensöhne.' Dass beide strophen innerhalb eines und desselben gedichts von demselben dichter herrühren, wird man schwerlich glauben können.

Es erhebt sich nun die frage, woher die fornyroislagstücke gekommen sind. Da ist zunächst die ansicht Bugges wenig befriedigend, nach der der verfasser des málaháttrgedichts selbst reste eines älteren gedichts in das seinige hineingearbeitet hätte. Einem autor wie dem der GuprúnarhvQt, der unbedenklich aus den Hampésmól ganze strophenteile übernommen hat (s. Ranisch, Zur kritik und metrik der Hampismál s. 19. 20), wäre ein solches verfahren zuzutrauen. Aber bei einem dichter von solcher darstellungskraft wie dem málaháttr-dichter der Akv. (s. darüber unten $\$ 12$ a) ist es nicht wahrscheinlich, dass ihm gerade an wichtigen stellen die worte ausgegangen seien und er zu fremden stroplien und zeilen seine zuflucht genommen habe. Ausserdem müssen wir die fornyrơislag-stücke nicht notwendig für älter als die málaháttrstücke halten, wie wir unten an str. 33 und 34 sehen werden.

Aber ich möchte diese teile auch nicht nur als product einer überarbeitung im fornyrðislag ansehen, wie Symons will; dazu sind sie zu fliessend und wolgebaut; vor allem aber ist dann nicht einzusehen, warum ein überarbeiter gerade nur diese strophen umgeschmolzen hätte und nicht auch die übrigen.

Als reine interpolationen können wir sie aber vollends nicht ausscheiden, denn mindestens str. 19. 21. 23. 24. 26 sind für den zusammenhang des gedichts ganz unentbehrlich.

Die letzte möglichkeit ist endlich die, dass wir zwei parallelgedichte annehmen, deren eines im málaháttr, das andere im fornyroislag abgefasst war; dass alsdann jemand aus stücken von beiden die uns vorliegende Atlakvipa zusammengesetzt habe, wobei er das málaháttr-gedicht stark bevorzugte. Auch Symons spricht von der möglichkeit eines parallelliedes, dem str. 40 entstammen könnte (ausgabe s. 433), obgleich er den gedanken an eine contamination zweier lieder für Akv. ablehnt, während er dies für Hampésmộ annimmt (einleitung der ausgabe s. Ccxxxv). 
§ 3. Die möglichkeit, dass die vorliegende Akv. aus teilen zweier verschiedener lieder zusammengesetzt sei, gewinnt an wahrscheinlichkeit, wenn wir einer dritten hand in der Akv. begegnen.

1) Die strophe 5 ist schon von Heinzel (Ueber die Hervararsaga s. $58 \mathrm{f}$.) verdächtigt worden:

voll lézk ykr ok gefa mundo víprar Gnitaheipạ,

af geire gjallanda ok af gyldom stọfnom,

stórar meipmar ok stape Danpar,

hris pat et mǽra es mepr Myrkvip kalla.

Heinzel macht auf die wörtlichen anklänge an stellen im liede von der Hunnenschlacht aufmerksam, dessen strophen sich in der Hervararsaga finden (besonders herausgegeben in den Eddica Minora von A. Heusler und W. Ranisch s. 3, str. 6 und 7):

str. 6 hafa vil ek hálft allt, pat er Heiđrekr átti,

al ok af oddi, einum skatti,

kú ok af kálfi, kvern piótandi,

pý ok af prǽli ok peira barni;

str. 7 hrís pat et mǽra, er Myrkvip heita,

stein pann enn fagra, er stendr á stǫđum Danpar.

Die in Akv. 5, 3. 4 auffallende ausdrucksweise af geire..., af gyldom stofnom ist in der Hunnenliedstrophe ganz erklärlich (af oddi, af kálfi, af práli), weil hálft allt vorhergeht (s. Heinzel s. 59). - Die stapir Danpar, die stätten, die in näherer oder fernerer beziehung zum flusse Dnjepr stehen, passen in die geschichte von einer schlacht zwischen Humnen und Goten, die einst in Russland sassen, aber nicht in die Nibelungensage (s. Bugge, Arkiv 1, 13). - Somit liegt es am nächsten, Akv. 5 als abhängig von den Hunnenliedstrophen anzusehen, nicht etwa das umgekehrte verhältnis anzunehmen.

Aber nun erhebt sich eine andere frage: ist Akv. 5 nur eine vom Hunnenlied inspirierte interpolation, oder ist etwa die strophe aus dem zusammenhang nicht zu lösen und daher die ganze Akv. abhängig vom Hunnenlied? Im letzteren fall müsste dies sehr alt sein.

Wenn ich (mit Heinzel s. 59) hier in Akv. eine interpolation annehme, so nötigt mich dazu erstens die art, wie hier im anschluss an Hunnenlied str.7 vom Myrkviðr gesprochen 
wird, was im gegensatz zu der auffassung der übrigen Akv. steht. Der Myrkviðr ist nämlich sonst (Akv.3,4. 13,4, siehe näheres in teil II) einfach die grenze zwischen Gunnars und Atlis reich, er ist also offenbar ein neutrales gebiet und nicht ein teil von Atlis land, den er verschenken könnte, wie hier angeboten wird; er heisst auch an den beiden genannten stellen der unbekannte, ist also wol ein unwirtlicher wald, und nicht ein 'herrliches gehölz' (Akv. 5, 7. Hunnenlied 7), das sich zum geschenk eignete.

Zweitens ist stilistisch auffallend der wenig geschickte anschluss von str. 5, mit indirecter rede: voll lézli gefa mundo. Indirecte rede findet sich in der ganzen übrigen Akv. nirgends, wie überhaupt in den älteren Eddaliedern fast nie (in Voluspá, prymskvipa, Vólundarkvipa nirgends, in Hampésmól 13,3 [wol verderbt s. Symons ausgabe s. 479] und 19).

Dazu kommt, dass sich in den folgenden eng mit 5 verbundenen strophen auch einiges verdächtige findet.

Strophe 6 ist die antwort auf Knefrods anpreisung der Gnitaheide in 5. Die schätze derselben, die hier im bereich Atlis gedacht ist (s. dazu in teil II \$ 27), lehnt Gunnarr ab, weil er selbst reich genug sei. Diese strophe ist von 5 nicht zu trennen und daher demselben interpolator zuzuweisen: über ihre eigentümliche tendenz wird sogleich-zu reden sein.

Strophe 7 zeichnet sich widerum stilistisch durch eine merkwürdigkeit aus: v. 5. 6.9 bringt sie in übertreibender weise drei superlative: baztan, hvassastan, hvítastan, während die ganze übrige Akv. nicht einen einzigen verwendet; dagegen finden wir gehäufte superlative bei dern späten verfasser der GuprúnarhvQt 16,5 harpast, 17,1 sárastr, 17, 5 grimmastr, 18, 1 hvassastr. Wir werden auch diese strophe, die die fortsetzung der antwort enthält, dem interpolator zuweisen können.

Wenn wir nun der tendenz von 6 und 7 nachgehen, so finden wir auch eine ganz andere stimmung als sonst in den gedichten der alten heldensagen. Sonst tragen die germanischen helden nach nichts so sehr ein naiv̌es und unverhohlenes verlangen als nach gold und schätzen ${ }^{1}$ ), hier aber ist Gunnarr so empfindlich im ehrenpunkte, dass man ihm kein gold anbieten

1) Z. b. Am. 13,5. 6 erwartet HQgni ruhig von Atli glutrotes gold. 
darf: hier hat offenbar ein späterer die 'ritterehre' der Niflunge zu steigern gesucht.

In str. 8, die Hognis antwort auf Gunnars fragen in form einer neuen frage bringt, findet sich nun ohne frage ein sehr alter sagenzug, die erwähnung des wolfshaars als warnungszeichens. Aber das alter des sagenzuges beweist noch nicht alter und echtheit der strophe. Und diese wird dadurch verdächtig, dass die strophe von etwas vergangenem erzählt, was nirgends in der übrigen erzählung der Akv., weder vorher noch nachher, an den stellen, wo man es vermuten sollte, erwähnt wird: weder wird bei Knefrođđs ankunft von der ablieferung des ringes mit dem wolfshaar gesprochen (während an der entsprechenden stelle in Am. 4, 4 deutlich gesagt wird: ápr hann fram selde), noch nimmt Guđrún bei der begrüssung str. 16. 17 beżug auf eine frühere warnung (während Am. 45 deutlich: leitapak i líkna at letja ylkr heiman).

Ferner ist der ausdruck at rippa eyrinde hier in bezug auf die Niflunge sinnlos, während er in str. 3 in bezug auf den boten Knefrọđ berechtigt war; er ist also wol gedankenlos aus 3 herübergenommen.

Endlich klingt der anfang von strophe 9 nipjarge hvotto Gunnar né noungr annarr 'keiner von den verwanten redete zu' nicht so, als wenn eben jemand abgeraten hätte, sondern als wenn eiue pause vorhergegangen wäre, in der Gunnarr auf Knefrođds einladung schwieg, und keiner der anderen ihm zuzureden wagte. Strophe 9 fiugt sich dagegen glatt an 4, wenn wir $5-8$ wegdenken.

Somit halte ich Akv. 5-8 für eine interpolation. Der interpolator mag dabei $u$. a. auch den zweck verfolgt haben, Hǫgni mehr zur geltung zu bringen, der sonst in Akv. ganz hinter Gunnarr zurücktritt und nicht ein einziges wort spricht.

Den verfasser der echten málaháttr-teile der Akv. bezeichne ich im folgenden mit $\mathbf{A}$, den der vorher behandelten fornyroislag-teile mit $B$, endlich den eben erwähnten interpolator (der sich auch einer art von málaháttr; mit eingestreuten viersilblern, bedient) mit c. ')

1) Auf die interpolation c wurde ich bei gemeinsamer lesung des textes von herrn professor Sievers freundlichst aufmerksam gemacht, der mich 
2) Als interpoliert ist nun noch einiges andere in Akv. anzusehen. Strophe 15,

En par drakk Atle

vín í valhọllo, verper sọto íte

at varpa [peim]') Gunnare, ef [peir] hans vitja kvǽme

mep geire gjallanda [at] vekja gram hilde.

enthält inhaltlich eine absurdität: die wächter Atlis warten, ob Gunnarr ihn aufsuchen werde, um mit ihm kampf zu beginnen; Atli kann das aber gar nicht von Gunnarr erwarten, denn er hat ihn ja auf das freundlichste eingeladen und nicht im entferntesten gekränkt: zu einem kriegszug kann überhaupt Gunnarr gar keinen grund haben. Diese furcht ist hier Atli untergeschoben worden, und zwar um $\mathrm{zu}$ zeigen, welchen respect die Hunnen vor den Niflungen hatten, also wider in der absicht, deren ehre zu steigern. Da ausserdem 15,6 an 5,3 wörtlich anklingt (mep geire gjallanda - af geive gjallanda), so liegt es nahe, die str.15 ebenfalls dem interpolator zuzuweisen.

In str. 17 sind die zeilen $4-7$

nár naupfolva léter norner gráta,
Húna skjaldmeyjar herve kanna,
en Atla sjalfan léter[pú] i ormgarp koma,
nú 's sá ormgarpr ykr of folgenn

von Sievers, Beitr. 6, 351 aus metrischen gründen als ursprünglich nicht in diesen zusammenhang gehörig bezeichnet worden. Ich möchte zunächst die zeilen 4 und 5 und mit ihnen die vor-

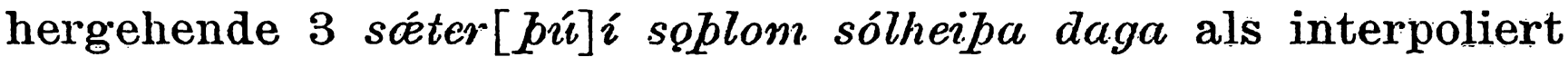
ansehen: es wird hier mit einer hypothetischen schlachtschilderung begonnen, wozu für Guđrún in diesem augenblick der höchsten gefahr, wo das schicksal ihrer brüder sich jeden augenblick entscheiden muss, gewiss kein anlass war. Der zweck der schilderung ist aber sichtlich der, Gunnars kriegstüchtigkeit hervorzuheben, seinen ruhm zu steigern.

Durch die letzte zeile der strophe wird sodann in ziemlich plumper weise die zukunft enthüllt: das finden wir zwar in

auch besonders auf die unterschiede in der tonhöhenlage von $A$ und $c$ hinwies, in welcher hinsicht sich auch zwischen A und B deutlich unterschiede wahrnehmen liessen.

1) Die klammern bezeichnen die teile, die Symons des metrums wegen tilgt. 
jüngeren heldenliedern ${ }^{1}$ ), aber sonst nirgends in der Akv. Die zeile ist auch insofern anstössig, als es der von Guđrún 16, 8 (looll gakili[bú]ór snimma!) ausgesprochenen mahnung widerspricht, dass Guđrún das schicksal der brüder schon für besiegelt erklärt. Wenn ich daher diese zeile für interpoliert ansehen muss, so ist auch die vorletzte zeile nicht zu retten, da sie von der schlusszeile inhaltlich, von der vierten zeile (... léter norner gráta) grammatisch nicht zu trennen ist (Sievers, Beitr. 6,351 , der: das léter der vorletzten zeile als widerholung des léter aus der vierten zeile streicht, da es metrisch stört).

3) Die angeführten interpolationen schlossen sich alle an A-strophen an: daneben finden sich auch einige anknüpfungen an strophen und zeilen von B. Wir mussten oben s. 195 str. 19 und 20,1.2 als fornyrðislag ansehen. Angeschlossen an 20 (sjau hijó Hogne sverpe hvosso) folgt nun mit verändertem versmass, verändertem rhythmus, und angeschlossen mit en, wie die interpolierte str. 15:

en enom átta hratt i eld heitan.
svá skal frókn verjask fiondom sínom
sem Hogne varpe hendr -

Ich halte dies widerum für eine interpolation, die in übertreibender weise Họni zu verherrlichen suclit: nachdem er sieben feinde gefällt hat, muss er noch einen achten ins feuer schleudern. Auf einen interpolator deutet ferner besonders der schluss der strophe, der in reflectierender weise auf Hǫgni als muster hinweist: etwas ähnliches findet sich in der Akv. nur noch an einer, gleichfalls sehr verdächtigen stelle (str. 34), von der sogleich zu reden sein wird.

Fassen wir weiterhin die schlüsse von str. 24 und 26 ins auge. Die ersten vier zeilen beider strophen sind in glattem und fliessendem fornyrdislag abgefasst (B). Dagegen fallen die beiden fünften zeilen im versmass (das unmöglich als fornyrdislag angesehen werden kann), vor allem aber durch die unbeholfenheit des rhythmus merklich von dem vorhergehenden $\mathrm{ab}$; sie sind aber einander sehr ähnlich:

str. 24, 9. 10 bif pesk họlfo meirr str.26,9. 10 bif pesk sváge mjok

es í brjóste lá

pás i brjóste lá

1) In Am. mehrfache hinweise auf das ende, s. dazu unten $\S 14$ a. 
Sievers, Beitr. 6, 352 hat schon auf den metrischen gegensatz dieser schlüsse zum vorhergehenden aufmerksam gemacht. Auch in diesen zeilen verrät sich die absicht, die einfache tatsache: 'es zittert sebr', 'es zittert wenig', zu steigern. Ich möchte auch diese zeilen als interpoliert ansehen; dagegen halte ich im gegensatz zu Grundtvig und Symons die anfangszeilen der beiden strophen 24 und 26: pá kvap bat Gumnarr, gumna drótten, und márr livapp pat Gunnarr, geirniflungr nicht für interpoliert, sondern für die alten anfänge dieser B-strophen.

Ich glaube nun annehmen zu dürfen, dass alle bisher angesetzten interpolationen, str. 5-8. str. 15. 17, 5--14. 20, 3-7. 24, 9. 10. 26,9. 10 von demselben überarbeiter c herrühren, hauptsächlich deshalb, weil sie alle die tendenz verraten, den ruhm der Niflunge zu steigern.

Wenn nun ein interpolator nicht allein ganze strophen eingefügt ( $5-8.15)$, sondern auch bereits vorhandene teile von A und B erweitert hat, so drängt sich von selbst der gedanke auf, dass eben dieser interpolator $c$ die alten texte $A$ und $B$ derart zusammengearbeitet haben möge, dass er strophen und strophenteile der zwei lieder zusammenschob und das ganze durch selbstverfasste strophen und zeilen abzurunden suchte. Diese annahme scheint mir die einfachste lösung des schwierigen problems zu bilden, das die gestalt der uns erhaltenen Akv. in sich trägt.

$\$$ 4. Von den bisherigen gesondert sind nocl zwei strophen zu betrachten, die schon von F. Júnsson und Symons als unecht angesehen worden sind; str. 33 und 3t:

Ok meirr papau menvorp bitols,
dolgrngine, dró til daups skókr. -
Lifanda gram lagpe i garp
panns skripeun vas, skatna menge,
innan ormom, en einn Gunnarr
heiptmópr hôrpo hende knipe;
glumpo strenger, svá skal golle
frókn hringdrife vip fira halda.

Im versmass stechen diese strophen aufs schärfste von dem vorhergehenden $a b$, während sie untereinander eng verwant sind: sie sind beide streng viersilbig, mit ausnahme ihrer letzten halbverse (33,3 ist dreisilbig, 34, 12 hat einen auf- 
takt); ferner sind rhythmisch auffallend, im gegensatz zu den B-strophen, die abgehackten halbversenden:

$$
\begin{aligned}
& \text { dolgrogne dró, } \\
& \text { til daups skókr, } \\
& \text { lifanda gram, } \\
& \text { lagpe i garp. - }
\end{aligned}
$$

Schon Bugge findet str. 34 'im höchsten grade verkünstelt' (Fornkvaeđi s. 432). Stilistisch fällt auf die unnatürliche auseinanderstellung von bitols und skólkr (33), die verschränkung und trennung zusammengehöriger satzteile in str. 34: lagpe $i$ garp, panns skripenn vas, skatna menge, innan ormom.

Weiter ist die häufung der kenningar (es sind deren 3 in 4 halbversen) zwar einem skalden der spätzeit, aber nicht einem Eddadichter zuzutrauen, auch wenn er, wie A, gern einmal eine kenning anwendet; s. näheres unten $\S 6.4$. Daher kann ich diese fornyroislag-strophen nicht dem dichter B zuweisen, dessen einfach-schöne strophen wir oben kennen gelernt haben.

Endlich bringt der schluss von str. 34 wider einen reflectierenden hinweis auf die musterhaftigkeit des helden, wie wir das schon in 20 bei dem interpolator c fanden. So werden auch diese zwei strophen einem interpolator zuzuweisen sein.

Wenngleich nun der schluss von 34 an dẹ von 20 (c) erinnert, so möchte ich doch 33 und 34 nicht dem interpolator $c$, sondern einer anderen hand zuweisen: einmal wegen ihrer von c abweichenden metrischen beschaffenheit (c bedient sich einer art von málaháttr, mit eingestreuten viersilblern, str. 33 und 34 zeigen dagegen strenges fornyrdislag); alsdann wegen ihrer besonders vertrockneten, verkünstelten technik, die wir in der weise bei c nicht finden. Ich möchte die beiden strophen daher als eine besondere interpolation in $\mathrm{A}$ ansehen und als d bezeichnen.

Nun ist freilich ihres inhalts wegen strophe 34 jetzt unentbehrlich: sie erzählt von Gunnars versenkung in der schlangengrube und von seinem harfenspiel. Gehört aber die strophe wegen der genannten eigenschaften weder zu A noch zu B, so wird man vermuten dürfen, der interpolator $d$ habe an dieser stelle bereits eine lücke in A vorgefunden und sie, nach der umlaufenden sage, auszufüllen gesucht. Man könnte viel- 
leicht auch (mit Bugge, Fornkvaeđi s. 432) die 12 halbverse von 34 als künstelnde umarbeitung einer älteren strophe von 8 halbversen ansehen; doch wäre der grund einer solchen -vereinzelten umarbeitung nicht recht klar.

Ausser den bisher behandelten stellen der Akv. finden sich noch einzelne kleinere, die in rein metrischer hinsicht gewisse bedenken erregen. Ich muss mich aber hier mit der behandlung der auffallendsten erscheinungen begnügen, da sonst erst nicht nur der gesammte málaháttr der Akv. (A und c) genauer zu untersuchen und mit dem der Am. zu vergleichen, sondern auch das fornyroislag ( $B$ und $d$ ) bis ins einzelne zu analysieren wäre, was in diesem zusammenhang nicht möglich ist.

§ 5. Nach dem gesagten können wir den überlieferten text der Akv. in folgender weise aufteilen:

A: str. $1-4$. $9-14$. $16-17,4$. 18. 22. $25,1-4.29-32$. 35-39. 41-45.

B: str. $19-20,2$. 21. 23. $24,1-8$. $25,5-26,8$. 27. 28. 40.46.

c: str. 5-8. 15. $17,5-14.20,3-7.24,9.10 .26,9.10$.

d: str. 33. 34.

Die hauptmasse der Akv. bildet also A: von den 348 hälbversen gehören zu A 209, zu B 62, zu c 63, zu d 14.') In A herscht der málaháttr: nur 10 proc. der halbzeilen (20 von 209) sind viersilbler (nach $R$, bei Symons 29,1 und 3 als fünfsilbler, 45,5. 6 gestrichen), während wir für die gesammte Akv. 19 proc. viersilbler fanden.

\section{Stilistische eigentümlichkeiten.}

Nach erledigung der vorfrage gilt es nun, die beiden lieder vergleichend $\overrightarrow{z u}$ betrachten, zunächst nach ihrer stilistischen eigentümlichkeit. Dabei wird stets zuerst die Akv. in der überlieferten gestalt den Am. gegenübergestellt werden, dann, soweit möglich, Akv. A allein gegenüber den Am. Die drei anderen stücke $B$, c, d eignen sich wegen ihrer kürze nicht zur vollständigen vergleichung mit Am., umsoweniger als gerade von B nur wenige bruchstücke vorliegen; doch wird überall angedeutet werden, welchem teil der Akv. eine jeweilen behandelte erscheinung angehört; wo eine besondere angabe fehlt, ist stets Akv. A gemeint.

1) Oder in procenten: A 60 proc., B 18 proc., c 18 proc., d 4 proc. 
§. Eigentümlichkeiten im wortschatz.

1) Im wortschatz' ${ }^{1}$ hat die Akv. eine vorliebe für zusammensetzungen mit val-, -holl, sowie für holl allein: valhollo 2, 3. 15, 2 (c), valraupa 4,6, valbaugar 29,6 , valbráper 39,6 . - valhollo 2, 3. 15, 2 (c), pyshollo 31, 7, suprhqllo 32,5. - holl: 1, 6. 7, 10 (c) , -16, 8. 36, 6. 37, 3. 44, 5.

Die gegenprobe in den Am. ergibt nur 43, 3 hollo. - Auf der anderen seite haben die Am. eine vorliebe für zusammensetzungen mit full-, stórr-, of-, und für fjolp mit dem genitiv: fulldrukket 8, 4, fulliýnenn 11,3, fullrápa 40,3, fullveget 49, 5, fullilla 81,3. - stórhugop 72, stórrápe 83,6, stórrápa 87, 4. ofrike 69,2 , ofmikla 71,8 , ofvalt $28,9.95,5$. - fjolp horna 8,3, fjolp fear 88, 7, meipma fjolp 89, 2. - Die gegenprobe in der Akv. ergibt nur fullrétt 46, 1 (B).

2) Die diction der Akv. ist ferner die reichere, prunkvollere, die der Am. die einfachere. Die Akv. hat zunächst eine im verhältnis ungleich grössere zahl von zusammengesetzten substantiven als die Am.2)

Akv. drótmeger 2,1, valhollo 2, 3. 15,2 (c), sopollilcépe 4, 5, salhís 7, 1, mjópranne 9, 7, gollstíaler 10,3, preftonnom 11,6, greystópe 11, 7, landrogne 12, 1, erfevgrbr 12, 6, libskjalfar 14, 2, subrbjópoin 14, 5, sessmeipom 14, 6, haimbrggbom 16,7, skjaldmeyar 45, 8. 17, 9 (c), ormgarp 17, 12.13 (c), rosmofjoll 18, 5, baldrípa 22, 4, pjóblionungs 22, 6. 46, 6 B, "liumblasmip 25, 3, geirniflungr 26, 2 B, rógmalme 29, 2, valbaugar 29,6, hvélvggnom 30, 1, rógboinom 31, 3, sigtíva 31,5, pyshollo 31,7, suprhollo 32, 5, hvílbebjav 32, 7, menvov'b 33, $2 \mathrm{~d}$, dolgrogne 33, $3 \mathrm{~d}$, hringdrife 34, $11 \mathrm{~d}$, vapnsongr 35, 7, olskáler 37, 1, olkváser 34, 4. 39, 7, valbráber 39, 6, gnduge 39. 8, gopvefjom 41, 3, hískarla 42, 4. 44, 6, fjarghísa 42, 8. 45, 6, banorp 46, $7 \mathrm{~B}$.

Am. samkundo 1, 3. 71, 7, einmále 1,5, húsfreya 3,1, manvite $3,2$. 45,5 , sendemenn 4,6 , svipvíse 7,3 . 70,3 , orbstafe 9,3 , ástkynné 14,3 , linkloebe 15, 5, hvítabjor'n 17, 3, naupmanne 22, 4, húskarlar 27, 7, bakfollom 34, 3, andspille 43,1, halsmenjom 43, 7. 68, 6, harbrcepe 46, 3. 81, 7, hvergoter 58,1, or/costo 58,9, illprcele 59,3, dagmeger 61, 6, ilkvistom 62, 2, ofvîke 69,2, grunnýbge 70,1, oldrykkjor 71,1, ofrhefndèr 72, 4, bar'nésko 74,1, glskólom 77, 4, fárhuge 83, 2, heiptyrbe 83,3, stórróbe 83,6, vibfarar 84,2 , ágcetes 96,7 , prámcéle 99,7 . auftreten.

1) Die wörter werden stets in der form gegeben, wie sie im text

2) Bei der zählung der belege werden hier die widerholungen derselben wörter nicht mitberechnet, da es sich nur um den vorhandenen schatz von zusammensetzungen handelt. 
Die zählung ergibt für die Akv. 41 (davon für A 35), für die Am. nur 33; hier ist aber noch, wie bei allen weiteren aufstellungen, in betracht $\mathrm{zu}$ ziehen, dass die Am. mehr als doppelt so lang sind als die Akv: die zahl der halbverse der Akv. beträgt nur 46 proc. von der der Am. (die zahl derer von $A$ beträgt 27 proc. von der der Am.). Bei gleicher länge der gedichte wäre also für Akv. : Am. ein verhältnis von ca. 89 : 33, für Akv. A : Am. sogar ein verh. von ca. $133: 33 \mathrm{zu}$ erwarten.

3) Aehnlich ist das verhältnis bei den zusammengesetzten adjectiven:

Akv. arengreypom 1,7. 3,7.17,3, mélgreypa 3, 3. 4, 8. 13, 3, ókunnan 3, 4. 13, 4, golltrópna 4, 3, silfrgyld 4,5, valraupa 4, 6, jafnmiket 6, 8 (c), belkksém.a 7, 7 (c), gránvarper 11, 3, blakfjaller 11, 5, óneiser 12, 2. 18, 6, gunnhvátan 12, 3, havpmób́gger 13,6, vandstyggva 13,7, algróna 13, 8, sólheipja 17,6 (c), naupfolva 17, 7 (c), slíbrbeito 22,5, óglíkt 26, 5. 24, 5 (B), áskunna 29, 3, heiptmóper 34, 7 (d), cyrskaan 35,3, niflfar`na 36,8, vínhófgar 37, 2, gransíper 37, 5, skírleita 38, 1, afkọ́r 38, 3. 41, 2, neffolom 38, 5, hv'cedreyı०og 39, 3, olreifa 40, 4 B berłarpa 41, 7, ófrópa 41,9, gaglbjarta 42, 2, óvarr 43, 1, helfússe 44, 3, aldrstamar 45, 9, fullrétt 46, $1 \mathrm{~B}$.

Am. ófó 1, 1, sannıábner 1,8, glvoever 5, 1, drótláta 10,3, illúpgar 13, 1, gìópraupo 13,6, endlongo 18, 2. 24, 2, velboren 20,1 , aflima 25, 7 , skammaer 26, 6, fagrbúmar 28,7, gqrvallan 30,5: 43, 8, fullrápa 40,3, fulld’ukket 8,4, fullvýnenn 11,3, fullveget 49,5, fullillä 81,3, óbúmer 41, 3, scelboren 46, 1, ondurban 49, 4, grimmúubgan 55, 5, halfyrkjan 57, 5, skapdaupe 57, 6, ánaupgan 60,3, pjóbgóban 61,1, vakklótom 61,3, sjalfskapa

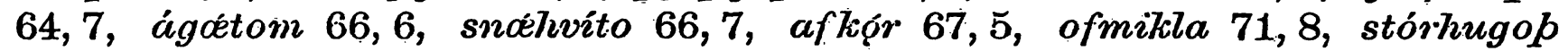
72, 1, kapsiinna 74,2, stórrába 87,4, óvágen 92, 2, ítrboren 98, 3.

Die zählung ergibt für die Akv. 37 (davon für A 29), für die Am. nur 36. Bei gleicher länge der gedichte wäre also für Akv. : Am. ein verhältnis von $80: 36$, für A : Am. sogar ein verhältnis von $107: 36 \mathrm{zu}$ erwarten.

4) Am auffallendsten tritt der reichtum der sprache in der Akv. gegenüber der einfachheit von Am. zu tage, wenn wir die kenningar der beiden gedichte vergleichen.

Von zweifellosen kenningar begegnen in der Akv.: sessmeipom 14, 6, kumblasmip 25, 3, baldrípa 22,4, syne pjóblconungs 22,6, vógmalme skatna 29,2 , valbaugas 29,6 , rógbornom 31,3 , sólo subrlupllo 32,5 , holleve hvílbepjar 32, 7, hringe Ullar 32, 8, sverpa deiler 39, 2, .fjarghúsá 42, 8 (= domus vitae, körper nach Symons' ausg. s. 435). Alle diese gehören A an. - Dazu kommen aus B: vin Borgunda 19,3, geirniflungr 26, 2, golz 
miplendr 40,7; - aus d: menvorb 33,2, dolgrogne 33, 3, bitols skókr 33, 2. 4, hringdrife 34,11 .

Dagegen finden sich in den Am. nur: borr skjaldar 28,5, dagmeger 61, 6, ilkvistom 62, 2.

Die zählung ergibt für die Akv.. 19 (davon für A 12), für die Am., das mehr als doppelt so lange gedicht, nur 3. Bei gleicher länge der gedichte wäre also für Akv. : Am. ein verhältnis von $41: 3$, für A : Am. sogar ein verhältnis von $44: 3$ zu erwarten.

5) Die Akv. hat überhaupt im verhältnis einen reicheren schatz von substantiven als die Am.: die Akv. hat 185 deren (davon A 134), die Am. haben 306. Bei gleicher länge ergäben sich -also diẹ verhältniszahlen 402 (bez. 496) : 306.

Im gegeñsatż dazu suḅstantivieren die Am. viel häufiger adjectiva als die Akv. (die folgende liste schliesst die widerholungen ein).

Am. vitre 3,5, frökner 4, 8, fríbr 5,6, svibre 6, 7, mórar 8, 1, drótláta 10,3, horsk 10,5, bjọt 11,7, vitre 12,3, velboren 20,1, fágrbúnar 28, 7, ljósar 28, 9, horskar 32, 3, ilt 37, 8, hvater 43, 3, sotlboren 46, 1, roskr 50,1, halfyrkjan 57,5, loskr 57, 8, ánaupgom 60,3, pjópgópan 61,1, ríkre 62,7 , dýrer 63,1, horskve 64,3, hollra 64,6, gópo 66, 4, stórhugop 72,1, lítla 72,5, kapsvinna 74, 2, horbo 76, 3, ilz 80, 8, roskv 85, 1, sannasta 85,5 , márre 89,1, hunske 94,1, ungre 94, 3, kvikve 94, 5, ítrboren 98, 3.

Akv. dyljendr 2,2, frékner 13,1; harpmópger 13, 6, vandstyggva 13, 7, ríkr 16,6, frékn 20, 5 (c), fréknan 21, 1 (B), skírleita 38, 1, mópogr 39, 5, miplendr 40, 7 (B), bjort 46, 7 (B).

Das sind für die Am. 38 fälle, für die Akv. nur 11 (A 7): also ergäbe sich bei gleicher länge der gedichte ein verhältnis wie $38: 24$ (bez. 26).

$\S$ \%. Adjectivische epitheta. Variationen.

Noch in anderen erscheinungen tritt der reichtum der sprache in der Akv. gegenüber den Am. zu tage. Zunächst gebraucht die Akv. häufiger als die Am. adjectiva als epitheta.

1) Folgende übersicht zeigt alle fälle, wo ein adjectivum, näher oder ferner von einem beziehungswort oder auch substantiviert ohne ein solches, in der function eines epithetons auftritt.

Akv. Kunnan 1, 3, arengreypom 1, 7. 3,7. 17, 3, svọsom 1, 8, kaldre 2,6, supréne 2, 7, hóvom 2, 8, mélgreypa 3, 3. 4, 8. 13, 3, ókunnan 3, 4. 13, 4, skafna 4, 2, gollhrópna 4, 3, silfrgyld 4, 5, valrauba 4,6, stórom 9,8, gamler, 
gránvarper 11,3, blalefjallev: 11,5, óneiser 12, 2, gunntvvatan 12, 3, óre 12,5, frékner 13, 1, harpmóbger 13, 5, vandstyggva 13, 7, algrǿna 13, 8, djüpa 14,2, họvo 14, 4, bundnom 14,7, bleikom 14, 8, rîkr 16,6, óneissa 18,6, slíbrbeito 22, 5, svinn 29,3, áskunna 29,3 , veltanda 29,5 , monom 31,2 , eyprskaan 35, 3, gyldom 36, 3, vínhofgar 37, 2, gransíber 37, 5, hvater 37, 6, skîrleita 38, 1, afkor 38, 3, hr•édreyrog 39,3, mópogr 39, 5, afkárr 41, 2, berlharba 41,7, svása 41,8, unga, ófróba 41,9, gaglbjarta 42,2, raubom 42,3 , stivan 42, 6, helfússe 44,3, heitom 44, 7, forn 45, 5, heitan 45, 10 .

Alle diese gehören allein Akv. A an. Dazu kommen aus B: hvosso 20,2 , fréknan 21, 1, blaupa 24, 4, frékna 24,6, frékna 26, 4, blauba 26, 6 , olreifa 40, 4, bjort 46,8; - aus c: víprar 5,1, gjallanda 5, 3, gyldom 5, 4, stórar 5, 5, mcéra 5, 7, éve 6, 3, beklisóma 7, 7, raupom 8,6, gjallanda 15, 7, sólheipa 17,6, naupfolva 17, 7, heitan 20,4; - aus d: heiptmópr 34, 7, frékn 34, 11.

Am. stóra 2,5, vitve 3,5, frékner 4, 8, frípr 5, 6, kapps gáleg 6, 3, svipre 6, 7, mórar 8,1, ljósom 9, 4, drótláta 10,3, horsk 10,5, bjort 11, 7, vitve 12, 3, glópraupo 13,6, hớr 15,3, endlongo 18, 2. 24, 2, velboren 20,1 , blípr 28, 5, fagrbúnar 28, 7, ljósar 28, 9, blíp 31, 2, horskar 32, 3, ivarr 37, 3, hvater 43,3 , salboren 46,1 , nokpan 46,5 , roskr 50, 1, vigleger 50,6 , svinna 53,5 , veglega 54,3, grimmúbgan 55,5, halfyrkjan 57,5, ánaubgom 60,3, bjópgópan 61,1, raklllotom 61,3, vikre 62, 7, dyjrer 63,1, horskre 64, 3, hollra 64,6, ágótom 66,6, sncehvíto 66,7, ofmikla 71, 8, stórhugop 72,1, kapsvinna 74, 2, mikila 75, 7, stóran 81,11 , roskv 85, 1, tigenna 88, 4, stórom 88, 6, mokrre 89, 1, góbar 89, 4, unger 91,5, hunske 94, 1, ungre 94, 3, steinda 97, 2, itrboren 98, 3, frób 98, 5 .

Das sind für die Akv. 82 (davon A 60), für die Am. 57. Bei gleicher länge der gedichte ergäbe sich für Akv. : Am. ein verhältnis von $180: 57$, für $A$ : Am. sogar ein verhältnis von $226: 57$.

2) In bezug auf variationen (s. besonders Heinzel, Stil der altgermanischen poesie s. $3 \mathrm{ff}$.) ist ebenfalls die Akv. ungleich reicher als die Am.

\section{a) Wortvariation.}

In der Akv. findet sich meist nominale, in den Am. meist verbale variation.

Akv. at gorbom Kvam Gjuika - ole at Gunnars hollo 1,5. 6, Knefrodr seggr enn subróne 2,5. 7, nipjarge - né.nóungr ànnarr 9, 1. 2, rýnendr né rábendr 9,3, ulfar - gamler, gránvarber 11,1. 3, landrogne - gunnhvatan 12,1. 3, heiler - ok horstker 12, 7, lyjba - reklka óneissa 18,4.6, Gunnar - vin Borgunda 19, 1. 3. (B), Gunnarr - gumna drótten 24, 1.2 (B), Gunnarr - geirniflungr 26,1.2 (B), Rín - ó svinn 29, 1. 3; rógmalme skatna - áskcunna arfe Niflunga (zu der gekreuzten wortstellung in str. 29 vgl. Heinzel a.a. o. s. 10). 29, 2. 3. 4, Atle - sifjungr peira 31, 1. 4, 
svarba - nefnda 32,3. 4, menvorp - dolgrogne 33 (d), melta - etc at olkrósom 39, 5. 7, Erp né Eitel - olreifa tvaa 40,3. 4 (B), ymr - afkárr songr - gnýr 41,1.2; buve svása - unga, ófróba 41,8.9, Guprún - en gaglbjarta kona 42,1.2, brunno - hnigo i eld heitan 45, 8. 10.

$\mathrm{Zu}$ dieser fällen, die den normalen charakter der variation tragen (s. Pachaly, Die variation im Heliand s. 3), treten noch einige, in demen eine nominale variation in anderen casus als ihr grundbegriff erscheint, indem sie gleichsam erst nachträglich hinzutritt: Akv.21 (B): frógo frélknan, ef fjor vilde Gotna bjóbann (nom.) golle kaupa; 22 hjarta slal mer Hogna $i$ hende liggja, blóbogt ór brjóste skoret baldriba (dat.) - syne bjópkonungs; 25 hló pa Hogne, es til hjarta skọro kvikvan kumbilasmiph (acc.).

Am. Kostber'a - kona kapps gáleg 6, 1. 3, eige hann jotnar galge ggrvallan 30,3. 5, ef at ypr lyge - á griph hygpe 30, 4. 6, Berá - blíp i hug sínom 31,1. 2; hrundo peir.Vinga - ok i hel drópo 38,1.2; feldan - lampan til heljar 41,4. 5; réb hoggvä - i heljo pann hafpe 47,7. 9; keppa svá kumne - kvọl hann vel polbe 61, 7. 8. - béta aldrege - né vinna pcss etke u.s.w. 68,9.10; - Atla til segja - dylja monk bik eige 75, 2. 3; toggtu tíblega - trúper vel joxlom 78, 7. 8; heimsko - harbrábe 81, 7, vógja - voétlee halda - kyrt of pví láta 95, 5-7, mund - meipma fjolb 89,1. 2, tebja - vinna et vergasta $59,7.8$.

Die zählung ergibt für die Akv. 25 fälle (davon für A 19), für die Am., das mehr als doppelt so lange gedicht, nur 15. Bei gleicher länge der gedichte wären also für die Akv. 54, für A sogar 70 fälle gegenüber den 15 fällen der Am. zu erwarten.

\section{b) Satzvariation.}

Die satzvariation unterscheidet sich von der ihr äusserlich ähnlichen verbalen variation dadurch, dass nicht speciell der verbalbegriff, sondern der sinn des ganzen satzes variiert wird; auch wenn dasselbe subject bleibt, tritt diese erscheinung zuweilen auf.

\begin{tabular}{|c|c|}
\hline $\begin{array}{l}\text { Ulfar mono rápa } \\
\text { gamler, gránvarper, } \\
\text { birner blakfjaller } \\
\text { gamna greystópe, }\end{array}$ & $\begin{array}{l}\text { Akv. } \\
\text { arfe Niflunga } \\
\text { ef Gunnars misser, - } \\
\text { bita preftonnom, } \\
\text { ef Gunnarr né komrat. }\end{array}$ \\
\hline $\begin{array}{l}\text { Rín skal rápa ró } \\
\text { ó svinn áskunna } \\
\text { i veltanda vatne } \\
\text { heldr an á hondom } \\
\text { seinat's nú syster } \\
\text { langt es at leita }\end{array}$ & $\begin{array}{l}\text { rógmalme skatna, } \\
\text { arfe Niflunga, - } \\
\text { lýsask valbaugar } \\
\text { skíne Húna bornom. } \\
\text { at samna Niflungom - } \\
\text { lýba til sinnes }{ }^{1} \text {. } 18 .\end{array}$ \\
\hline
\end{tabular}

1) Sievers, Beitr.6, 351 statt sinnes til. 
- - - i fjotor setto - ok bundo fastla. 19,2. 4 B.

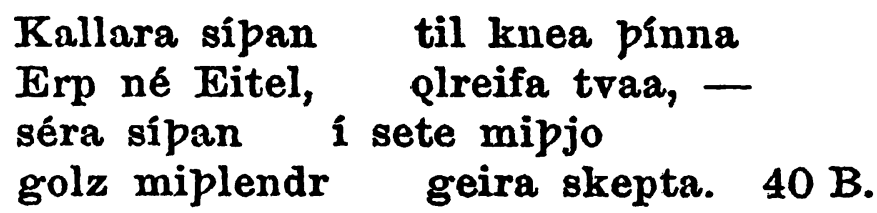

golle sere Guprún -

hringom raupom reifpe húskarla 43,1 . 3. 4. -

Am.

siglep ér sæ̉ler - ok sigr of árnep 31,3. 4.

blópgan hugpak mǽke boren ór serk pinom -

geir hugpak standa i gegnom pik mipjan. 22.

eggjak ypr, jarla, auka harm stórom

vifs ens reglega - - - klekkve Guprún. 54.
kostep svá keppa, at

hrǽddr vas hvergǽter, helta in lengr rúme -

kunne kløkr verpa, kleif i rọ hverja. 58,1-4.

at pú sọk sétter - né slékper ápra 95, 3. 4.

Die zählung ergibt für die Akv. 6 fälle (davon für A 4), für die Am. 5. Bei gleicher länge der gedichte wären für die Akv. 13, für A 15 fälle zu erwarten.

Nicht hierher gestellt habe ich, als nicht zur eigentlichen variation gehörend, die in den Am. häufigen parallelsätzchen abstracten inhalts, die den gedanken eines satzes, entweder im voraus oder hinterher, abstract aussprechen sollen. Diese sätze werden vielmehr da zu besprechen sein, wo von der hinneigung der Am. zu prosaischer, abstracter sprache die rede ist $(\S 8,5)$.

$\S$ 8. Epische und prosaische sprache.

Im gegensatz zu dem specifisch epischen stil der Akv. steht der stil der Am. der prosa näher.

1) Schon einige syntaktische erscheinungen weisen nach dieser richtung. Annäherung an die prosasprache zeigt zunächst das häufige auftreten indirecter rede und frage in den Am.

In der Akv. finden sich nur folgende 3 fälle: frógo freknan, ef fjor vilde (B) 21, $1 \mathrm{ff}$., voll lézk gefa mundo $5_{2} 1$ (c), at varba Gunnare, ef hanns vitja kvokme 15, 4 (c).

In A, der hauptmasse der Akv., findet sich nicht ein einziger fall. Dagegen in

Am. bupo beir heim Hogna, ef pá heldr fóre 7,1, héi pa ferb Gunnarr, ef Hogne vilde, Hogne pví hlítte, es hinn of répe 7,5-8, gaéttesk pess 
Glaumvgr, at voere grand svefna 20,3. 4, eige hann jotnar, ef á ypr ${ }^{1}$ ) lyge, galge gorvallan, ef á grip hygbe 30,3-6, moklte af manvite, ef mundo scéttask 45, 5. 6, vesall lézk vígs beira, es skylde váss gjalda 58,5. 6, tóm lézk at eiga tepja vel garpa 59,5. 6, fegenn lézk bó Hjalle, at hann fjor bóge 59, 9. 10, samr lézk ol Atle at sína gerva 71, 3. 4, frétto, hvat slcylde 72, 10, enn frétte Atle, hvert farner voére 74,5, sagpale at kalfs vdere 78, 4, gat fyr Guprinno, at vcére grimmr Atla 83, 7. 8, talpe happ honom, ef hann hefnt ynne 84, 3. 4, lotomk pví valda 86, 3.

Die zählung ergibt für die Am. 17 fälle gegen nur 3 in der Akv. Bei gleicher länge der gedichte wäre ein verhältnis von $17: 7$ (bez. 0) zu erwarten.

2) Dazu kommen zwei kleinigkeiten. Erstens finden sich die in der prosa so häufigen nebensätze mit póat in den Am. an 4 stellen: bót ver ógn fregnem 13, 8, pót hann reiphr vóre 50, 2, poót vóret skaplekt 86, 8, poót pat lítt rélijałk 91,2, in der Akv. nicht ein einziges mal. ${ }^{2}$ ) Sodann findet sich der für die prosa charakteristische gebrauch des plural eines pronomens bei einem namen, wo eine andere person oder mehrere hinzugedacht werden, in den Am. an zwei stellen: pau Hogne 10, 2 (Hogne und Kostbera), pau Atle 39,1 (Atli und seine leute); in der Akv. ${ }^{3}$ ) findet er sich nicht. ${ }^{4}$ )

3) Eine besondere eigentümlichkeit der epischen sprache sind die wörtlichen widerholungen, die z. b. in prymskvipa und Vólundarkvipa besonders deutlich auffallen. Diese erscheinung zeigt nun die Akŕ. in stärkerem, die Am. in geringerem masse.

Akv.

vín í valhollo $2,3=15,2 \mathrm{c}$

mar enom mélgreypa Myrkvip ókunnan 3,3. 4 \}

mare ena mélgreypo Myrkvip ókunnan 13,3. 4$\}$

mep hjalmom arengreypom at sékja heim Atla 3,7. 8 \}

sem hjalmom arengreypom at sea heim Atla 17,3.4

1) $\mathrm{Zu}$ diesem vers s. Detter und Heinzel, Kommentar 2, 547: 'Der satz' zeigt unvollkommen entwickelte oratio obliqua.'

2) Sie finden sich überhaupt in den älteren Eddaliedern sehr selten: in der Voluspa nirgends, in der Volundarkvipa einmal $(35,11)$, ebenso bei prymskvipa $(4,2)$ und Hampésmọ́l $(30,5)$.

3) Ebensowenig in Voluspá, prymskvipa, Hampésmọ́l; Vølundarkvipa an den correspondierenden stellen 42,3 it Vélundr und 43,3 vit Vélundr.

4) Zwar überliefert Akv. 15, 4 (peim Gunnare, ef peir ...) und Akv. 45, 3 (.beira Gunnars); aber beidemale ist das pronomen, weil metrisch ganz störend, mit Symons zu streichen, während Am.10,2. 39,1 keinen anstoss bieten. 


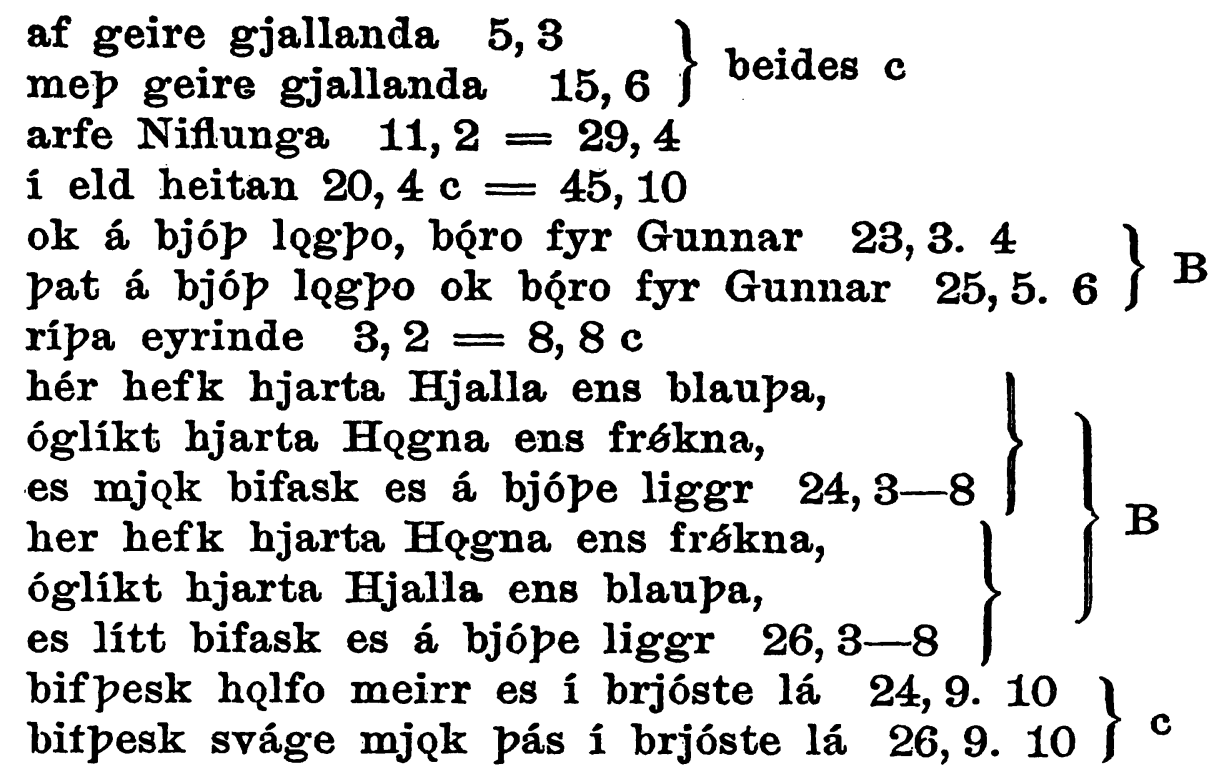

An 3 stellen $(15,2.20,4.8,8)$ hat der bearbeiter c einen ausdruck aus A widerholt. Die grösste ausdehnung haben die widerholungen von $B$, wo bis 3 langverse parallel sind.

\section{Am.}

sýn vas svipvise ef peir sín gápe $7,3.4$,

sýn vas svipvise ef haun sín gápe 70,3.4

at endlọngo húse $18,2=24,2$

loket prí léto $19,7=71,5$

roskr tọk at rópa $50,1=85,1$

ef reyner gorva 73,8

ef gorva reyner 75,6

dylja monk pik eige, dótter Grímhildar 75,3. $4=86,1.2$

sem pú sízt skylder $77,2=80,6$

lýgr pú nú - $\quad 91,1=96,1$

kvap at orpe $-29,1=31,1$.

Die zählung ergibt für die Akv. 10, für die Am. 9 fälle. Also wäre bei gleicher länge der gedichte für Akv.: Am. ein verhältnis von $22: 9 \mathrm{zu}$ erwarten. Von den 10 fällen der Akv. fallen 2 sehr beträchtliche partien auf $B, 3$ anf $A$, 5 kleinere auf c, der teils an $A$ sich angelehnt hat, teils sich selbst widerholt hat. - Im gegensatz zu B, das grössere strophenteile parallel hat, fällt es auf, dass sich diese erscheinung in A nicht häufiger findet. Aber auch in den Hampésmọl finden sich keine widerholungen, die das mass eines langverses überschreiten: es scheint als ob im gegensatz zu den rasch dahinfliessenden fornyroislagliedern die in dem schwerfälligeren, prunkvolleren málaháttr abgefassten lieder widerholungen grösserer strophenteile schon in älterer zeit vermieden hätten. 
4) Besonders charakteristisch für die Am. ist ferner deren neigung zu abstracter ausdrucksweise. Das tritt schon darin zu tage, dass die Am. einen viel grösseren schatż von abstracten substantiven ${ }^{1}$ ) haben.

Am. sankindo 1, 3. 71, 7, foestom 1, 4 , einmoele 1, 5, skop 2,1. 33, 3. 45,3 , hyggjo 2,4 , bop 2, 7, manvite 3,2 . 45, 5, $\operatorname{lag} 3,3$, orpa $3,3.29,1$ u. ö., fárs 4, 3, sabr 6, 7. 44, 7, porf 6, 8. 85, 4. 97, 5, svipvíse 7, 3, ferp 7,5. 88,2 , beine 8, 2, fjolp 8, 3. 88, 7. 89, 2, skil 9,2, rớbom 11,2. 61, 4. 66, 2. 62,7 , sinn 11, 4. 14, 4, bane 12,7. 68, 7, kynne 13,2, loes 13,3, ógn 13, 8, ástkyıne 14,3, pronmon 16, 7, heitom 18,5, hugr 19,5. 31,2 u. ö., réba 19, 8, déme 20, 2. 81,6, grand 20,4, svefna 20,4. 22, 3. 85, 2, rek 21, 5, glaumr 23, 3, flaugon 23, 4, leiper 20,6, pjóste 24, 3, nótt 25, 2, verb 29, 5, vilja 29, 6, glépr 29, 7. 81, 11, Jeváma 29, 7. 36, 5, grip 30, 6, sigr 31, 4, balffollom 34,8, lok 35,2, lífe 40,4. 85, 8, andspille 43, 1, ekka 43, 6, hjaldre 46,7, kvebja 44,6, mun 44,8, likna 45,1, harbrcebe 46, 3. 81, 7, słiéro 47, 5, pjorko 48, 1, sókn 48, 7, morgen 49, 1. 64, 5. 76, 5, dag 49, 2. 4 . 58, 7. 63, 2, ótto 49, 3, hljótt 52,1, hav'm 53, 8. 54, 2. 64, 3, hnekking 56, 5, rúme 58,2 , vígs 58,5 . 65, 2. 86, 7, váss 58,6 , tóm 59,5 , leik $60,6.68,3$, skraékton 60, 8, krol 61, 8. 94,5, íprótta 63, 4, iprar 65,3, aldre 65, 7, ón 67,1 , sátter 67,3 , sakar 67,4 . 95, 3, kostom 69,1.94, 2. 61,2 , ofríke 69,2 , grunnzýbge 70,1, svipvíse 70,3, oldrylikjor 71,1, erfa 71,2. 81,12, svorfon 71,8 , cétt 72,2 , ofrhefnd 72,4 , elle 73,4 , vó 73,7 , reipe 73,7 , barnésko 74,1 , vọ 75, 7, aptann 76, 7, hlut 79,3. 90, 6. 96, 3, vile 81, 1, heims7o 81,7, sorger 82,6, daupa 82, 7, fúr.huga 83,2, heiptyrbe 83, 3, heipt 83, 5, stórróbe 83, 6, vipfarar 84,2, happ 84, 3, rơn 85, 8. 87,5, céve 86, 4, lyge 87,5, sóme S8, 3, sémb 89,5, róg 91,6, hags 91,10, aupno 92, 7, 7urázlo 93, 4, nafn 94, 4, angr 94, 3, pinge 95, 1, gózko 96, 6, ágcétes 96, 7, strip 98, 2, drọl 98, 7, dégra 98, 7, afreke 99, 3, brámcéle 99,7.

Akv. vreipe 2, 4, rocldo 2,6 , eyrinde $3,2.8,8 \mathrm{c}$, vernop $8,4 \mathrm{c}$, vegr 8, 7 c, móbe 9, 8, hugr 12,8, fetom 13, 1, hilde 15, 7 c, harmbrogbom 16, 7, sinnes 18,4, tyja 28,5 B, eipa 32,3, daups 33, $4 \mathrm{~d}$, menge $34,4 \mathrm{~d}$, morpe 35, 4. 45, 3, dymr 35, 5, vápnsongr 35, 7, gjold 36, 4. 44, 8, níp 38,6, ymr 41, 1, songr 41, 2, gnýr 41, 3, skop 42,5, leikr 43, 5, banorp 46, 7 B.

Die zählung ergibt für die Am. 120 verschiedene abstracta, für die Akv. 26 (für A 19). Bei gleicher länge der gedichte würde man für die Akv. doch nur 57, für A 70 gegenüber den 120 der Am. erwarten.

5) Auf die vorliebe der Am. für abstractionen ist auch die grosse menge von parallelsätzen allgemeinen, abstracten

1) Unter der bezeichnung 'abstracta' fasse ich hier alle wörter zusammen, die sich nicht auf greifbare dinge beziehen, sondern auf eigenschaften, vorgänge, gemütszustände, zeit, raum, gelegenheit, geschick, lautliche äusserung u.a. 
inhalts zurückzuführen, die wir oben $\$ 7,2 \mathrm{~b}$ von den epischen variationen streng scheiden mussten. Sie stehen bald vor, bald hinter einem satz mit concreterem inhalt, den sie in abstracter, allgemeiner form widerholen:

Am.

a) Der abstracte parallelsatz steht voran: skop óxo skjoldunga : skyldo fara feiger 2, 1, horsk vas hisfieya, - : hugbe at manvite 3, 1.2, kend vas Kostbera, - : knonne skil rün 9,1.2, dulpe pess vatke, : sagbe horst hilme 10,4. 5, hygg bú at ropom - : far i sinn annat 11,2. 4, loket pví léto, - : lídde lıver rófa 19, 7. 8, etke at réposk, : aller ní kvọ́bo 45, 7. 8, brá ba barnésko brébra en kapsvinna, skiptet skaplega - : skar á hals búba 74,1-4, greipt glep stóran - : ggrt hefr bí bitt erfe 81, 11. 12.

b) Der abstracte parallelsatz steht nach: felde stop stóra - strídde sér harpla 2,5. 6, fare sem fyrer mcelek - fcést eige pví níta. 31, 5. 6, vepr mon par vaxa - verpa ótt snimma 17, 1. 2, hirpa oss hrcepa haf bat fram sjalclan 37, 5. 6, pjorko bar gorbo beive vas vip brugbet brá of alt annat, es zun bo born Gjikka 48,1-4, skerep ór hjarta - skolop bess govver 55, 3. 4, á galga festep - bellep loví bragbe 55, 6. 7, eggjak ypr, jarlar, aulic harm stórom vifs equs veglega - viljak pat líta 54, 1-4, kostcp sví keppo at klekkve Guprín - sea pat mcettak, at sér né ynpet $54,5-8$. - In der

Akv.

findet sich nư an folgenden 3 stellen ähnliches: - lét - skíran maln vaba - aéva fljóp.etke gábe fjarghísa 42,5-8, vápn hafbe etke varnabet vip Gupríno 43, 3. 4, hló pí Họgne - klekkva sízt hugbe 25, 1. 4 .

Diesen 3 fällen stehen die Am. mit einer überzahl von 18 gegenüber. Bei gleicher länge der gedichte würde man für die Akv. 7 fälle gegenüber den 18 der Am. erwarten.

6) Ueberhaupt ist der ausdruck in den Am. gern abstract, blass, der in der Akv. dagegen sinnlich, anschaulich. Während die Am. einen vorgang durch einen abstracten verbalbegriff bezeichnen, fasst die Akv. gern die in die sinne fallenden nebenumstände ins auge (vgl. Heinzel, Stil der altgermanischen poesie s. 20). Einige beispiele aus parallelen stellen der gedichte mögen das zeigen:

Am. 26 sagt Gunnarr: 'es ist sehr wahrscheinlich, dass wir kury leben werden'.

Akv. 11 sagt Gunnarr: 'die wölfe mögen über das Nibelungenerbe walten, wenn Gunnarr verloren geht, schwarzfollige bären mögen beissen u. s. w.'

Am. 71, 7. 8 wird gesagt: 'dies gelage fand mit grossem lïrm statt'. 
Akv. 37: 'es erklangen die weinschweren trinkschalen Atlis, als in der halle zusammen sich die Hunnen unterhielten'.

Am. 84, 5 ff. heisst es: 'erschlagen ward da Atli — - der sohn HQgnis und Guprún selbst erschlugen ihn'.

Akv. 44: 'sie gab den betten mit der schwertspitze blut zu trinken, mit mordgieriger hand'.

7) Aus der vorliebe der Am. für abstractionen wird es endlich wol auch zu erklären sein, dass sich in diesem gedicht, im gegensatz zur Akv., so überaus häufig die litotes findet.

Am. fellskat sabr svipre sie benahm sich höflich 6,7, dulpe pess voétke $=$ sie redete offen $10,4, \quad y k r$ mon ástkynne eige $--=$ es geht euch schlecht 14,3, dyljomk pat eige $=$ es ist mir klar 14,5, prommon peyge svá lítel = grosse balgerei 16,7. 8, sér réb lítt eira = war frech 30, 2, hugpe lítt voegja = war rücksichtslos, kühn 37,2, varr at vettoge = furchtlos, tapfer 37,3, haf pat fram sjaldan $=$ schweige von so etwas 37,6, fóra foelt peyge = gieng furchtlos, mutig 44, 3, hég vasat at hjaldre = war unsanft, rauh 46,7, peyge hendr skulfo = ihre hände griffen fest zu 47,10, mákak bví leyna = es ist offenkundig 51, 6, knákak pess njóta $=$ das ist schlimn für mich 51,8 , helta in lengr rúme $=$ lief hin und her 58,2 , pá vas kostr enge etc. $=$ er musste sterben 61,2 , ón es pess enge ich lehne ab 67,1, skọmm mon ró reipe $=$ der zorn beginnt zu toben 73,7, skiptet skaplega $=$ handelte übel 74,3, dylja monk bik eige $=$ ich werde es dir offenbaren 75,3, glaba mont pit minzt $=$ ich werde dir schmerz bereiten $75,5, \quad$ hvartke sér unpe $=$ beiden war es ungemiitlich 84,4 , emkale lítt leikenn $=$ mir ist sehr mitgespielt worden 85, 7, banḋs kvap porf onga = fühlte sich tötlich getroffen 85,4 , lífs telk vọ́n enga $=$ mit mir ist es aus 85,8, bót vcéret slcaplekt $=$ obwol es schlecht gehandelt war 86,8 , varpa vón lyge = es war wahrheit 87,5, fannkak i hug heilon hjóncu vcétr síban = beiden gatten war es stets schlimm zu mute 90, 9.10, pót pat lítt rélijait = obwol es mir gleichgiltig ist 91,2.

In der Akv. einige wenige fälle: nibjarge hvotto né nóungr etc. $=$ alle schwiegen $9,1.2$, bjóre vas lítt drukken = war sehr nüchtern 16, 4, klekikva sízt hugbe = war fest, tapfer 25,4 , kallara sípan - - séra sípan $=$ mit ihnen ist es aus 40 (B), aéva fljóp etke gábe = sie gab reichlich 42, 7, ferrat svá síban brúpr i brynjo etc. = Gựrúns rache war einzigartig 46 (B).

Den 29 fällen der Am. stehen also 6 in der Akv. (4 in A) gegenüber (verhältnis wie $29: 13$ [bez. 15] bei gleicher länge der gedichte).

$\$$ 9. Schlussbemerkung.

Es gilt, das bisher festgestellte kurz zusammenzufassen. Die Akv. hat eine prunkvolle, reiche sprache, zahlreiche zusammensetzungen, zahlreiche kenningar, zahlreiche epitheta, 
zahlreiche variationen; ihren specifisch epischen stil bekundet sie ausserdem durch zahlreiche widerholungen. Die Am. dagegen haben eine einfachere sprache; sie gleichen den mangel an substantiven durch substantivierungen aus, nähern sich aber sonst in ihrer sprache der prosa, indem sie gern indirecte rede und frage anwenden, constructionen wie pau Hogne und neben-

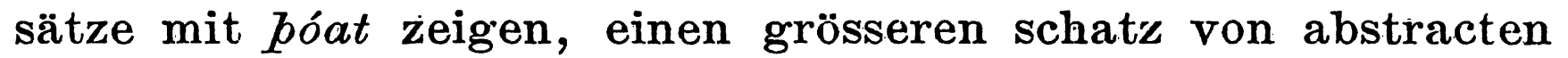
substantiven aufweisen, abstracte parallelsätze in fülle haben, abstracten ausdruck lieben, statt des sinnlichen in Akv., sehr oft die litotes zeigen.

Alles dies spricht dafür, dass die Akv. hinsichtlich der sprache einer älteren strengeren, die Am. einer jüngeren freieren kunststufe angehören. Es gilt nun, die lieder nach ihren poetischen eigentümlichkeiten $\mathbf{z u}$ betrachten.

\section{Poetische eigentümlichkeiten.}

$\$$ 10. Darstellung: im allgemeinen.

Während die diction sich in Akv. durch reichtum, die der Am. durch einfachheit auszeichnete, finden wir in bezug auf die poetische darstellung ein umgekehrtes verhältnis: für die Akv. ist kurze, straffe darstellung, für die Am. dagegen breite charakteristisch.

In rascher folge drängen sich die ereignisse in Akv.: der bericht des boten, der entschluss Gunnars, sein abschied, die fahrt durchs Hunnenland, die ankunft bei Atlis burg, die begrüssung durch die schwester, die fesselung Gunnars, gegenwehr Hognis, die frage nach dem gold, das ausschneiden des herzens bei Hjalli und Hogni, die wegführung Gunnars zur mordstätte, Guđtrúns fluch, Atlis rückkehr und begrüssung durch Guđrún, das gelage und die enthîllung der greuel, Guđrúns letzte geschenke, Atlis ermordung, der saalbrand.

Dabei ist mit wenig strichen manches schöne bild in die erzählung eingeflochten: von den glänzenden goldringen in den wellen des Rheins $(29,5)$, von den jugendübungen der knaben $(40,5$ ff. B), von den früheren umarmungen der gatten im kreis der fürsten $(43,5)$ : aber die darstellung ist auch hier stets kurz und knapp, wie in einer ballade, jede breitere ausführung einer scene wird vermieden.

Dagegen sind in den Am. einige scenen breiter ausgeführt, 
teils durch dialoge (s. u. $\S 13 \mathrm{~b}$ ), teils durch schilderung. In zwei nächtlichen dialogscenen werden sieben traumbilder entrollt. Dann gehört hierher die abschiedsscene am Fjoro, wo Glaumvor und Kostbera die scheidenden begleiten, sie vergeblich zurückhalten wollen, Vingi gefragt wird, ob er es ehrlich meine, Kostbera segenswünsche, Hogni trostworte spricht, und beide teile blicke tauschen, bis sie sich trennen. - Sodann ist Guđrúns eingreifen in den kampf geschildert: sie wirft den mantel ab; nimmt das nackte schwert, legt unsanft hand an, indem sie zwei männer niederschlägt, dem einen von ihnen den fuss abhaut. - Auch die scene, wo Guđrún ihre kinder schlachtet, hat der dichter der Am. (im gegensatz zu dem der $A k v$.) reicher ausgeführt. Guđtún lockt die kleinen herbei, legt sie an den pfeiler, sie werden furchtsam, aber weinen nicht, flitchten sich in den schoss der mutter, die ihnen nach kurzem zwiegespräch die hälse abschneidet. - Eine scene voll lebendiger kleinmalerei bildet vor allem die episode mit Hjalli. Als er liört, dass es ihm ans leben gehen soll, läuft er ängstlich hin und her, verkriecht sich und beklagt seinen unstern, der ihn von seinen schweinen hinwegreisse. Als man dann das messer nach ihm zïckt, schreit er laut auf, ehe er noch die spitze gefühlt hat, und fleht um gnade, bis Hogni der posse ein ende macht.

Diese anschaulichkeit der schilderung geht aber keinesweg's durch das gedicht durch. Sehr kurz behandelt wird die einladung $(7,1.2)$ im gegensatz zu Akv. str. 3 ff.; ferner die erschlagung Atlis (84,5.7.8, vgl. Detter und Heinzel s. 563). Breite der darstellung bedingt noch nicht zugleich anschaulichkeit. In der tat hat die breite und die daraus folgende länge des gedichts nur zu einem teil ihren grund in der bevorzugung der schilderung. Sehr beträchtlich wirken mit erstens die vielen abstracten parallelsätze (s. oben $\S 8,5$ ), zweitens die vorliebe für lange reden, drittens die vorliebe für häufige subjective äusserungen: von den beiden letzteren eigentïmlichkeiten wird unten zu reden sein $(\$ 13 b, 14)$.

\$ 11. Zeit und ort.

Die erzählung der Akv. spielt sich in sehr kurzer zeit ab, alle ereignisse von der abreise Gunnars bis zum ende des 
gedichts werden von einem tag umschlossen. Die erzählung der Am. erstreckt sich auf einen längeren zeitraum. Aber wir vermissen an einigen stellen die überleitung, sodass sprünge in der darstellung entstehen. Zunächst findet sich ein solcher zwischen str. 61 und 62 (s.Mogk, Grundriss 22, 649), wir erfahren nicht, wann Gunnarr zu den schlangen gebracht worden ist. Dieser sprung lässt sich vielleicht durch annahme einer lücke im text entschuldigen (s. Symons ausgabe s. 454); unmöglich ist das dagegen bei dem nächsten falle: vor str. 71 liegt ein unausgefüllter zeitraum: denn einmal war es allgemeine sitte, 30 tage bis zum erbmahl verstreichen zu lassen '), und zweitens sagt Guđrún selbst str. 76, dass sie seit dem tod der brüder sehr selten geschlafen habe: es liegen also nächte dazwischen. Einen weiteren nicht überdeckten sprung finden wir in der mitte von str. 74, wo Atli sogleich nach der ermordung der kinder sich nach ihnen erkundigt und eifährt, dass er ihre herzen gegessen hat. Auch ist nicht klar, wann Guđrún die kinder geschlachtet hat. Die Akv. (36) lässt ganz klar ersehen, dass sie vor der rückkehr Atlis geschlachtet worden sind: in den Am. wird dagegen hintereinander erst vom gelage, dann vom mord, dann von Atlis frage erzählt. Ein weiterer sprung in der erzählung liegt, wie Mogk; Grundriss 22, 650 zeigt, zwischen str. 82 und 83: der anstoss zur ermordung Atlis geht von dem Niflung aus, er ruft erst wider der Guđrún die Hogua vipfarar ins gedächtnis: das dentet auf eine dazwischenliegende zeitstrecke (s. unten dazu in teil II, $\$ 43$ ).

Wie die zeitliche, so ist die örtliche orientierung in der Akv. völlig klar. Atlis reich liegt südlich von dem Gunnars, man gelangt hin durch den Myrkviðr und kommt durch grüne felder zur burg Atlis; die Niflunge treten in den saal, wo sich der kurze kampf abspielt; die schlangengrube befindet sich in Myrkheimr; nach diesem ort wird Gunnarr auf einem wagen gefahren; in der halle findet das gelage statt, die enthüllung, der lärm; in seinem schlafgemach wird alsdann Atli getötet. Ander's in Am. Zunächst wird die himmelsrichtung, nach der die Niflunge fahren, nicht bezeichnet; dass der kampf ausser-

1) Vgl. Homeyer, Der dreissigste, s. 199 ff. (Philologische abhandlungen der Berliner acad. d. wissenschaften, 1864). 
halb der halle stattfindet, wird gesagt (43); aber im weiteren ist nicht klar, wo die schlangen sich befinden, auch nicht, wo der kindermord, wo das gelage stattfindet; da nacheinander vom gelage, vom mord, von Atlis frage berichtet wird, so müssen wir wol annehmen, dass Guđđuńn während des gelages, aber in einem andern raum die kinder getötet hat. Endlich ist auch bei Atlis tod die situation nicht klar; es heisst 83, dass die gatten zusammensassen; dann kommt die unterredung des Niflung mit Guđrún; dann wird von beiden der schlafende Atli getötet: wo, erfahren wir nicht näher, während die Akv. (44) durch erwähnung des bettes die scene deutlich in das schlafgemach verlegt.

\section{\$ 12. Charakterzeichnung.}

a) Atlakĩipa.

In der Akv. sind die einzigen wirklichen persönlichkeiten Gunñarr und Guđrún.

Gunnarr, der in allen drei stücken, A, B und c, besondere züge trägt, tritt am greifbarsten natürlich in A hervor. Er zeigt sich zunächst vor der abreise als ein mutiger, verwegener held, der das unheimliche schweigen bricht, indem er sich tollkühn, beim klang der goldenen trinkschalen, zur fahrt entschliesst und den wölfen und bären sein erbe überlässt für den fall, dass er nicht widerkomme (10.11); aber ruhig und gefasst antwortet er seiner schwester auf die unglücksbotschaft (18); zähen sinnes will er sein gold lieber in den wellen des Rheins geborgen wissen, als in den händen der Hunnen (29). Gunnarr tritt ganz in den vordergrund gegenüber $\mathrm{H}_{2} g n i$, der in A überhaupt nicht redet; ihm ist daher auch das letzte wort vor dem ende aller Niflunge gelassen, wie im Nibelungenlied dem Hagen, wie in den Am. dem Hịgni. - In B ist Gunnarr speciell der mistrauische, der stets zweifel hegte, solang sein bruder lebte, und der erst mit dessen tode beruhigt ist (28). - In $c$ ist Gunnarr der empfindliche, dem es gegen die ehre geht, geschenke anzunehmen, da er selbst reich genug ist (6.7).

Guđrún ist herb, wortkarg und tränenlos, eine frauengestalt, wie sie die jüngeren dichtungen nicht mehr kennen, aber keine leblose statue; als treue schwester Gunnars warnt sie diesen $(16,5 ; 8 \mathrm{c})$, und als er zum tode geführt wird, schleu- 
dert sie einen fluch gegen den wortbrüchigen Atli, den tränen wehrend (31.32); den heimkehrenden empfängt sie mit unheimlich zweideutigen worten (36), und sie klärt ihn hernach kalt über seine Thyestesmahlzeit auf (39); keine träne vergiesst sie, während die männer weinen, über den tod der brüder und söhne (41); die hausknechte beschenkt sie, und sie gewährt ihnen sowie den hunden die rettung (42. 43), aber alle andern, die beim mord Gunnars zugegen waren, auch die schildmädchen, verbrennt sie zusammen mit dem ermordeten gatten, als busse für die brüder $(44,8.45)$.

In $\mathrm{B}$ ist sie insofern etwas milder gefasst, als sie mit zarten worten an die früheren jugendbeschäftigungen der knaben erinnert (40, vgl. Symons ausgabe s. 433).

Die charakterzeichnung dieser beiden gestalten in Akv. A, auf so knappem raume, mit so wenig mitteln ausgeführt, kennzeichnet den verfasser als einen echten und grossen dichter, der die gestalten der sage tief $\mathrm{zu}$ erfassen und einheitlich darzustellen wusste.

Die anderen personen der Akv., Atli, Hoggni ${ }^{1)}$, Hjalli, Knefrođđr, Hognis sohn und Fjornir haben auf der anderen seite wenig oder gar keine individuellen farben: sie steigern aber durch ihre blässe die wirkung der beiden hauptpersonen.

\section{b) Atlamól.}

Da sich die Am. durch eine grössere personenfülle auszeichnen, so seien zuerst die hauptpersonen betrachtet, dann die nebenpersonen.

\section{a) Hauptpersonen.}

Gunnarr tritt ganz hinter Họgni zurück. Er macht seine zustimmung zur fahrt erst von der. Hognis abhängig $(7,5)$ und erklärt hernach in matten worten (vgl. damit Akv. 10. 11) seinen entschluss zur fahrt (26). Er wird zwar von Atli der grimmige genannt $(55,5)$, tritt aber nirgends im kampf hervor; auch spricht er weder beim abschied noch in Atlis land, und er zeichnet sich erst durch sein harfenspiel bei den schlangen aus, das bewegung unter den zuhörern hervorruft (62).

Hǫgni steht dafür im vordergrund. Schon rein äusserlich

1) HQgnis wilde tapferkeit charakterisiert 20 (B und $\dot{c}$ ), seine unerschrockenheit 24 und 26 (Hjallis herz und seines) B. 
fällt es auf, dass seine gattin, Kostbera, die boten begrüsst, Gunnars gattin für die bewirtung sorgt (6), dass die boten Hogni und nicht Gunnarr einladen (7), dass zuerst und am intensivsten Hogni von seiner gattin gewarnt wird, die die runen beim feuer gelesen hat (9 ff.), dass zwei erwachsene söhne Hognis und sein schwager mit namen eingeführt werden (Snǽvarr, Sólarr, Orkningr 28), dass Hqgni das abschiedswort spricht (32). Seine gesinnung charakterisiert er selbst str. 13: argwohn liegt ihm fern, er will von verderben nichts wissen, ehe es nicht so klar vor ihm liegt, dass er es rächen muss. Auch in Atlis land steht Hogni ganz im mittelpunkt: er klopft am gitter (35), er erwidert Vingi (37), er wird zuerst genannt, als Atli den befehl zur tötung gibt (55), er antwortet ruhig und sicher dem letztern (56); um seine heldenhaftigkeit ins licht zu setzen, wird Hjallis feigheit so ausführlich dargestellt, während Akv. darüber kurz hinweggeht (57-59); er verlangt selbst den tod, um das geschrei Hjallis nicht länger anhören zu müssen (60); er hinterlässt einen sohn und rächer (84). Aber Hogni ist es auch, der seiner. schwester innerlich am nächsten gestanden hat: um ihn vor allen klagt sie, mit dem sie zusammen aufgewachsen sei, gespielt habe, von der mutter beschenkt worden (67.68); und als sie zur rache schreitet, da ist es die behandlung Hognis, die ihr wider in den sinn kommt $(84,2)$.

Mit der prachtvollen, lebenstrotzenden gestalt Gunnars in der Akv. kann sich diese ziemlich typisch gezeichnete gestalt allerdings nicht messen; aber sie ist dem dichter der Am. unter den hauptpersonen entschieden am besten gelungen: sie ist aus einem guss.

Die Guđrún der Am. ist der der Akv. in ihrer schwesterlichen liebe verwant, wie wir schon sähen. In der hauptsache ist sie aber wesentlich anders gezeichnet als jene.

Zunächst wird in den Am. viel stärker als in der Akv. ihre klugheit betont (direct vom dichter str. 3 und 70); nicht nur warnt sie die brüder durch runen (3. 4), sondern sie stellt sich sogar später, nach anfänglicher zornesaufwallung, Atli gegenüber resigniert (69), und heuchelt leichten sinn் $(70,7.8)$, um ihr ziel zu erreichen.

Ferner ist Guđrún in den Am. eine streitbare frau, die 
früher mit Siguror und ihren zwei brüdern auf heerfahrt ausgezogen war (92.93), hernach in den kampf zwischen Atli und den brïdern selbst eingreift und dabei zwei männer erschlägt (47).

Endlich ist diese Guđrún ebenso schlagfertig mit der zunge wie mit dem schwert: sie erwidert Atli auf seine klagen mit so scharfen worten, dass er ihre brüder martern lässt (53. 54. 55); sie droht Atli nach deren tode mit einer schlimmen erbschaft und erklärt jede versöhnung für ausgeschlossen (65. 67); sie sagt ihren kindern, dass es sie schon lange gelüstet habe, sie vom leben zu heilen (73); sie lohnt Atli seine höhnische ankündigung des morgens, indem sie ihm den abend ankündigt (76), und erklärt ihm, keine behandlung sei schlimm genug für einen solchen fürsten (81); sie wirft noch dem sterbenden die früheren zwistigkeiten in seiner familie und seine feigheit vor (91. 95).

Durch diese beiden züge, die streitbarkeit und die zungenfertigkeit, hat die gestalt an äusserer lebhaftigkeit gewonnen. Dass sie aber umgekehrt an feinheit und an wirklicher grösse dadurch verloren hat, lehrt der vergleich mit der Guđrún der Akv. Dadurch dass die Guđrún der Am. schon am anfang der katastrophe als kriegerisches weib auftritt, erscheint ihre rachetat an Atli (von der beihilfe des Niflung ganz zu schweigen) bei weitem nicht so bedeutend wie in der Akv., wo Guđrún sich erst am schluss über die schwäche ihres geschlechts erhebt. Auch wird durch die langen vorhergehenden und nachfolgenden reden der eindruck ihrer taten nur abgeschwächt, im gegensatz zu denen der wortkargen Guđrún der Akv. Zu wirklich psychologischer vertiefung haben auch die reden Guđrúns nicht geführt: nur streiflichter beleuchten hier und dort das seelenleben der nordischen frau: wie wenig dem dichter eine wirkliche vertiefung des gesammten charakters gelungen ist, kann Guđrúns brutale unterhaltung mit ihren kindern vor dem mord derselben (73) zeigen. Hier halte man zum vergleich die analoge scene in Euripides' Medea daneben, wo die heldin in allen ihren seelenkämpfen vorgeführt wird. - Auch die motivierung lässt öfters zu wünschen übrig: es wird uns nicht verständlich, wie Guđrún die ermordung HQgnis vergessen konnte, an die sie erst wider durch den Niflung 
erinnert wird (84); wir verstehen auch nicht, was sie zum schluss zur milde gegen Atli bewegt (97.98). - Dem gegenüber ist die Guđrún der Akv. einheitlich und klar gezeichnet: sie hält sich vom kampf fern $(31,7)$, redet wenig, führt aber mit der ganzen dämonischen wildheit eines gemishandelten weibes ihre rache sofort schlag auf schlag aus bis zur letzten conséquenz.

Atli ist in den Am. im gegensatz zur Akṽ. wol eine wirkliche persönlichkeit, aber eine wunderliche. Zunächst ist er ein grausamer, habgieriger tyrann, der Guđrúns mutter aus habgier getötet hat, ihre nichte hat verhungern lassen $(53,3 \mathrm{ff}$.$) ,$ der, um Guđrún schmerz zuu bereiten, ihre brüder grausam töten lässt (54.55). - Mit diesèr eigenschaft verbindet sich aber eine auffallende sentimentalität: Atli beklagt sich in langer rede über das unheil, das ihm durch die verwanten und das verderbliche weib zugefügt sei, über den tod der schwester, den er am meisten empfinde $(50-52)$; er sagt, als er die wunde empfangen hat, Guđrún habe übel getan, einen vertrauensvollen freund zu betrügen, und erinnert sie an seine brautwerbung mit ihrer reichen ausrüstung und an seine stattlichen brautgeschenke (88. 89); er beklagt sich über ihre geringe dankbarkeit, und über ihre unfreundlichkeit gegen ihre schwiegermutter (90). - Ausserđem ist Atli feige. Nach dem mord sucht er die zornige gattin durch geschenke zu beschwichtigen (66); nach dem tod der kinder lässt er jene trötz angedrohter todesstrafe leben (82), und noch am schluss muss er sich seine feigheit, seine nachgiebigkeit gegenüber der thingversammlung vorwerfen lassen (95).

Wenn sich nun die feigheit auch mit dem bild eines grausamen tyrannen verträgt, so mutet der sentimentale einschlag in Atlis charakter seltsam an." Auch bei dieser gestalt ist es dem dichter nicht gelungen, ein einheitliches bild zu zeichnen. Der grund ist wol darin zu suchen ${ }^{1}$, dass er dem heroischen zeitalter schon zu fern stand, um die alten sagengestalten noch vọllig erfassen zu können. Dadurch erklärt sich auch die anpassung der sage an specifisch nordische verhältnisse, an die umgebung des dichters: das gelage, bei dem

1) Vgl. Mogk, Grundriss $2^{2}, 651$. 
Guđrún Atli bewirtet, ist zum erbmahl, erfi, geworden (71); den staat Atlis kann sich der dichter nicht ohne eine thingversammlung denken, die die macht des fürsten einschränkt (95).

$\beta$ ) Nebenpersonen.

Besser als Guđrún und Atli sind dem dichter die nebenpersonen Kostbera, Glaumvǫr, Vingi, Hjalli gelungen. Hier konnte er einfache gestalten nach dem leben zeichnen. Wenn wir Atli und Guđ̈ún als verunglückte figuren ansehen müssen, sind jene als wolgelungene typen zu bezeichnen.

Das gilt zunächst von Glaumvqr und Kostbera, 'zwei. frauen in ihrer liebe zum gatten und mit ihrem weiblichen ahnungsvermögen einander gleich' (Mogk, Grundriss 22, 648).

Sodann ist Vingi im gegensatz zu dem Knefrođr der Akv. eine greifbare und lebendige gestalt: er fälscht selbständig die runen, die Guđrún ihm übergeben hat (4); er schwört, als Glaumvor ihn auf seine redlichkeit prüfen will, die joten mögen ihn holen, an den galgen wolle er kommen, wenn er auf schaden sänne (30); als aber die Niflunge am tor vor Atlis gehöft anlangen, da offenbart er ihnen, dass betrug hinter seiner einladung verborgen gewesen sei, und fordert sie jetzt, wo es zu spät ist, höhnisch auf, wider umzukehren, sonst sollten sie warten, bis er ihnen den galgen gezimmert habe (36).

Eine sehr lebendige gestalt ist endlich Hjalli, der koch. Wie er den vorschlag, ihn statt Hǫgni zu töten, hört, läuft er hin und her, verkriecht sich und beklagt sein geschick, dass er für anderer leute streit büssen solle, seine schweine und seine reichliche nahrung verlassen müsse. Als er dann das das blanke messer sieht, da sehreit er und will gern die grasplätze düngen und die schmutżigste arbeit verrichten, wenn er nur sein liebes leben retten könne (58.59).

Ganz blass gezeichnet sind dagegen Snǽvarr und Sólarr, die beiden söhne, und Orkningr, der schwager Hognis, der wol als deren erzieher gedacht ist (28, spec. v. 4): sie fallen alle drei, nachdem sie im tapfern kampf achtzehn feinde gefällt haben (49, $7 \mathrm{ff}$.). Ebenso sind Beiti, der haushofmeister Atlis (57) und der Niflung am schluss des gedichtes (83 ff.) gestalten dritten ranges.

Beiträge zur geschichte der deutschen sprache. $\mathbf{X X X I I I . ~}$ 
Wenn wir die stellung der charaktere in den beiden Atliliedern im ganzen vergleichen, so fällt auf, dass dem dichter der Am. viel mehr daran gelegen ist als, dem der Akv., die personen in den vordergrund zu rücken, während jener als echter epiker den hauptnachdruck auf die taten und ereignisse legt. Das führt uns zu einer weiteren beobachtung.

\$ 13. Lyrisches und rhetorisches element.

Die Akv. ist ein rein episches gedicht: in den Am. stossen wir dagegen auf zwei andere elemente: das lyrische und das rhetorische.

a) Es lag in der entwickelung der eddischen poesie, dass sich das lyrische verweilen beim ausdruck von gefühlen immer stärker in den vordergrund drängte, wie wir das in Guprúnarkvipa I, Sigurparkvipa en skamma, Helreip, Odrúnargrátr am deutlichsten ausgeprägt finden.

Lyrisches betonen des gefühlslebens zeigen nun auch in den Am. einige stellen. Am schönsten str. 68. 69, wo sich Guđđún an ihre mit Họgni verlebte jugend erinnert und dann zu ihrem gegenwärtigen geschick zurückkehrt:
Alen vit upp vọ́rom
i eino húse,
lékom leik margan ok í lunde f́xom, gédde okr Grímhildr bana mont mer brópra golle ok halsmenjom - bóta aldrege etc.

Aber - so fährt sie mit erheuchelter ergebung fort - : das los des weibes ist, zu leiden:

$$
\begin{aligned}
& \text { kostom drepr kvenna } \begin{array}{c}
\text { karla ofríke, } \\
\text { i kné gengr hnefe, }
\end{array} \text { ef kvister prerra, } \\
& \text { tré tekr at hniga, ef hoggr tốg undan: } \\
& \text { nú mátt einn, Atle, }
\end{aligned}
$$

An einer anderen stelle (76) sagt Guđrún dem Atli, wie sie selten geschlafen habe seit dem tode der brüder: einst habe er ihr den morgen angesagt, nun sei es abend geworden.

Sonst aber herscht in den Am. ein kräftiger ton. Scharfe invectiven sind mehr beliebt als eigentlich lyrische äusserungen. Insofern stehen die Am. in der mitte zwischen den alten rein epischen gedichten, wie Akv. und Hampésmọ́l, und einem von hoher lyrik durchzogenen, wie Gđkv. I (besonders str. 17 ff.).

b) Dazu tritt, oft mit dem lyrischen verbunden, das rhetorische element. Hier sei von subjectiven rhetorischen äusse- 
rungen des dichters noch nicht die rede. Dagegen sei die tatsache hervorgehoben, dass die personen der Am. sich gern in langer rede aussprechen auch da, wo es der gang der handlung durchaus nicht nahelegt oder gar notwendig macht. Schon äusserlich fällt auf, dass die Am. 6 längere dialoge (11-19,6. 21-26. 50-56. 64,5-69. 75-82. 85,5-97) und zwei kurze (36-37, 6. 73) besitzen, während die Akv. A und c nur je einen kürzeren (c 6-8. A 16,5-17,4. 18) aufweisen. Heusler (Der dialog in der altgermanischen erzählenden dichtung, Zs. fda. 46,193 ) hat berechnet, dass allein auf die unterhaltung zwischen beiden gatten in den Am. 248 kurzverse fallen, in der Akv. nur 30.

Eine lyrisch gefärbte rhetorik finden wir da, wo Guđrún dem Atli enthüllt, was aus seinen kindern geworden ist (75 -79); Akv. A hat an der entsprechenden stelle nur eine strophe (39). Rhetorisch ist ferner Atlis klage über den tod seiner mannen, seiner brüder, seiner schwester $(50-52)$. Vor allem gehört hierher Atlis vorwurfsvolle rede, worin er auf seine glänzende brautfahrt linweist $(86,7-90)$, und Guđrúns ablehnung dieser vorwürfe und erzählung von ihrer glücklichen vergangenheit, als sie Sigurds gattin war, von ihrer schmerzlichen verwittwung und noch schmerzlicheren zweiten vermählung, von Atlis feigheit; in der Akv. fällt am schluss zwischen den gatten kein wort mehr. Auch hinsichtlich solcher rhetorischen rückblicke stehen die Am. in der mitte zwischen den alten einfach epischen gedichten und den jüngeren sogenannten übersichtsliedern.

$\S$ 14. Hervortreten des dichters.

In beiden gedichten kommt gelegentlich der dichter selbst. zu worte. Dieses subjective moment der darstellung erscheint aber in der Akv. sehr selten, in den Am. sehr häufig und intensiv.

a) Von reflexionen hat die Akv. sehr.wenig; 9,5.6 sagt der dichter in bezug auf Gunnars kühne worte: lcvadde $\not p a ́$ Gunnarr, sem konungr skylde; in-bezug auf den mord Atlis sagt er 43, 5 ff. opt vas leikr betre, pás pau lint slcyldo optar. um fapmask - -. Dem bearbeiter c gehören alsdann die worte 20,5 svá skal frekn verjask figndom sinom. sem Hogne varpe - - ; dem interpolator d.34, $10 \mathrm{ff}$. svá slcal golle frekn 
hringdrife vip fira halda. In den Am. findet sich derartiges häufig. Besonders liebt der dichter hinweise auf das nur ihm bekannte ende, die die objective darstellung der Akv. gar nicht kennt. Von der ratsversammlung an Atlis hof heisst es 1,6 yggt vas beim sípan, ok et sama suinom Gjüka, es vóro sannrápner. Weiter reflectierend str. 2

Skọp óxo skjoldunga, skyldo fara feiger, illa rézl Atla, átte pó hyggjo; felde stop stóra, strídde sér harpla.

Von Vingi sagt der dichter 4,3 färs vas flýtande. In bezug auf die einladung Vingis 7, 3 sýn vas svipvíse, ef peir sín gópe. Ueber die geringe zahl der Niflunge sagt er 27,8 hugat vas pví illa. Als sich dann am fjorđ die wege trennen, da sieht

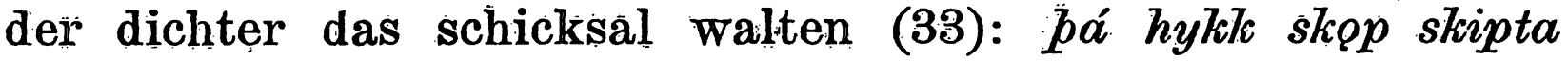
(1. pers. sing.!). Von Vingi vor Atlis gehöft sagt er (35, 7. 8): orp kvap pá Vingi, pats betr án vóere. Von Gựrúns begrüssung $(44,6)$ : sú vas hinzt kvẹjaa. Reflectierend ist auch eine parenthese wie 60,2 gorva svá fáre (als nämlich Hǫgni für Hjalli fürbitte einlegt).

b) Auch lobeserhebungen und preis der heldentaten sind in den Am. stärker vertreten als in der Akv. Aus letzterer gehört (abgesehen von den oben s. 227 besprochenen reflexionen 9,5 . 20,5. 34, 10) hierher nur die schlussstrophe 46 (B), die sich immer noch in bescheidenen grenzen hält:

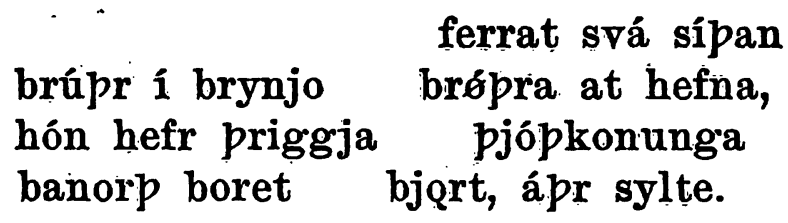

Stärker in den Am. Vom kampf der Niflunge 48

pjorko par gorpo, peire vas vip brugpet, brá of alt annat, es unno bqrn Gjúka.

Von den getöteten brüdern 63,3.4 léto a leste lifa íprótta. Mit prachtvollen worten feiert namentlich in der schlussstrophe der dichter die kinder Gjúkis als unsterblich:
sǽll es hverr sípan, es slíkt getr fópa
jóp at afreke; sem es ól Gjúke:
lifa mon pat epter á lande hverjo
peira prámǽle, hvarges pjóp heyrer.

Diese starke betonung des nachruhms hängt aufs engste mit 
dem gesteigerten selbstbewusstsein des dichters zusammen. Der dichter weiss, dass er es ist, der den heldentaten die unsterblichkeit sichert.

c) Das subjective moment zeigt sich noch in einer dritten erscheinung, die nur den Am. eigen ist. Während der dichter der Akv. die ereignisse einfach erzählt, ohne weitere worte darüber zu verlieren, liebt es der der Am., die ereignisse einzuleiten, vorher zu besprechen, ehe er sie darstellt, besonders auch die personen in directester weise $\mathrm{zu}$ charakterisieren und die seelenvorgänge $\mathrm{zu}$ bezeichnen, um das verständnis beim hörer zu erleichtern (s. zum letztern Mogk, Grundriss 22, 651).

Man vergleiche den anfang der beiden lieder. Akv. beginnt einfach: Atle sende ár til Gunnars; die Am. dagegen leiten ein: Frétt hefr old ófó, pais endr of gerpo etc. Als die Niflunge zu Atlis burg kommen, sagt Akv. einfach str. 14 land soo peir Atla ok lipskjalfar - -; die Am. dagegen geben eine

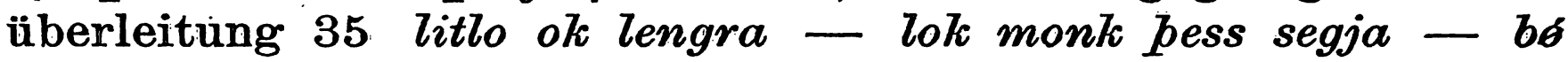
soo peir standa - - Als Hogni das herz ausgeschnitten wird, sagt die Akv. einfach, 25

hló pá Hogne, es til hjarta skiọ́ro

kvikvan kumblasmip, kløkkva sizt hugpe.

die Am. dagegen str. 61, mit einleitung:

prifu peir pjópgópan - pá vas kostr enge
rekkom rakklótom ráp enn lengr dvelja.
hló pá Hogne, heyrpo dagmeger,
keppa svá kunne, kvQl hann vel polpe.

Wie Gunnarr bei den schlangen gestorben ist, sagt Akv. einfach 35 Atle lét rinna lands sins á vit jó eyrskaan - - ; die Am. dagegen charakterisieren Atlis stimmung 64 stórr póttesł Atle, sté of pá bápa. Als Guđrủn sich nach dem mord der Niflunge verstellt und ergebung heuchelt, hebt der dichter Atlis leichtgläubigkeit und Guđrúns falschheit hervor:

70, 1-4 gnótt vas grunnýpge, es gramr pví trúpe. sýn vas șipvíse, ef hann sín gǽpe.

Weiter hebt er ihre verstellungskunst, ihre rachsucht, ihre grausamkeit hervor (str. 70. 72. 74):

70,5-8 krqpp vas pá Guprún, kunne of hug mæala; létt hón sér gørpe, lék hón treim skjpldom. 
72,1-4 strong vas stórhugop, strídde ǽtt Bupla, vilde ver sinom vinna ofrhefnder.

74, 1-4 brá pá barnósko brópra en kapsvinna, skiptet skaplega.

Nach alledem ist die darstellungsform der Akv. als eine mehr objective, die der Am. als eine mehr subjective zu bezeichnen.

$\$$ 15. Schlussbemerkung.

Die betrachtung und vergleichung der poetischen eigentümlichkeiten der beiden gedichte liess starke gegensätze hervortreten. Kurze, knappe darstellung fanden wir in der Akv., breite schílderung, lang ausgesponnene dialoge, lyrik und rhetorik in den Am.; klarheit und einfachheit in bezug auf zeit und ort in der. Akv., mehrfache sprünge und unklarheiten in den Am.; grossartig heroische charakterzeichnung bei dẹn hauptpersonen, gänzliches zurücktreten der nebenpersonen in der Akv., unbeholfenheit in bezug auf zwei hauptpersonen, liebevolle zeichnung der nebenpersonen in den Am.; völliges zurücktreten des dichters in der Akv., starkes hervortreten desselben in den Am. Nach alledem können wir sagen, dass die Akv. 1) das werk eines klassikers ist, die Am. das eines epigonen.

4. Einige literaturgeschichtliche fragen.

$\$$ 16. Beziehungen der lieder zu einander.

Bisher haben wir die beiden lieder stets als selbständig nebeneinander gestellt. Nun aber erhebt sich zunächst die frage, ob etwa das eine im anderen benutzt worden sei. Die übereinstimmung in gewissen (s. unten \$ 22) grundzügen der sage beweist hierfür nichtș. Nur formale anklänge könnten solche beziehungen beweisen.

1) Befragen wir zunächst den wortschatz. Unter den zusammengesetzten substantiven (in der Akv. 41, in den Am. 33) finden sich nur 2 gemeinsame: qlskáler und hiıskarlar. Unter den zusammengesetzten adjectiven (in der Akv. 37, in den Am. 36) kehrt nur 1 in beiden gedichten wider: afkairr. Unter den abstracten substantiven (Akv. 30, Am. 134) sind 6 gemeinsame,

1) Hier ist wider speciell Akv. A gemeint, da sie für uns der einzige wirklich greif:bare teil des gedichts ist. 
aber es sind auch ganz gewöhnliche wörter: skop, hugr, leikr, reipe, daupe, meipmar. - Der wortschatz spricht also nicht für benutzung.

2) Wenn wir weiter nach wörtlichen anklängen suchen, so finden wir allerdings einen gemeinsamen halbvers, Akv. 25, 1 = Am. 61, 5 hló pá Hogne. Aber auch damit ist nicht viel -zu erweisen, denn der versanfang $h l o ́$ pá + name findet sich noch mehrfach in den heldenliedern (Hampésmọl 20 hló $\not a ́$ Jormunrekkr, Brot 10 hló bá Brynhildr, Sigurbarkvipa 30 hló bá Brynhildr, Guprúnarkvipa III, 9 hló $\not p a ́$ Atla hugr), ist also formelhaft, und so können beide dichter ihn unabhängig von einander gebraucht haben. Ebenso möglich ist es aber auch, dass die übereinstimmung der beiden texte auf der erinnerung an eine gemeinsame quelle, an ein älteres drittes lied (vgl. Symons ausgabe s. 453) beruht. Das ist sogar hier insofern wahrscheinlicher, als beide mal der viersilbler aus dem gefüge des sonst eingehaltenen Málaháttr herausfällt.

Sonst finden sich keine wörtlichen anklänge zwischen irgend einem teil von Akv. und Am.

3) Auf der anderen seite spricht gegen beziehungen der lieder unter einander das, was sich uns am schluss des zweiten teiles, nach betrachtung der sagengestalt der beiden lieder, herausstellen wird (s. unten § 48). Demnach werde ich im folgenden die beiden Atli-lieder immer als zwei von einander unabhängige denkmäler behandeln.

$\S$ 1\%. Das relative alter der lieder.

Da directe beziehungen zwischen den beiden liedern nicht nachzuweisen sind, fehlt es natürlich auch an directen anhaltspunkten für die entscheidung der frage nach dem relativen alter. Als das ältere gedicht ist zwar die Akv., als das jüngere die Am. schon mehrfach in anspruch genommen worden, aber von einem strengen beweis für die richtigkeit dieser anschauung dürfen wir bisher doch kaum reden. Ein solcher beweis lässt sich aber, wie mir scheint, durch herbeiziehung der Guprúnarkvipa II (en forna) führen. Ich glaube nämlich zeigen zu können, dass diese vom dichter der Am. benutzt worden ist, ihrerseits aber die Akv. benutzt hat, also in der mitte zwischen den beiden. Atli-liedern steht. 
1. In den Am. finden sich zwei nächtliche scenen, die ihrer anlage nach in der Edda nur in Gokv. II etwas ähnliches haben. Am. 14-19 werden von Kostbera dem Hogni drei beängstigende träume erzählt; die dieser jedesmal ins gleichgiltige deutet. Dann werden Am:21-25 von Glaumvor dem Gunnarr vier träume erzählt, deren einer, 22, von Gunnarr ebenfalls ins gleichgiltige ausgelegt wird; die deutungen $z$ weier träume (21a und 24a) scheinen verloren, und der letzte trâum, 25, wird von Gunnarr kurz abgetan 26 seinat's at segja. Mit diesen scenen ist $\mathrm{zu}$ vergleichen Gokv. II str. 39-44. Str. 39 erzählt Atli einen schlimmen trâum, str. 40 deutet ihn Guđrún ins gleichgiltige und günstige; str.41. 42.43 erzählt Atli weiter drei schlimme träume, woraüf ihn Guđrún str. 44 widerum mit einer deutung ins gleichgiltige zu beruhigen sucht. ${ }^{1}$ )

Dass die anlage dieser nachtscene in Gðkv. II für Am. vorbildlich gewesen sein möge, hat schon Finnur Jónsson, Litt. hist. 1, 296 ausgesprochen. Zur näheren begründung der vermutung möchte ich zunächst auf einiges inhaltliche hinweisen, das beziehungen zwischen Gokv. II und Am. in dem genannten sinne wahrscheinlich macht.

Auffallend ist zunächst Glaumvors zweiter traum (22). Sie erzählt, sie habe den gatten durchbohrt gesehen, nachdem sie vorher (str. 21) erzählt hat, daiss sie ihn zum galgen habe schreiten sehen, und dass ihn schlangen lebendig gefressen hätten. Dieser letztere traum (21) soll ganz einfach das vorhersagen, was sich nachher wörtlich so ereignet $(55,6$. 7. 8). Der dritte traum (24) ist symbolisch, der vierte (25) führt im sinne des seelenglaubens das motiv fort. Dagegen ist der zweite traum (22) hier ohne sinn und zweck: er gibt direct eine todesart Gunnars an, die hernach gar nicht eintritt. ${ }^{2}$ ) Erklärlich wird uns dagegen die abschweifung des dichters, wenn wir annehmen, dass ihm der erste traum Atlis (Gokv.

1) In den Eddaliedern findet sich ausser Am. und Gбkv. II keine ähnliche seene, dagegen in der prosaliteratur, vgl. Gunnlaugssaga c. 2 (Asmundarson s: 3 f.).

2) Der verfasser der Volsungasaga hat gefühlt, dass die beiden träume 21 und 22 mit zwei verschiedenen todesarten nebeneinander nicht passen; er hat nur den zweiten behalten (cap. 35), vielleicht weil ihm der erste zu deutlich erschien. 
II, 39) vorschwebte, nach welchem Atli von Guđrún durchbohrt wird.

Auffallend und für sich allein unverständlich ist sodann an der stelle, wo Guđrún die busse Atlis abweist, die bemerkung (Am. 67, 3. 4): sleit ek pá sátter, es vóro sakar minne 'ich lehnte versöhnung ab, als es sich um geringere schuld handelte'. Verständlich wird sie dagegen sofort, wenn man sie als reminiscenz an Gokv. II, 18-21 auffasst. Grimhild fragt ihre söhne, wer der Guđrún busse für den erschlagenen sohn und gatten zahlen wolle:

18 hverr vilde sun systor bǿta, epa ver vegenn vilde gjalda.

Beide erklären sich bereit, gold zu bieten:

19 gorr lézk Gunnarr goll at bjópa sakar at bóta, ok et sama Hogne.

Dann kommen ihre bez. Atlis boten zu Guđrún und bieten ihr kleinode als sühne für den schmerž:

21 hverr vilde mér
hnosser velja, ok hosser velja,
ef mǽtte mér mat mála,
tryger vinna - mara súta

Sie lehnt die busse ab, wie sie an der genannten stelle der Am. sagt. Da betäubt sie Grímhild mit einem trank und raubt ihr mit gewalt - zwar nicht die erinnerung an Sigurds tod (str. 30) - aber den zorn gegen die brüder: né sakar mynpak; sakar nennt auch in Am. 67 Guđ̛ún jene frühere schuld. Dass Guđrún den tod ihres gatten und söhnchens immer noch für ein geringeres (sakar minne) als den untergang ihres ganzen geschlechts bei Atli ansieht, ist selbstverständlich.

$\mathrm{Zu}$ diesen beiden stellen in Am. treten nun noch mehrere wörtliche anklänge, die von $R$. Lieonhardt in seiner untersuchung über den málaháttr der Am. hervorgehoben worden sind. An

Grkv. II, 26, 3 fjolb alz fear erinnert Am. 88, 7 par vas fjolb fear; an Grkv. II, 2, 7 eba goll glóbrautt erinnert Am. 13, 5. 6 - golle reifa glóbraupo; an Grkv. II, 10, 1 svarape Hogne erinnert Åm. 32, 1 Hogne svarabe; an Gðkv. II, 19,4 ok et sama Hogne erinnert Am.1,7 ok et sama sunom Gjüka.

'Dass diese übereinstimmungen nicht auf zufall, sondern auf (bewusster oder unbewusster?) nachbildung berühen, ergibt sich aus folgendem: a) goll mit attribut. glópraupr erscheint 
nur an den citierten stellen der Am. und Gokv. II, sonst nirgends in der Edda. Eine präteritalform von svara begegnet im vers nur noch Hampésmọ́l 13, 1. Die verbindung fjolp fear ist in der gesammten Edda ausser in Am. und Gðkv. II nur noch einmal, Gróttaş̨ngr 5,3, zu belegen. Dem allgemeinen dichterischen formelschatz gehören diese wendungen also nicht an. b) Jeder der vier verse der Am., die anklänge an Gðkv. II zeigen, enthält irgend eine metrische unregelmässigkeit' (Leonhardt a.a. $0 . \S 15,5$, s. dort auch das nähere über diese unregelmässigkeiten).

Damit ist wol als erwiesen anzusehen, dass der dichter der Am. die Gðkv. II kannte und benutzte.

2) Nun zu den beziehungen zwischen der Gðkv. II und der Akv. Dunkel und merkwürdig bleibt zunächst trotz aller erklärungen str. 40 der Gðkv. II, in der Guđtrún Atlis ersten traum deutet:

pat's fyr elde, es iarn dreyma,
fyr dul ok vil drósar reipe;
monk pik vip bolve brinna ganga,
líkna ok lákna, pót mér leipr seer.

'Träumt man von eisen, ist aussicht auf feuer, und frauenzorn deutet auf frohsinn und stolz, ein gebrechen dir werd ich durch brennen heilen, ob auch wenig dir hold, dich warten und pflegen'

übersetzt es Gering, der an ausbrennen eines geschwüres denkt (übersetzung s. 248 n. 1). Merkwürdig bleibt es immerhin, wie Guđrún hier von dem schwert, von dem Atli getränmt hat 39, 7, auf das feuer kommt, zumal sie daneben sogleich in der zweiten zeile eine andere deutung des mordtraumes versucht. Dem dichter scheint ein mit Guđrún in zusammenhang stehendes feuer vor augen geschwebt zu haben: was liegt da näher, als an den saalbrand zu denken, den Guđrún nach Akv. 44, 5 ff. (in den Am. kommt er nicht vor) entfacht? Die erinnerung daran könnte bei dem dichter der Gðkv. II die hier etwas unangebrachte erwähnung eines feuers durch Guđrún veranlasst haben.

Schwerer fällt schon in die wagschale der wörtliche anklang zwischen Akv. 39, 3. 4 und Gokv. II, 42, 5. 6:

Akv. hjorto hrǽdreyrog vip hunang of tuggen

Grkv. II hjorto hugpak peira vip hunang tuggen.

Schon Müllenhoff (D.A.5,395) hat vermutet, dass hier die Gðkv.II 
von der Akv. beeinflusst sei. Um zu entscheiden, welche stelle die ursprüngliche, welche die nachgebildete sei, nehmen wir widerum $\mathrm{zu}$ einer metrischen beobachtung unsere zuflucht. Sievers hat nämlich (Beitr. 6, 343) darauf hingewiesen, dass in Gokv. II als in einem fornyrdislaggedicht der halbvers hjorto hugpak peira anstössig sei; dass man nun zwar leicht peira streichen könne, aber dass damit der parallelismus zu 43,5 (hold hugpak beira) verloren gehen würde. Schlecht ist also der vers in Gokv. II, wir dürfen ihn aber nicht verbessern, sondern müssen ihn hinnehmen wie er ist. Ist ferner der entsprechende vers Akv. 39,3.4 metrisch ganz unauffällig, so müssen wir ihn auch als den ursprünglichen und damit als das vorbild für Gðkv. II, 46, 5. 6 ansehen. Indem der dichter im ersten halbvers der zeile hjorto, im zweiten vip hunang tuggen widergab, suchte er zugleich im ersten noch das verbum mit subject (hugbak) und das bestimmende pronomen (beira) unterzubringen: darunter musste der halbvers leiden.

Einen weiteren anklang ${ }^{1}$ ) zeigen die stellen Akv. 44, 4 ok hvelpa leyste und Gokv. II, 43, 2 hvelpa losna, der nach dem vorher festgestellten auch als ein zeichen der abhängigkeit der Gðkv. II von der Akv. anzusehen ist.

Die stellen, welche uns zur annahme dieses verhältnisses von Akv. und Gokv. II geführt haben, gehören nun alle der Akv. A an. Wir können daher mit bestimmtheit nur sagen, dass $A$, das alte málaháttrgedicht, älter ist als die Guprúnarkvipa: damit auch älter als die Atlamǫl, die von der Gðkv. abhängig sind.

In welchem zeitlichen verhältniss dagegen das uns als 'Atlakvipa' erhaltene zusammengesetzte und interpolierte gedicht zu den. Am. steht, können wir nicht wissen.

§ 18. Die bezeichnung en grónlenzka, grónlenzko.

1) Beide Atli-lieder werden im Codex Regius als grönländisch bezeichnet. In bezug auf die Am. ist die herkunft aus dem amerikanischen Grönland.über jeden zweifel erhoben durch Gröndal (Ant. Tidskr. 1861-63, s. 373) und Bugge (Fornkvæđi 433). Es sei gestattet, ausserdem auf einiges in der darstellung der Am. hinzuweisen, was an grönländische ver-

1) S: Detter und Heinzel 2, 506. 
hältnisse erinnert, wie wir sie aus der sàga von Eiríkr dem roten und dem Grónlendinga páttr kennen lernen. Gestalten aus der geschichte seiner heimat mögen dem dichter vorgeschwebt haben, als er die gestalt Guđrúns ausmalte. Wenn er sie erzählen lässt, dass sie in ihrer jugend zusammen mit ihren brüdern und Sigurđr auf seefahrten ausgezogen sei (Am. 92), so wird man erinnert an frauen wie Guđriđr, porsteins gattin, oder Freydíss, Eiríks des roten tochter, die zusammen mit den männern auszogen, um nach dem verheissungsviollen Vinland zu gelangen (Gr. p. Storm s. 63. 66. 69). Besonders mag auf die charakterzeichnung der grönländischen streitbaren Guđrún eingewirkt haben eine gestalt wie Freydíss, die mit dem schwert in der hand, als die ihrigen sich zurückziehen, den feindlichen Skrælingar entgegentritt (Eirikssaga Storm s. 40. 41); die aber auch mit Guđrún die grausamkeit gemein hat, indem sie dàs brïderpaar, mit dem sie nach Vínland gefahren ist, ermorden lässt und eigenhändig mit der axt mehrere frauen tötet (Gr. p. s. 71). Auch die bestattung in einer kista (Am. 97) findet sich hier mehrfach (Eirikssaga s. 24 ; Gr. p. s. 64.65$)$.

2) In bezug auf die Akv. hat dagegen Bugge (a.a.o. s. 428) angenommen, dass die bezeichnung en grónlenz̧ka fälschlich von den Am. auf die Akv. übertragen worden "sei. Die frage concentriert sich. für uns zunächst auf die beiden alten teile des gedichts, A und B.

In der darstellung findet sich nichts, was für entstehung an đer grönländischen küste spräche. Die landreise der Niflunge durch den Myrkviđr, zu pferde (in den Am. finden sich nirgends solche erwähnt), durch grüne felder (str. 13), könnte eher dagegen sprechen. Ferner können wir, wenn Akv. A und B grönländisch sind, ihre entstehung nicht viel vor dem jahr 1000 ansetzen; da wir aber $A$ und auch gerade $B$ mit seinen starken epischen widerholungen für sehr alt halten müssen, so möchten wị nicht gern. schon das jahr 985 als obere grenze ansetzen, sondern wol eher etwas weiter ins 10. jh. hinaufgehen. Darum ist es auch mir nicht wahrscheinlich, dass die alten teile der Akv. grönländisch sind. Mogk macht auch (Grundr. 2 2, 648) darauf aufmerksam, dass es für Grönland schwerlich denkbar sei, dașs sich hier die deutsche Nibelungensage. in so reiner 
form erhalten habe, wie wir sie in der Akv. finden (s. dazu unten am schluss von teil II $\S 48$ ).

Auf der anderen seite ist aber die überschrift in $R$ auch nicht ganz ausser acht zu lassen. Auf reine gedankenlosigkeit eines abschreibers (wie F. Jónsson, Litt. Hist. 1, 306 will) können wir sie schwerlich zurückführen, da in $R$ die Akv. vor und nicht hinter den Am. steht (Mogk, Grundriss 22,646). Daher halte ich es für das wahrscheinliche, dass der redactor der uns erhaltenen Akv. diese aus alten europäischen liederteilen (A, B) in Grönland zusammengesetzt habe. Dann konnte das fertige werk in der tradition sehr wol als grönländisch gelten (vgl. auch Symons' einleitung zur ausgabe s. ccxxxv).

$\S$ 19. Heidnische und christliche urheberschaft.

Auch in bezug auf die religion scheinen die Atli-lieder in ihrer herkunft verschieden zu sein.

1) In der Akv. tritt noch die altheidnische religion offen zu tage. Das Niflungenerbe stammt von den asen 29, 3, Guđrún ist mit siegverleihenden göttern (sigtivar) in verbindung gebracht (in der verderbten str. 31); dem Gunnarr hat Atli eide geschworen, ausser bei anderen heiligtümern, bei Sigtýrs berg, bei Ullrs ring 32. Man darf wol annehmen, dass der verfasser der Akv. A, dem die genannten stellen gehören, noch heide war; von christlichen elementen findet sich jedenfalls in der Akv. nichts.

2) In den Am. ist es anders. Kein einziger göttername erscheint; nur den göttern im allgemeinen dankt Gưđrún 53, 9. Strophe 21, 5 findet sich rok ragna, das göttergeschick; aber da auf einzelgötter hier nirgends ein bezug ist, wird dieser ausdruck wol nur in abgeblasstem sinne, gleich: ende der welt, $\mathrm{zu}$ verstehen sein. Weiter findet sich allerdings aus dem gebiet der niedern mythologie der helglaube, der seelenglaube, der riesenglaube; die hel (unpersönlich) erscheint 38,2. 41, 5. 47,9 . 51, 3. $52,5.91,7$; den seelenglauben spiegeln wider die träume 18 und 25 , von dem bluttriefenden adler und von den toten frauen; die riesen, joten, sollen Vingi holen, wenn er lügt $(30,3)$.

Nun treten aber, wie bekannt, in den Am. auch einige züge von specifisch christlichem gepräge auf, die den gedanken 
nahe legen, dass die Am. von einem christen verfasst seien (Jessen, Zs. fdph. 3, 38 und Mogk, Grundriss 22,651 nehmen das an). Hier ist nun zunächst zu betonen, dass die eben zusammengestellten mythologischen züge jedenfalls nicht dagegen beweisen. Die vorstellung vom ende der welt stimmt zu der christlichen lehre vom weltgericht. Die vorstellungen von unterirdischem aufenthalt der toten, von folge- und schutzgeistern (Am. 18.25) sind durch das christentum nicht ausgerottet worden, das zwar die götter vertrieb, aber den niedern aberglauben nicht vertreiben konnte.

Ebensowenig wie diese züge spricht gegen christliche urheberschaft der in den Am. so stark ausgeprägte fatalistische schicksalsglaube. Er tritt ganz unpersönlich auf $(2,1$ skqp óxo skjoldunga, 33, 3 pá hykk skop skipto, 45, 3 skopom vippr mange).

Christlichen einfluss verrät dagegen zunächst der schluss der Am., wo Guđrún von bestattung in einem sarg spricht, kisto steinda 97,2 (Jessen a.a.0. s. 38). Wenn ausserdem von einem schiff die rede ist (knqm mon ek kaupa), so soll nach Weinhold (Altnordisches leben s. 479) Atlis sarg auf ein schiff gesetzt und den wellen übergeben werden, wie Scylds leiche im Beowulf $26 \mathrm{ff}$. (die aber nicht in einen sarg geschlossen ist). Man kann aber auch an ein schiff im grabhügel denken (s. Weinhold ebda. s. 495 ff.).

Specifisch christlich ist sodann die äusserung Guđrúns 82,7.8 frípra vilk daupa fara i ljós annat, wie Detter und Heinzel 2,565 und Mogk, Grundriss 22,651 hervorheben. In der Akv. fahren die toten nicht in ein anderes licht, sondern ins dunkel (niflfarna 36,8, was an Niflhel erinnert).

Auch die tatsache, dass Guđrún dem sterbenden gatten die bestattung zusichert und auch ihr versprechen hält (97. 98), mag auf christliche-stimmung zurückgehen.

Nach alledem ist es wol als sicher anzusehen, dass der dichter der Am. christ war oder zum mindesten christlichen kreisen nahe stand.

§. 20. Beziehungen zwischen den Atli-liedern und anderen heldenliedern der Edda.

1) Von den beziehungen der Atli-lieder zur Gokv. II war schon oben in $\S 17$ die rede. Im weitern findet man zunächst 
in den Hampésmọ́l einige stellen, die an stellen der Akv. erinnern. Dass die Hm. allein ausser Akv.B (40) die namen Erpr und Eitill kennen (Hm. 8, 2. 3), kann nicht viel beweisen, zumal str. 8 von Ranisch (Zur kritik und metrik der Hampismál s. 5. 6) als eine interpolation wahrscheinlich gemacht worden ist. Dagegen besteht zweifellos eine beziehung zwischen $\mathrm{Hm}$. und Akv. A: Hm. 10 brépbr grátr [paic] pina ole bure svása erinnert alliterierend an Akv. 41, 7.8 brepr [sina] berharpa ok bure svása; Hm. 23, 6 i borg enne hovo erinnert an Akv. 14, 4 á borg enne hóvo; Hm. 25, 10 i eld heitan erinnert an Akv. 45, 10 i eld heitan; die beiden letzten übereinstimmenden ausdrücke (borg enne hovo, i eld heitan) finden sich ausser an den genannten stellen nirgends in der Edda; deshalb und wegen Hm. 10 müssen wir eine beziehung zwischen den beiden gedichten annehmen. In welchem sinne diese aber zu deuten ist, d. h. ob Akv. A oder Hm. älter ist, kann ich nicht entscheiden; die am meisten auffallenden. verse Hm. 10 und Akv.41 werden beide durch ausscheidung der pronomina (Symons' ausgabe s. 434; Ranisch a.a.o. s. 55) unanstössig, sodass ein metrischer anhalt fehlt.

Dagegen ist die entscheidung wol leichter bei den beziehungen zwischen der Akv. und drei jüngeren liedern: Odrúnargrátr, Sigurparkvipa en skamma und Guprúnarhvǫt.

2) In Odrgr. erzählt Odrún der Borgný, wie ihr geliebter Gunnarr in der schlangengrube endete und Hogni das herz ausgeschnitten wurde, wobei die stelle Odrgr. 26, 5. 6 peir ór Hogna hjarta skóro alliterierend anklingt an Akv. 25, 1. 2 hló pá Hogne, es til hjarta skóro. Ferner findet sich die kenning sverpa deiler. (Odrgr. 31, 7) in der Edda sonst nur noch Akv. 39, 2.

Daher darf man wol annehmen, dass der dichter des Odrgi. die Akv. (A) gekannt habe.

3) Dasselbe gilt von Ghv., wo Guđrún erzählt, dass dem Gunnarr die glänzenden würmer auf den leib krochen (til fjors skripo), und Hogni nach dem herzen geschnitten wurde, wobei die stelle Ghv. 18,2-4 es hjarta.til konung óblaupan kvikvan skoro anklingt an Akv.25,2.3 - - es til hjarta slcóro kvikvan - - - (Symons' ausgaibe s. 471).

4) Endlich zeigt Sg. sk., wo Brynhild das ende Gunnars in der schlangengrube prophezeit (58), wörtliche anklänge an 
die Akv.; alliterierend Sg. sk. 16,7.8 gótt's at rába Rínar malme, zu vergleichen mit Akv. 29,1.2 Rín skal rápa rógmalme - - ; Sg. sk. 20, 3. 4 yngra — - ófrópara, zu vergleichen mit Akv. 41,9 unga, ófróba; ungr und ófrópr findet sich alliterierend nur an diesen beiden stellen der Edda; ferner Sg. 4, 1 seggr enn supróne = Akv. 2, 7; auch dieser ausdruck findet sich sonst nirgends in der Edda; endlich Sg. sk. 55, 4 skatra menge $=$ Akv. 34, $4 \mathrm{~d}$; auch dieser ausdruck ist sonst nirgends zu belegen. Es ist demnach anzunehmen, dass die Akv. von der Sg. sk. benutzt worden ist, und zwar, da die letzte stelle 34,4 dem d gehört, offenbar Akv. A und ihre interpolation $\mathbf{d}$.

5) Vielleicht hat ausserdem die Sg. sk. auch die Am. benutzt. Auffallend ist erstens die tatsache, dass nur Sg. sk. als einziges von allen Eddaliedern ausser den Am. den Siguror enn hunskr. nennt (Sg. sk. 4, 7. 9, 1. 18,5. 65,5. 66,1 - Am. 94,1); ferner erinnern die stellen Sg. sk. 2, 2 meipma fjolip (sonst iu der Edda nur noch prymskv. 23,5) und 39,4 meiphmar piggja (nirgends sonst) an Am. 89, 2 meipma fjölp piggja; auch das particip fullveget Sg. sk. 33, 2 findet sich in der. Edda nur noch Am. 49,5.

Damit ist wol als sicher anzusehen, das eins der lieder das andere benutzt habe; welches der beiden lieder aber das ältere ist, kann ich nicht entscheiden.

\section{Sagengeschichtlicher teil.}

\section{§ 21. Vorbemerkung.}

Da wir Akv. und Am. als zwei von einander unabhängige denkmäler der Nibelungensage ansehen (s. § 16), so köṇnen wir auch zunächst nicht der sagengestalt eines, der beiden lieder in bezug auf ursprünglichkeit den vorrang erteilen. Vielmehr soll, soweit unterschiede in der sagengestalt vorliegen, jeder einzelne fall daraufhin untersucht werden, ob Akv. oder Am. das ältere oder jüngere zeigen. Auf diesem wege soll versucht werden, die züge zusammenzutragen, die einst der den beiden liedern vorausliegenden althordischen sagenform angehört haben; zugleich soll die entwicklung der sagenzüge innerhalb der nordischen sage aufgezeigt werden, soweit das 
möglich ist. Im gegensatz zu der als altnordisch bezeichneten form wird mehrfach von der 'älteren deutschen' form die rede sein: damit ist die deutsche Nibelungensage aus der zeit vor ihrer wanderung nach dem norden gemeint, auf die wir als auf die quelle der nordischen sage stets rücksicht nehmen müssen. Vorangestellt sei eine übersicht über das gemeinsame in dem inhalt der beiden lieder, wie sie uns vorliegen; dass dies noch nicht gleich der zu grunde liegenden altnordischen form ist, werden wir am schluss sehen. Mit den unterschieden in der sagengestalt der beiden lieder werden wir es dagegen in den folgenden abschnitten zu tun haben.

\section{$\S$ 22. Das gemeinsame.}

König Atli aus dem geschlecht der Buplunge (Akv. 45. Am. 51. 90) schickt an die Gjúkunge (Akv. 1. Am. 99) Gunnarr und Hogni eine einladung (Akv. 1 ff. Am. 4 ff.) und erweckt hoffnung auf geschenke (Akv. $4 \mathrm{ff}$. Am. 13, 5. 6). Ihre schwester Guđrún, Atlis gattin, warnt die brüder (Akv. 8. Am. 3). Man zögert mit der zusage (Akv. 6 ff. Am. 7, 5 ff.), entschliesst sich aber endlich zur reise (Akv. 11. Am. 26). Feierliche begleitung der Gjúkunge (Akv. 12. Am. 28). Ankunft bei Atli (Akv.15. Am. 39). Guđrún tritt hervor und begrüsst die brüder (Akv. 16, 5 ff. Am. 44. 45). Ein kampf zwischen den Niflungen (Akv. 26, 2. Am. 44, 5) und Atlis leuten (Akv. 19. 20. Am. 42.47 ff.). Die gäste unterliegen (Akv. 19. Am. 49). Hogni wird das herz ausgeschnitten, er lacht (Akv. 25. Am.61, 5). Ein Hjalli spielt dabei eine rolle (Akv. 23 ff. Am. 57 ff.). Zornige rede Guđrúns gegen Atli (Akv.32. Am. 53). Gunnarr wird schlangen übergeben (Akv. 34. Am. 55, 8), schlägt die harfe (Akv.34, 7. Am. 62) und stirbt als letzter (Akv. 35, 4. Am. 63, 1). Guđrún tötet ihre und Atlis söhne und bewirtet diesen mit einem trank und den herzen der kinder; darauf sagt sie ihm, was er gegessen hat (Akv. 36. 39. Am. 71-78). Guđrúns kostbarkeiten (Akv. 42. Am. 43). Guđrún nimmt rache an Atli (Akv. 44. Am. 84, 5-8). Ein sohn Hǫgnis bleibt leben (Akv. 12,6. Am. 83,5).

Das ist alles, was sich von gemeinsamem inhalt in beiden liedern findet.

\$23. Gunnarr und Hogni.

Ein hauptunterschied in der sagengestalt der einzelnen

Beiträge zur geschichte der deutschen spracho. $\mathbf{X X X I I 1 . ~}$ 
Atli-lieder besteh" zunächst darin, dass Gunnarr und Ḣogni eine verschiedene stellung einnehmen. Wie wir schon bei der betrachtung der charaktere in $\$ 12$ (s. $220 \mathrm{ff}$.) sahen, steht in der Akv. Gunnarr ganz im vordergrund, Hogni tritt zurück, obwol seine tapferkeit in str. $20 \mathrm{~B}$, c hervorgehoben wird; in den Am. dagegen steht Hogni in erster linie und Gunnarr tritt hinter ihm zurück. In den:Am. zeigt sich das besonders darin, dass Hogni zwei erwachsene söhne hat, die er auf die reise mitnimmt, und dass er einen sohn und rächer hinterlässt, während von Gunnarr keine nachkommenschaft erwähnt wird. Wir können dies verhältnis nicht nur der willkür der dichter zuschreiben. Die beiden söhne Snǽvarr und Sólarr mögen wie die namen von dem dichter der Am. erfunden sein: aber die sage, dass Hogni nachkommen hat; ist älter als die Am.: schon in der Akv. begegnet ein erfevorpr Hogna ${ }^{1}$ ), und dieser ist hier gewiss keine ausschmückung des dichters A, denn derselbe stellt überall gerade den andern bruder, Gunnarr, in den vordergrund: zu Gunnarr wird der bote gesant $(1,2.6)$, Gunņarr lädt er ein $(3,5)$, Gunnarr wird bei der abreise begleitet (làndrogne 12,1), Gunnarr von Guđrún begrüsst $(16,5)$, Gunnarr wird nach dem gold gefragt und verweigert das gold (22. 29), Gunnarr wird als letzter zum tode geführt (30), wegen des eidbruchs an Gunnarr flucht Guđrún dem Atli (32), alle die vom morde Gunnars heimgekommen sind, verbrennt Guđrún $(45,3)$.

Wenn wir nun trotzdem auch in der Akv., in übereinstimmung mit den Am., nur Hǫgni im gegensatz zu Gunnarr eine nachkommenschaft aufweist, so lässt das vermuten, dass einmal Hogni in der altnordischen sage eine hervorragendere stellung als sein bruder einnahm, dass die glänzende stellung Gunnars in der Akv. A dagegen eine neuerung bedeutet. Dafür sprechen nun ferner die beiden deutschen sagenformen (NL.

1) In der prosa der Edda (Dráp Niflunga) begegnet als dritter sohn Hęgnis ein Gjúki. Vermutlich hat der sammler der lieder diesen namen aus dem geschlechtsnamen der Gjúkunge für den namenlosen erben Akv. 12,6 abgezogen (nach dem nordischen brauch, dass der enkel oft den namen des grossvaters erhielt), ähnlich wie Volsungasaga 38 die bezeichnung Hniflungr für den namenlosen sohn HQgni (Am. 83,5) als eigennamen gefasst wird (er Niflungr hét). 
und ThS.). Hagen steht überall im vordergrund der handlung, während der schwache Gunther eine passive rolle spielt. Er ist der mörder Siegfrieds (NL. Bartsch Av. XVI und ThS. 347), er strebt nach dem schatz Siegfrieds (NL. XIX. 1107) und waltet eigenmächtig darüber, indem er ihn in abwesenheit der fürsten versenkt (1137); er, der dienstmann Gunthers, wird von Kriemhilt danach gefragt (NL. 1741, zum zweiten mal 2367; ThS. 373); Hagen ist der führer auf dem weg zum Hunnenland und steht in den kämpfen daselbst im vordergrund; er überlebt Gunther und stirbt als letzter der Nibelungen: (NL. 2373. ThS. 393).

So wird auch in der altnordischen sage Hogni im vordergrund der handlung gestanden haben, bis Gunnarr ihn zurückgedrängt hat. In diesem fall hätten die Am. gegenüber der Akv. den älteren zug bewahrt.

\$ 24. Burgunden und Goten.

Akv. 19, 3 B heisst Gunnarr vinr Borgunda, 21, 3 B Gotna pjópann. In den Am. finden sich beide völkernamen nicht. Dass beide in demselben gedicht für den gleichen herscher verwant werden, braucht uns nicht zu verwundern. Golther macht (Germania 33, 474 f.) darauf aufmerksam, dass zur zeit, als die sage entstand, die Burgunden an der Rhone und Saone, hinter ihnen die Goten sassen, beide als feinde der Franken: so habe die sage Burgunden und Goten im gegensatz zu dem fränkischen geschlecht der Wälsungen als ein volk aufgefasst; diese identification sei nicht als eine nordische neuerung aufzufassen. Es hat vielleicht auch eine erinnerung an die schlacht bei Chalons 451, in der der Gotenkönig Theodorich im kampf gegen Attila fiel, dazu mitgewirkt, dass man den Burgundenkönig, der bei dem Hunnenkönig sein leben lassen musste, als Gotenkönig bezeichnete. Ob aber diese identification älter ist als die wanderung der sage in den norden, können wir nicht wissen, da in der aussernordischer sage Gunther nie als Gote bezeichnet wird.

Das auftreten des Burgunden-namens an dieser einzigen stelle der Edda brauchen wir nicht nachträglicher deutscher beeinflussung zuzuschreiben, wie Edzardi wollte (Germ. 23, 86). Dass der Burgunden-name auch schon in ausserdeutscher sage 
sehr alt ist, zeigen die angelsächsischen gedichte Widsiđ und Waldere (Widsiđ 19 Burgendum Gifica; 65 f. Burgendum Guđhere; Waldere B 14 wine Burgenda für Guđhere). Die Akv. hat demnach in diesem namen einen besitz aus der älteren deutschen sage bewahrt, der sich in den Am. und allen anderen Edda-liedern nicht mehr findet.

Der name der Goten erscheint ausser Akv. 21 noch mehrfach in den heldenliedern der Edda, in verschiedener bedeutung. Für das volk der Niflunge (wie Akv. 21) erscheint er Gðkv. II, 17, 6 (Grimihildr, gotinesk kona); Brot 9, 4 (Gjúka arfe ok Gota menge); Gríp. 35, 6 (Gunnare til handa, Gotna drótne); für JQrmunreks volk, die historischen Ostgoten, Ghv. 2, 12: 8, 6. 16, 4; Hm. 3, 8. 23, 4. 24, 4. 30, 2. Ausserdem herschte der von Brynhild getötete könig á Gotpjópo (Helreip 8, 2).

Im übrigen müssen wir mit der möglichkeit rechnen, dass Akv. 21. Brot 9. Grip. 35 gotar oder gotnar einfach 'männer' bedeutet, während in der Gôkv. II, 17 mit gotnesk kona doch nur der volksname gemeint sein kann.

§ 25. Hunnen und Hưnmork.

In der Akv. wird das volk Atlis als Hunnen bezeichnet $(2,4.4,4.7,12.13,5$. 16, 7. 17, 9. 29, 8. 37, 4. 41, 4). Dieselbe auffassung findet sich in der Edda noch Gðkv. II, 27, 1. Gðkv. I, 6, 2. 24, 8. Die Am. dagegen kennen keinen namen für Atlis volk. Auch hier hat die Akv. im gegensatz zu den Am. einen alten sagennamen bewahrt: dass Attila könig der Hunnen ist, weiss schon Wịsid (35 Attla weold Húnum).

Was weiter die lage des hunnischen landes betrifft, so haben wider die Am. darüber keine angabe und keinen anhalt, es zu bèstimmen: Vingi fährt zu den Gjúkungen über den Limafjord (an diesem wasser, nicht am Rheine sitzen sie, Am. 4, 7. 8, vgl. Akv. 18), aber von welcher himmelsrichtung er kommt, erfahren wir nicht. In der Akv. ist die lage klarer orientiert: die Hunnen sind das südvolk (suprp̧jóp 14,5): wenn man von. den felsen des Rheins (18) durch den Myrkviðr zieht, gèlangt man nach der südlich gelegenen Húnmǫrk $(13 ; 5)$. Im übrigen kann man aber nicht sagen, dass dieses gebiet des südvolkes mit dem in der oberdeutschen sage feststehenden Ungarn (Pannonia schon im Waltharius 4 u. ö.) identisch sein 
müsse. Im g:egenteil dachte man sich im norden den sitz Atlis sicher ebenfalls in Deutschland, nur südlich von dem Gunnars. Immerhin mag die Akv. in der vorstellung, dass man vom $\mathbb{R}$ hein aus in annähernd südlicher richtung (nicht etwa in nordöstlicher, nach Westfalen zu) zu Atli gelangt, einen zug noch aus der älteren deutschen sage bewahrt haben.

Darauf aber, dass man sich Atlis reich in Deutschland gelegen dachte, deutet die weiterentwickelung des begriffes hunskr, der schliesslich in abgeblasstem sinn $=$ 'südländisch, deutsch' verwant wird. ') So wird in den Am., die den Hunnennamen für Atli und sein volk nicht kennen, Sigurar enn hunske genannt (Am. 94, 1): ausserdem nennt noch Sg.sk. Sigurđr den hunnischen $(4,7.9,1.18,5.65,5.66,1)$, wie sie ihn 4,1 seggr enn supréne nennt -: wörtlich ebenso, wie in der Akv. der wirklich hunnische bote Atlis genannt wird $(2,7)$. An diesen beiden stellen (Akv. 2, 7 und Sg. sk. 4, 1) sieht man die entwickelung des begriffes hunskr von seiner eigentlichen ethnologischen bedeutung $\mathrm{zu}$ der von suprénn.2)

\section{$\$$ 26. Atlis boten.}

Akv. 1 wird ein bote, Knefrođr, an Gunnarr gesant, in den Am. 4. 6, 4 zwei boten, deren einer Vingi heisst. Welcher der beiden namen der ältere ist, lässt sich nicht entscheiden.

In der Akv. ist der bote ein reines werkzeug Atlis, über dessen weiteres schicksal nichts verlautet; in den Am. dagegen ist er eine lebhaft handelnde persönlichkeit: fárs vas flýtande heisst es mit recht von ihm Am.4,3. Er fälscht die runen 4,2, er verschwört sich mit einem meineid, dass er es ehrlich meine 30, er enthüllt höhnisch, wie es zu spät zur umkehr ist, seinen trug und reizt damit Hogni, ihn zu erschlagen 36 -38 (vgl. oben $\S 12 \mathrm{~b} \beta$ ).

1) S. Jiriczek, Deutsche heldensage s.91 (Sammlung Göschen), vgl. auch Petersen, Gammel nordisk geografi, 1834, I, $263 \mathrm{f}$. $273 \mathrm{f}$.

2) Ferner werden in Ghv. 3, 10. 6, 2 Húnkonungar erwähnt, mit denen offenbar die südländischen, deutschen helden Gunnarr und HQgni gemeint sind; Hm. 11, 5 reiten die brüder auf morom húnlenzkom, südländischen, deutschen pferden. - Unklar ist die lage von Húnaland im Odrúnargrátr 4, 3: hier ist es jedenfalls einmal im fernen osten gedacht, da es Mornaland heisst $(1,3)$. 
Da wir bei dem dichter der Am. auch sonst die neigung beobachtet haben, nebenpersonen näher auszuführen, so werden wir wol auch die erweiterung der rolle, des boten auf den dichter selbst zurückführen, die einfachere gestalt in der Akv. für die ältere halten dürfen. Auch den spielleuten der ThS. (leikmenn 359.360) und des NL. (XXIV) ist keine rolle von der bedeutung Vingis zugewiesen.

Der dichter der Am. hatte überdies einen besonderen grund, Vingis höhnende rede einzuführen (36): er brauchte eine motivierung dafür, dass Atli die Niflunge angreift: denn das alte motiv der goldgier kannte er nicht, wie wir bald sehen werden (\$ 34): mit der erschlagung Vingis schuf sich der dichter einen neuen anlass zum angriff.

Gemeinsam ist im übrigen den boten in beiden gedichten nur der zug, dass sie hoffnung auf geschenke zu erwecken suchen; am deutlichsten Akv. 4, 1 (5 c ff.); in den Am. bringen die boten zwar selbst geschenke mit $(5,5)$, sie erwecken aber offenbar hoffnung auf weitere, wie aus Hognis worten hervorgeht: 13,5. 6 okr mon gramr golle reifa glópraupo.

§ 2\%. Gnitaheide.

In der interpolierten str. 5 der Akv. bietet Atlis bote dem Gunnarr die Gnitaheide an, ein golḍreiches gebiet, wie aus Gunnars antwort hervorgeht $6,5 \mathrm{ff}$. Diese bedeutung der Gnitaheide weicht $a b$ von der uns geläufigen: hier ist sie ein teil von Atlis reich, während wir sie sonst nur als die heide kennen, wo Sigurđ̛r den Fáfnir erschlug.

Wenn wir aber fragen, woher diese geläufige auffassung der Gnitaheide stammt, so finden wir sie durchweg in prosaischen quellen, mit ausnahme Gripispá, str. 11:

\section{mont einn vega orm enn frána}

panns grộpogr liggr á Gnitaheipe.

Im übrigen die prosa der Reginsmól (nach str. 14), die der Fáfnismọ́l (anfang); endlich Vọlsungasaga c. 13. 33 und Snorra Edda 40 a (aber nicht in cod. U, der zwar noch die verwandlung Fáfnirs in einen drachen nach Hreiđmars tode, aber nicht den namen Gnitaheide kennt). ${ }^{1}$ ) Dazu kommt eine

1) Im folgenden ist stets damit $\mathrm{zu}$ rechnen, dass der weitere exkurs über die Nibelungensage von Fáfnirs verwandlung ab (c. 40b-42) nicht 
notiz aus dem Itinerarium des abtes Nicolaus aus der mitte des 12.jh.'s (Grimm, H.S.3 N.27), der von der gegend zwischen Mainz und Paderborn zu erzählen weiss: og bar er Gnitaheidr er Sigurdur vá at Fáfni. Dagegen schweigen die strophen der Fáfnismǫl, wo wir den namen am ehesten suchen sollten, völlig.

Ich möchte glauben, dass der interpolator c hier einen alten sagenzug erhalten hat: dass nämlich die goldreiche heide ursprünglich im besitz Atlis war. Reichtum ist ein wesentlicher zug Attilas in der sage. Wie der Etzel des NL. über unermessliche schätze verfügt, so verheisst der Atli der Akv. A (4) schätze und wertgegenstände, so erwartet in den Am. $(13,5)$ Hogni von Atli glutrotes gold. Nun wusste man von Sigurđr, dass er einen unermesslichen goldhort gewonnen hatte; zweitens erzählte man, dass er aus dem süden stamme, ja man nannte ihn selbst einen Hunnen (Am. und Sg.sk., s. oben § 25) -: da lag es nahe, ihn den hort im hunnischen süden, und zwar auf Atlis Gnitaheide, holen zu lassen. So wird die Gnitaheide mit Sigurdr in verbindung gekommen sein. Dass sie einst Atli gehört hatte, geriet dann in vergessenheit, wie die entsprechende stelle der Volsungasaga zeigt, deren verfasser die antwort $6,5.6$ nicht mehr verstanden hat, sie vielmehr im neuern sinne umdeutete. Gunnarr sagt c. 33 en enga. lconunga veit ek jafnmiket gull eiga sem okkr, pvi. at vit hofum pat gull allt, er á Gnitaheipe lá (Symons, Beitr. 3, 240 f.).

Die Gnitaheide ist allein der nordischen sage eigen, weder NL. noch ThS. kennen sie. Der bericht des abtes beweist nichts für bekanntschaft des namens in Deutschland: der in Niederdeutschland, wie ThS. zeigt, bekannte drachenkampf mag an dem genannten orte localisiert gewesen sein, die bezeichnung Gnitaheide dagegen brachte der nordische gelehrte hinzu.

\$ 28. Der Myrkviðr und die grenze gegen Atlis reich.

In anlehnung an str. 7 des liedes von der Hunnenschlacht spricht der interpolator Akv. 5 von stapir Danpar und Myrkviðr. Aber beide localitäten führt er in veränderter bedeutung

in cod. U überliefert und nach Symons (Beitr. 3, 209 ff. Einl. s. xLVII) als späterer zusatz eines bearbeiters anzusehen ist, der die liedersammlung der Edda und sogar die Volsungasaga gekannt hat. 
ein: während sie im liede von der Hunnenschlacht im besitz des Gotenkönigs Angantýr sind, sind sie hier im besitz des Hunnenkönigs. Der interpolator führte sie deshalb ein, um neben der Gnitaheide noch zwei andere wertvolle örtlichkeiten zu nennen: denn in der Hunnenliedstrophe 7 heisst das gehölz Myrkviðr das herrliche, der stein im gebiet Danps der schöne. Er verstiess jedenfalls mit seiner einführung des Myrkviðr in diesem zusammenhang, wie wir oben $\S 3$ sahen, gegen die schon in Akv. A herschende vorstellung von demselben als grenzwald. In dieser steht Akv. A nicht allein.

Der name Myrkvior erscheint ausser Akv. A 3, 4 und 13, 4 noch H.Hb. İ, 53, 4. V̈kv̀. 1, 2. Lok. 42, 5. Während aus der stelle im Helgilied sich nichts ersehen lä́sst, stimmen Akv̈., Vkv. und Lok: darin überein, dass der Myrkvior ein grenzwald nach süden ist: in Ak $\hat{v}$. ist er der grenzwald gegen das südliche Hunnenreich ${ }^{1}$; in Lok. der grenzwald gegen die Muspelsöhne: 42,4.5 en es Múspelz syner rípa Myrkvip̄ yfer; in Vkv. ist. er der wald, über den hinweg sunnan, von süden $(1,1)$ die weiber des südens; dróser suprenar $(1,7)$, nämlich die valkyrien, nach norden fliegen.

Schon die verbreitung des namens Myrkviðr als eines grenzwaldes gegen süden in verschiedenen nordischen sagen legt den gedanken nahe, dass hier in der Nibelungensage das auftreten eines waldes als grenze gegen das südliche reich Atlis specifisch nordisch ist ${ }^{2}$ ), zumal wir in allen anderen überlieferungen der Nibelungensage eine wassergrenze gegen Attilas reich finden, deren überschreitung einen wichtigen teil der reise oder gar die ganze reise ausmacht.

1) Myrkheimr, wo Gunnarr nach Akv. 45, 4 seinen tod gefunden hat, mit dem Myrkviðr gleichzusetzen (wie Gering will, Uebs. s. 262, n. 5) liegt insofern sehr nahe, als dieser ort nach 35,1.2 offenbar an der grenze von Atlis gebiet liegt (von wo er zurückreitet lands síns á vit), also wol der grenzwald selbst ist.

2) Dass an sich die vorstellung von einem grossen walde, der "gleichsam auf der grenze von süden und norden liegt und die scheide beider weltgegenden macht' uralt ist, hat Müllenhoff (Zs. fda. 23, 168f.) durch den hinweis auf den saltus Hercynius und den Miriquidui des Thietmar von Merseburg (Erzgebirge) wahrscheinlich gemacht: aber speciell für die Nibelungensage können wir die vorstellung in der älteren deutschen sage nicht nachweisen. 
Mogk hält (Grundriss 2 ${ }^{2}, 648$ ) die waldgrenze der Akv. für das ursprünglichere und erinnert an die landreise der Burgunden zur Donauebene. Am ufer der Donau befindet sich allerdings ein wald (NL. 1565), aber mit der Donau liegt doch noch das entscheidende hindernis, eben das wasser, vor ihnen, bei dessen überschreitung der dichter entsprechend lange verweilt.

Daher möchte ich mit Boer (Untersuchungen über den ursprung und die entwickelung der Nibelungensage, Halle 1906, bd. 1, 132) die wassergrenze von Am. 4, 28, 34 für das ursprünglichere halten; dieselbe vorstellung finden wir im NL., ThS., Grimhilds hævn A und C, im färöischen Högnilied: in den Am. ist es ein fjord, im NL. die Donau; in der ThS. findet sich die unklare vorstellung vom zusammenfluss des Rheins und der Donau 1) (cap. 363); in Gr. h. A 18, C 13 und im Högnilied 50 ist das meer die grenze. So hätten in diesem fall die Am. den älteren zug bewahrt.

Dagegen ist die tatsache, dass der meeresarm in den Am. fjorb Lima heisst $(4,7)$, aus der geschichtlichen bedeutung des Limafjorđs im 11. jh. zu erklären, wie Mogk (a.a.o. s. 648) hervorhebt.

§ 29. Warnung und begrüssung durch die schwester.

Der zug, dass die schwester ihre brüder warnt, findet sich in beiden Atli-liedern, aber in verschiedener weise dargestellt. Am einfachsten ist der vorgang in der Akv. A 16. Guđrún tritt ihren brüdern, sobald sie in den saal kommen, entgegen und erklärt dem Gunnarr, er solle schleunig die halle verlassen, da er verraten sei. Mehr erzählt A nicht.

Als eine alte weiterbildung dieses einfachen motivs sehe ich alsdann das an, was sich in der interpolierten strophe 8 findet. Guđrún hat (durch wen wird nicht gesagt) den brüdern einen ring mit eingeflochtenem wolfshaar gesant, ein symbol dafür, dass ihre fahrt wölfisch sein werde. Solche symbolische botschaften gehören einer zeit an, die die schrift noch nicht

1) Boer $(1,139)$ hält die worte par sem saman kemr Dúná oc Rín für den zusatz des umarbeiters, der südlichere quellen benutzte (daher die Donau einfïhrte), während soust entsprechend der norddeutschen localisation des Hunnenreichs der Rhein die grenze sein müssẹ. 
kennt oder übt; eine ähnliche symbolische botschaft senden bei Herodot IV, cap. $131 \mathrm{f}$. die Scythen dem könig Darius, um ihm anzudeuten, dass er bei ihnen $\mathrm{zu}$ grunde gehen werde.

Eine parallele darstellnng desselben sagenzuges weisen die Am. auf. Guđrún schneidet warnende runen, Vingi fälscht sie, ehe er sie abliefert $(4,1-4)$, Kostbera liest die gefälschten zeichen und erkennt, dass Atli den brüdern nach dem leben trachtet (9. 11. 12).

Ausser dieser letzteren warnung ist in der sagengestalt der Am: noch der alte zug erhalten, wo die schwester ihren brüdern entgegengeht, er hat aber den charakter der warnung verloren und ist zu einer einfachen begrüssung geworden, bei der Guđrún über das unentrinnbare schicksal klagt (45).

Eine spur der alten warnung der brüder durch die schwester findet Boer (Untersuchungen 1, 143 und $244 \mathrm{ff}$.) in der gestalt des Eckewart (ThS. 367. NL. 1631), die der von Boer herausgearbeiteten quelle II von ThS. und NL. angehört. Ursprünglich sei Eckewart zur warnung der brüder von Kriemhild abgesant worden: als dann aber Kriemhild die feindin ihrer brüder wurde, konnte der dienstmann Kriemhildens nicht der warner bleiben: so trat Dietrich in dessen rolle ein, selbständig, wie er in ThS. 375 und NL. 1724. 1726 auftritt (in Boers quelle I). Diese von Boer bezeichneten stellen lassen jedenfalls annehmen, dass schon in der älteren deutschen sage die schwester die brüder gewarnt habe.

$\$$ 30. Die träume der frauen.

In den Am. hat in der nacht vor der abreise Kostbera drei träume, Glaumvor deren vier, während in der Akv. nichts derartiges erscheint. Wenn wir Kostberas dritten traum (Am. 18) und Glaumvors vierten traum (Am. 25) mit dem traum der Uote NL. 1509 und dem der Oda ThS. 362 vergleichen, so finden wir, dass sie im engsten zusammenhang mit dem seelenglauben stehen. In Kostberas traum erscheint ein bluttriefender adler und wird als hamr Atla, als folgegeist Atlis, angesehen. GlaumvQ̨r sieht tote frauen, die Gunnarr zu ihren bänken einladen: es sind die disar, die schutzgeister, die seelen verstorbener anverwanter, die Gunnarr nicht mehr schützen können (weil sie kraftlos, aflima, geworden sind), sondern ihm seine 
baldige vereinigung mit ihnen andeuten. Auch Uotens und Odas traum, nach dem alle vögel des landes tot sind, das land verödet ist (NL. 1509, ausführlicher ThS. 362), bewegt sich in demselben gedankenkreis: als vögel erscheinen oft die seelen nach altgermanischer vorstellung (Mogk, Grundriss 1, 1009): so erscheinen hier die seelen der dem tod geweihten als tote vögel.

Die gemeinsamkeit der grundrichtung der frauenträume vor dem auszug der Nibelunge macht es mir wahrscheinlich, dass trotz der stark subjectiven behandlung') doch Am. in dem traummotiv als solchem ein altes element erhalten hat, das in der Akv. verloren ist.

Wir haben oben s. 232, $\S 17$ gesehen, dass der dichter der Am. in der ausführung der traumscenen von Gðkv. II alhängig ist. Die träume in Gokv. II sind also literarisch die älteren, sagengeschichtlich dürften sie dagegen jünger sein. Denn träume Atlis, die sich auf den bevorstehenden untergang seines hauses beziehen, finden sich nirgends in der sage als eben in der Gðkv. II; sie eignen sich auch weniger für Atli als für eine frau und sehen wie eine erfindung des dichters aus, der die ereignisse der Akv. A, die er kannte, vorher andeuten wollte.

\$ 31. Unheilvolle zeichen auf der fahrt.

Die Am., die eine wassergrenze gegen Atlis reich kennen (oben s. $248 \mathrm{f}$. $\$ 28$ ), erzählen in str. 34, wie die Niflunge beim starken rudern das halbe schiff zerbrechen, wie die ruderbänder zerreissen und die ruderpflöcke brechen. 'ThS. 366 erzählt ähnliches zweimal, was sich nach Boer (Untersuchungen 1, 242. 243) folgendermassen anf die beiden quellen I und II verteilt: I, das steuerband reisst, das steuer bricht, das schiff schlägt um; II, Hogni zerbricht durch starkes rudern ruder und ruderpflöcke, das schiff schlägt um. NL. 1564 f. erzählt ebenfalls, dass das ruder in Hagens hand zerbricht. Dann berichtet Grimhilds hævn (Grundtvig; D.G.F. Kopenhagen 1853, 1, $44 \mathrm{ff}$.), dass das ruder zerbricht: A 19 in Falquors hand, C 15 in Hogens hand. Endlich weiss auch das färöische Högni-

1) Sie sind 'voll von künstlicher symbolik', wie Henzen (Ueber die träume in der altuordischen sagaliteratur, Leipzig 1890, s. 79 f.) hervorhebt. 
lied, 57 (Hammershaimb s. $37 \mathrm{ff}$ ), dass die ruder in Högnis händen zerbrechen.

Wilmanns sieht (Der untergang der/Nibelunge in alter sage und dichtung, Berlin 1903, s. 13) in den unheilvollen vorzeichen der Am. und ThS. einen gemeinsamen sagenzug. Obgleich sich nün züge wie däs zerbrechen der ruder auch sonst in nordischen erzählungen finden (vigl. Friđpjófssaga str. 13 brusto bádir halsar), so führ̈t mich doch diese ähnlichkeit in kleinen zügen an demselben punkt der Nibelungensage in den genannten fünf quellen dazu, mit Wilmanns hier einen alten, nicht einen specifisch nordischen zug zu erblicken, den die Am. bewahrt haben.

Altertümlich ist ohne frage in den Am. gegenüber allen anderen gènannten quellen das fehlen eines besonderen fährmannes: die helden iudern von anfang an selbst. Dass der fährmann nicht alt in der sage ist, erkennt man daraus, dass er im NL., der ThS. und den übrigen seine function gar nicht verrichtet, sondern getötet wird, sodass die helden doch selbst rudern müssen.

\section{§ 32. Gorpot far festa.}

Die Am. erzählen weiter 34, 7, dass die Niflunge das fahrzeug nicht festmachten, ehe sie vom strande giengen. Im NL. (1581) schlägt Hagen das schiff in stücke. Während Hagen dieses verhalten NL. 1583 damit begründet, dass er erklärt, kein feiger solle entrinnen, fehlt in den Am. für das ähnliche verhalten der Niflunge jede angabe eines grundes. Denn obgleich Gunnarr und Hognni vor der abreise düstere ahnungen gehegt haben (str. 26. 32), so geben sie doch keineswegs von vornherein die hoffnung auf rückkehr auf, da ihnen ja nicht (wie dem Hagen des NL.) der untergang feststeht.

Vielleicht ist dieser zug in den Am. nichts als ein zeichen einer ursprünglichen völligen arglosigkeit der helden. Etwas ähnliches ist es, wenn in der Akv. Gunnarr ohne brünne zu Atlis halle kommt $(17,1.2)$. Ursprünglich waren gewiss nur die frauen voll trüber ahnungen, erst später übertrug sich das auf die helden selbst. Dass diese mit freiem willen in etwas hineingehen, wo ihnen der tod wahrscheinlich (Am. 26) oder gewiss (NL. XXV) ist, lässt sich psychologisch nicht als 
das ursprüngliche ansehen, sondern setzt eine entwickelung der sage voraus, die das in das gemütsleben der helden vorher aufgenommen hat, was sie nachher trifft.

Gerade dass dieser zug: gorpot far festa so unvermittelt in den Am. auftritt, spricht dafür, dass er älter ist als die Am. und dass er vielleicht von dem dichter selbst nicht mehr verstanden wurde. Wegen der ähnlichkeit mit der situation NL. 1581 werden wir annehmen dürfen, dass schon der älteren deutschen sage der zug eigen war, dass die helden nicht mehr für ihre rückkehr vorsorge trafen bez. sich dieselbe unmöglich machten, und dass ihn aus der deutschen die altnordische sage iibernommen hat.

\section{$\S 33$. Der kampf.}

Während nach den Am. 27. 28 ausser Gunnarr und Hogni noch drei andere helden und zehn hausgenossen zu Atlis gehöft ziehen, kommen in der Akv. die zwei brüder ganz allein, ohne begleitung, zu Atlis halle. Das letztere geht unzweideutig hervor aus str. 18

seinats nú, syster, at samna Niflungom,

langt es at leita lýpa til sinnes,

of rosmofjoll Rinar rekka óneissa,

ebenso aus $12,1-4$

leiddo landrogne lýpar óneiser, grátendr gunnhvatan ôr garpe Niflunga;

die recken bleiben weinend $\mathrm{zu}$ hause; vor allem aus 12,7.8 heiler farep ok horsker, hvars ykr (Dual!) hugr teyger! Von begleitern Gunnars ausser Hogni ist nicht die rede. Das primitive der situation (dass zwei könige allein zur halle eines anderen königs reiten) erscheint auf den ersten blick altertümlich; dass aber im gegensatz zu den Am. und NL. die Akv. hierin einen älteren zug bewahrt habe, soll nicht behauptet werden, da sonst germanische könige nie ohne gefolge ausreiten.

Akv. ThS. NL. sind darin einig, dass ein kampf in einem saal oder eingehegten raum stattfindet; die Am. kennen dies nicht $(39.43,2.3)$.

Dass in der Akv. der kampf im saal beginnt, ist aus 16,2. 8 und c 20,4 ersichtlich (snemst at $i$ sal kvómo - holl 
gakk ór snimma! - en enom átta hratt i eld heitan). Quelle I der ThS. kennt den kampf in einem baumgarten, II den kampf in einem saal, der angezündet wird (s. Boer, Untersuchungen 1, 153 ff. 158 ff. 167). Das NL. kennt nur den kampf in einem saal (Av. XXXIII ff.).

So wird hier wider die Akv. gegenüber der unklareren vorstellung der Am. einen alten sagenzug erhalten haben.

In bezug auf den kampf selbst ist möglicherweise etwas über die erste phase desselben in unserm text verloren gegangen (Symons, Ausgabe s. 428); denn es fällt doch sehr auf, dass wir nichts von heldentaten Gunnars hören, der doch sonst in der Akv. ganz im mittelpunkt steht (oben s. 242). Nur Hǫgni (Akv.20 B, c) zeichnet sich im kampf aus: er schlägt sieben feinde mit dem schwert nieder und schleudert den achten ins feuer. Ueber seine gefangennahme finden wir nichts: da aber Vs. 37 davon berichtet (en pó varp hann at lyktum ofrlipi borinn ok hondum tekinn), so nimmt Symons (Ausgabe s. 429) hier widerum eine lücke im text an.

In den Am. $40 \mathrm{ff}$. entwickelt sich aus dem wortwechsel zwischen Atlis leuten und einem der Niflunge (nach Vs. 36 ist es Hǫgni) ein kampf, den Guđrún für einen augenblick durch ihr erscheinen unterbricht; sie greift aber, als sie ihn nicht aufhalten kann, selbst in ihn ein, indem sie "den mantel abwirft und mit dem schwert dreinschlägt. Im übrigen stehen ihre taten ganz im vordergrund. Die Niflunge werden zwar im allgemeinen gerühmt (48), aber weder von Hogni noch von Gunnarr wird eine besondere tat erwähnt; dagegen bringen Beras zwei söhne und ihr bruder $(49,9.10)$ vor ihrem tode achtzehn feinde $\mathrm{zu}$ fall.

Der kampf selbst spielt sich in der Akv. kurz ab; dagegen berichten sowol die Am. als NL. und ThS. von einem langausgedehnten kampf. Die länge des kampfes in der deutschen sage hat vornehmlich ihre begründung in der grossen zahl von helden, die daran teilnehmen; die bedeutenderen teilt Wilmanns (a.a.o.s. 15.22) in zwei gruppen, eine ältere (Osiđ, Irinc, Dietrich) und eine jüngere (Gernot, Giselher, Rüedeger, Blœdel, Hildebrand): keiner von diesen findet sich in der nordischen sage am kampf beteiligt (auch nicht Dietrich, vgl. Jiriczek, Deutsche heldensagen 1,160). Die 
länge des kampfes in den Am. beruht dagegen vorwiegend auf der teilnahme Guđrúns und der einführung von Snǽvarr, Sólarr, Orkningr und zwei unbenannten brüdern Atlis.

Was die söhne und den bruder Kostberas betrifft, so sind sie ohne zweifel gegenüber der älteren nordischen sage eine neuerung und erst vom dichter selbst eingeführt. Auch das eingreifen Guđrúns in den kampf, das nur die Am. erzählen, halte ich für eine neuerung, die wol vom dichter herrührt; es gehört zu der ganzen specifisch grönländischen charakteristik Guđríns, von der oben s. 236 gehandelt ist; zudem musste der dichter den wunsch haben, Guđrúns tapferkeit auch äusserlich hervortreten zu lassen, weil sie sich ja am schluss mit dem Niflung in das rachewerk teilen muss. Auch bei den beiden brüdern Atlis, die im kampf fallen $(51,4)$, liegt schwerlich eine alte historische erinnerung (an Bleda) vor; die vier brüder, von denen Atli str. 51 erzählt, sind gewiss alle zusammen der phantasie des dichters entsprungen (oder einer jüngeren phase der nordischen sagenentwicklung?).

So war jedenfalls in der altnordischen sage kein grund vorhanden, den kampf der Niflunge so weit auszudehnen: demnach wird der kurze kampf der Akv. als das ursprünglichere anzusehen sein. $\mathrm{Zu}$ beachten ist ferner, dass auch in der älteren qnelle I der ThS. der kampf sich kurz abspielt (s. Boer, Untersuchungen 1, 158).

Wenn wir endlich die frage aufwerfen, ob einige der von Wilmanns hervorgehobenen helden der ThS. schon der älteren deutschen sage zuzuschreiben sind (sodass sie dann der altnordischen sage verloren gegangen oder überhaupt nicht nach norden gewandert wären), so müssen wir antworten, dass jedenfalls weder Irinc (nach Wilmanns s. 15 ein alter gott) noch Dietrich von Bern ursprünglich etwas mit der Nibelungensage zu tun hat, in der es sich um den gegensatz zwischen den Burgunden und dem Attila der fränkischen (nicht der gotischen) überlieferung handelt; ebensowenig Rüedeger und Hildebrand; auch Gernot ist in der älteren sage (bez. ihren historischen grundlagen) nirgends zu finden. Deshalb muss man diese gestalten als deutsche neuerungen ansehen. Bei Osiđ (den Wilmanns a.a.o. s. 16 mit Ospirin, Attilas gattin im Waltharius, zusammenstellt), bei Blœdel - Bleda und Giselher - 
Gislaharius wäre es denkbar, dass sie schon der älteren deutschen sage angehört hätten und dass ihr fehlen im norden dann als verlust zu bezeichnen wäre, obwol Wilmanns bei Bleda und Gislaharius an spätere aufnahme in die sage durch gelehrte hand denkt (s. 23. 24). Ich muss diese frage offen lassen.

\$34. Atlis fragen nach dem gold.

Das motiv, das Atli zu seinem verräterischen überfall führte, ist nach der Akv. 21. 27. 28 (alles B) und 29 (A), ferner 34,10 (d) deutlich: die goldgier.

Nicht so einfach liegen die dinge in den Am. Denn leider stossen wir hier wider an einer sagengeschichtlich wichtigen stelle auf eine lücke im text, zwischen str. 40 und 41 der Am. (Symons, Ausg. s. 447). Symons vermutet, Atli habe in der lücke den angriff motiviert durch die begierde nach dem horte und (mit fragezeichen) durch den wunsch, Sigurds tod zu rächen; er schliesst beides aus Vs. 36, wo es heisst: fyrir longu hafba ek pat mér i hug - - at ná ypru lífi, en rápa gullinu ok launa ypbr pat nípingsverk, er pér svikup yparn inn bezta mag, ok skal ek hans hefna. Hier steht die nackte goldgier direct neben der heuchlerischen anklage bezüglich Sigurds, und beides nebeneinander nimmt sich merkwürdig genug aus.

Wenn nun der sagaschreiber sich an dieser stelle wirklich streng an seine liedervorlage gehalten hat, was bezweifelt worden ist (Symons, Beitr. 3, 242), so hat er doch, wie ich glaube, aus den Am. höchstens die motivierung durch Sigurds tod entnommen, den der dichter der Am. auch sonst kennt (94); die heuchlerisch-pathetische anklage passt ganz gut zu dem zwitterhaften charakterbild Atlis in den Am., das wir oben s. 224 kennen gelernt haben. Schwerlich kann aber an dieser stelle von dem gold die rede gewesen sein, sonst würde es nicht hernach in der langen scene, in der Atli' den befehl zur grausamen tötung der brüder gibt und die mit dem tode der beiden endet, so völlig fehlen: der anlass zur marterung ist nicht irgendwelches gold, sondern Guđrúns harte rede, die Atli reizt. Das Niflungengold findet sich überhaupt an keiner stelle der Am. auch nur angedeutet. Ich halte daher die worte 
der Vs. en rápa gullinu für eine erinnerung des verfassers an die sagengestalt der Akv.

In Vs. 36 (anfang) findet sich ausserdem eine stelle, wo Atli in güte zur auslieferung des schatzes auffordert. Symons glaubt (Ausgabe s. 447, im gegensatz zu seiner früheren ansicht Beitr. 3, 242), 'dass dem sagaschreiber eine an dieser stelle' (zwischen str. 39 und 40) 'vollständigere redaction der Atlm. vorgelegen hat', dass also diese aufforderung Atlis aus den Am. stamme. Nach dem eben gesagten kann ich das nicht für wahrscheinlich halten. Viel eher könnte meines erachtens die aufforderung zur herausgabe des goldes in der schon s. 254 aus anderen gründen constatierten lücke, zwischen Akv. 18 und 19 (Symons, Ausg. s. 428) gestanden haben: in die Akv. passt eine solche aufforderung ganz zwanglos, denn dort spielt ja das gold die beherschende rolle. Ferner richtet sich die frage Atlis in der Vs. an Gunnarr, der ja gerade in der Akv., im gegensatz zu den Am., im vordergrund steht (oben s. 242). Auch Gunnars stolze antwort passt sehr gut zu dem Gunnarr der Akv. A: die worte kann vera at pú veitir pessa veizlu - af lítilli eymp vip orn ok uilf tragen einen ähnlichen charakter wie Akv.11, wo Gunnarr die wölfe und bären einlädt für den fall, dass er nicht heimkehre.

Die Akv., wie sie dem verfasser der Vs. vorlag, wird also zwei fragen Atlis enthalten haben, eine gütliche vor dem beginn des kampfes, und eine an den gefangenen, wo es sich um tod und leben handelte (str. 21). Im NL. finden wir nun auch zwei fragen nach dem hort (nur ist es nicht Etzel, sondern Kriemhild, die sie stellt): die eine vor dem ausbruch der feindseligkeiten (1739.1741), die andere an den gefesselten (2367). Wenn hier Kriemhild die fragende ist, so ist auf sie als auf die eigentlich handelnde etwas von Etzels früherer habgier übertragen worden (s. unten $\$ 47$ zu Wilmanns' ansicht): denn das motiv ihres handelns ist sonst rache für den gatten. So fragt sie zweimal, vor und nach dem kampf, nach dem schatz, wie Atli in der dem sagaschreiber vorliegenden Akv. Aus dieser übereinstimmung darf man wol schliessen, dass schon in der älteren deutschen sage und weiter dann in der altnordischen zwei fragen traditionell geworden waren: eine an 
den freien in güte, eine an den gefangenen, wo es sich um lösung des lebens handelt.

\section{$\S$ 35. Der tod der schwester Atlis.'}

Wenn das gold in den Am. nicht der anlass zu Atlis überfall war, so könnte man mit Grimm, HS. ${ }^{3}$ s. 11 vermuten, Atli habe Brynhilds tod rächen wollen; nnd zwar im hinblick auf Atlis worte 52,5.6 sendop systr heljo : slikss ek mest kennomk, womit gewiss Brynhild gemeint ist, die in der Edda als schwester Atlis in Gðkv. I, 24, 1, Sg. sk. 32. 38, 6. 55, 9. 10, Gðkv. II, 28, 3. 4, Odrgr. 15 erscheint; ausserdem als Bupla dóttir noch Brot 8, 2. 14, 2, Helreip 4, 2, Gríp. 27, 5. Aber die vorstellung, dass Atli Brynhilds tod durch seinen verrat habe rächen wollen, findet sich weder an der betreffenden stelle der Am., noch überhaupt in irgend einem poetischen oder prosaischen bericht des nordens; sie ist erst von neueren combiniert worden aus der tatsache von Brynhilds tod und der, dass Brynhild Atlis schwester oder Buđlis tochter heisst.

Was zunächst Am. 52, 5. 6 betrifft, so wird hier jedenfalls der tod der schwester keineswegs derartig betont, dass man in ihm den anlass zu Atlis überfall sehen könnte: er wird nur erwähnt als letzter von vielen vorwürfen, die Atli gegen sein weib und seine verwanten $(51,5.7)$ schleudert; nachdem er zuvor über den tod seiner krieger, seiner brüder geklagt hat, nennt er als den herbsten verlust den tod der schwester. Gemartert werden die Niflunge nicht deshalb (wie sie auch nicht deshalb überfallen worden sind), sondern um Guđrún zum weinen zu bringen (54).

Ferner könnte noch Helreip 4, 5 ff. zu der annahme veranlassen, dass man sich zuweilen Atli als den rächer Brynhilds gedacht habe. Die worte in Helreip 4 legen einen solchen gedanken allerdings für den ersten blick nahe: ' $\mathrm{du}$ hast Gjúkis söhnen verderben bereitet und das glück ihres hauses vernichtet.' Dass aber hier die katastrophe bei Atli gemeinnt wäre, die Brynhild durch ihren tod herbeigeführt hätte, ist unmöglich. Brynhild ist ja eben erst tot, ist noch auf dem helweg: da kann Atli ja kaum erst nachricht von ihrem tode erhaltèn, geschweige denn ihn schon gerächt haben. Vielmehr will die riesin sagen: 'du hast zwietracht und mord 
in Gjúkis haus getragen und seine beste stütze in Sigurđr vernichtet.'

Auch in Odrgr. überfällt Atli die Gjúkunge nicht, um die schwester zu rächen, obwol er offenbar um deren todes willen eine abneigung gegen sie hegt (sodass er keinen mahlschatz vom sohne Gjúkis annehmen will, 20). Vielmehr überfällt er sie wegen des verbotenen liebesverkehres, den Gunnarr und Odrún gepflogen haben; s. unten $\S 36 \mathrm{zu}$ dieser jüngern motivierung.

Der liedersammler geht allerdings im Dráp Niflunga einen schritt weiter: er sucht sich zu erklären, warum Guđrún den Atli heiratet und erzählt daher: Ofripr var $\not a i$ milli Gjükunga ok Atla: kendi hann Gjúkungom vold um andlát Brynhildar. Aber er fährt fort: pat var til sátta, at peir skyldu gipta honum Guprünu, ok gáfu henni óminnisveig etc. Also wird Atli durch die hand Guđrúns beruhigt, und davon, dass er seinen spätern überfall aus rache für Brynhilds tod ausführte, findet sich kein wort, weder im Dráp Nifl., noch in der Vs., noch in der Sn. E.

$\$$ 36. Abschliessendes über Atlis motiv.

Wir müssen uns also damit abfinden, dass der mordplan Atlis gegen die Niflunge in den Am. schlechterdings keine ausgesprochene begründung gefunden hat. Der dichter selbst spricht davon wie von etwas, was er eigentlich nicht begreifen könne: 2, 3 ff. illa rézk Atla, átte pó hyggjo, felde stop stóra, stridde sér harpla. Man merkt, dass er selbst nicht weiss, wie Atli zu seinem plan gelangen konnte.

Dass diese sagenform der Am. im gegensatz zu der der Akv. mit ihrer klaren motivierung secundär ist, liegt an sich schon auf der hand. Es ist aber überhaupt keine frage, dass die Akv. in der goldgier Atlis ein altes sagenelement erhalten hat. Die vorhin angeführten stellen des NL. (1739. 1741. 2367), ferner ThS. 359 (en Attila konungr er allra manna fégiarnastr etc.), vor allem endlich die geschichte vom Sigfridskeller, wo der habgierige Attila verhungern muss (ThS. 393. $423 \mathrm{ff}$.), beweisen, dass man sich Attila einst auch in Deutschland als habgierig vorstellte, obgleich das NL. nichts mehr davon weiss : dass also die habgier Attilas schon der älteren deutschen sage 
angehört und schon dort den grund zur vernichtung der Nibelunge gebildet hat. Im norden hat das die Akv. bewahrt, in den Am. ist das motiv verloren gegangen. ${ }^{1}$ )

Der mangel eines deutlichen motivs gab dann (nachdem das alte motiv der goldgier in vergessenheit geraten war) anlass zu einer neumotivierung; wie sie im Odrúnargrátr vorliegt: Atli vernichtet die Gjúkunge aus zorn über den verbotenen liebesverkehr Gunnars mit Odrún.

$\$$ 3\%. Die herkunft des goldes.

Akv̌. 29, 3 heisst dàs Nibelungenerbe áskupr (nominativ nach Gering, Wörterbuch z. Ėdda, 1903) 'von den asen stammend;. Das muss sich ${ }^{2}$ ) auf irgend eine fassung der geschichte von der otterbusse beziehen, die Sn. E. 39 (auch in U) und (mit kleinen abweichungen) Vs. 14 erzählt wird und von der der erste teil der Reginsmǫil (prosa und str. 1-12) handelt. Diese vorgeschichte des hortes, die von den asen nicht zu trennēn ist, betrachtet män als specifisch nordische neuerung. Das wird richtig sein; immerhin nötigen uns die strophen der Reginsmọ́l im zusammenhang mit Akv.29, die entstehung der geschichte ziemlich hoch hinaufzuschieben.

Anschliessend sei auf eine naheliegende frage eingegangen. Seit Richard Wagner ist uns die vorstellung geläufig, dass der Nibelungenhort aus dem Rhein stamme, Rheingold sei, wie er im Rheine sein ende findet (s. unten \$ 38). Ist diese vorstellung ín der nordischen sage nachweisbar?

Der Rhein scheint seit alters in naher beziehung zum begriff des goldes gestanden zu haben. Schon Vkv. 15 wird in bezug auf Wielands gold gesagt: fjarre hykh várt land fjollom Rínar. Sodann reden manche kenningar von solchen beziehungen: bei Einarr Skalaglamm (Sn. E. I, s. 404), einem dichter des 10. jh.'s., heisst das gold Rinar grjót; bei Hárekr ór pjóttu (Heimskringla c. 158), einem zeitgenossen Olafs des heiligen: Rínar leygr, lohe des Rheins; in den Bjarkamál 6:

1) In anderem zusammenhang findet sich in den Am. eine erinnerung an Atlis habgier: 53,3. 4 mópor tókt mina ok myrper til hnossa.

2) Vorausgesetzt, dass sich ásk̈unna hier auf arfe Niflunga und nicht auf $\phi(\operatorname{Rin})$ hezieht, mit welcher möglichkeit Detter und Heinzel, Commentar 2, 532 rechnet, in beżugnahme auf Grimnismọ́l 27, 8. 
Rinar raupmalmr ${ }^{1}$; in der Sigurparkvipa en skamma 16, 8 heisst Sigurds gold direct Rinar malmr. Namentlich dass der letztere ausdruck bei lebzeiten Sigurds, also vor der versenkung des hortes in den Rhein, von Gunnarr gebraucht wird, kann den gedanken erwecken, man habe sich den Nibelungenhort als in letzter instanz aus dem rheine stammend gedacht, also den Andvarafors (Rgm. pr., Vs. 14) oder das wasser in Schwarzalfenheim (Sn. E. 39), in dem Andvari schwimmt, mit dem Rheine gleichgesetzt.

Dagegen ist $\mathrm{zu}$ beachten, dass nirgends der Rhein tatsächlich als letzte quelle des hortes genannt wird. Ferner sagt die stelle Vkv. 15, wo erst von Grani, dann von den felsen des Rheines die rede ist, keineswegs, dass Granis last aus dem Rhein stamme. Aber auch die angeführten kenningar beweisen nicht, dass man sich den Nibelungenhort aus dem Rhein stammend dachte. Zum teil mögen sie auf die sage von der Rheinversenkung gegründet sein; im übrigen lassen sich solche ausdrücke, wie Boer (Untersuchungen 2, 71) hervorhebt, ebenso wie Aegis eldr erklären, als 'gold' schlechthin, und müssen gar nicht stets 'Nibelungengold' heissen. So wird auch das 'Rheinerz' Sg. sk. 16, 8 in diesem abgeblassten sinn $=$ 'gold' zu verstehen sein, weil der dichter nur an das metall als solches denkt, nicht an den hort mit seiner geschichte. Den anlass dazu, in solchen fällen gerade den Rhein zu nennen, bot die schon oft hervorgehobene tatsache, dass das mittlere Rheinbett goldhaltig war.

Es verdient daher hervorgehoben zu werden, dass die vorstellung von einem Nibelungen-Rheingold, das aus dem Rhein stamme, in der nordischen sage nirgends nachweisbar ist.

$\$$ 38. Die versenkung des goldes in den Rhein.

Ueber das ende des Nibelungenerbes belehrt uns widerum Akv. 29:

$$
\begin{array}{ll}
\text { Rín skal rápa } & \text { rógmalme skatna, } \\
\text { Q́ svinn áskunna } & \text { arfe Niflunga. }
\end{array}
$$

Abgesehen von unserer stelle ist die versenkung in den Rhein durch vier denkmäler bezeugt: durch das NL. 19, 1137 ff., dann

1) Auf die drei letzteren stellen macht Grimm, HS. ${ }^{3}$ N. 10 aufmerksam; im context citiert und erklärt bei Hungerland, Arkiv 20, s. 21. 24. 29. 
später 28, 1742; durch Sn. E. c. 42 (en ápr peir fóru heiman, pá fálu peir gullit Fáfnisarf $i$ Rin, ok hefir pat gull aldri sípan fundizt); durch das norwegische volkslied von Sigurd svein str.49 (Landstad s. 123); durch das Sigfridslied str.167. Im NL. ist es Hagen, der es versenkt, in der Edda sind es die Niflunge, im liede von Sigurd svein und dem Sigfridslied ist es Sigfrid selbst.

Nun hat Boer (Untersuchungen 2, 70. 71) geleugnet, dass in der alten sage der hort überhaupt in den Rhein versenkt worden sei. Den ausdruck NL. 1742 den hiezen mîne herren senken in den Rîn fasst er als von hause aus bildlich gemeint auf, = 'der schatz ist zum henker'. Aus dieser stelle sei alsdann die erzählung von der Rheinversenkung NL. Av. 19 abstrahiert, die Boer einem jüngeren verfasser zuweist. Bei dieser auffassung stützt er sich auch auf Akv. 29. Auch diese strophe glaubt er bildlich fassen zu müssen: hier könne von einer tatsächlichen versenkung des goldes nicht die rede sein, denn der gefangene könne nicht über den schatz verfügen.

Hiergegen lässt sich aber verschiedenes geltend machen. Zunächst wäre es doch sehr merkwürdig, wenn ein bildlicher ausdruck (nicht ein concreter sagenzug) ein so langes leben gehabt hätte, dass Akv. und NL. ihn beide noch aus der älteren deutschen sage besitzen sollten. Noch merkwürdiger wäre es, wenn dieser ausdruck mit genau derselben folgerichtigkeit von zwei getrennten jüngeren autoren misverstanden worden wäre: Sn.E. c. 42 und NL. 19 hätten ihn nämlich beide im eigentlichen sinne ausgelegt. Dass endlich in der Akv. von einer tatsächlichen Rheinversenkung nicht die rede sein könne, lässt sich nicht aufrecht erhalten. Allerdings kann der hort nicht von dem gefangenen versenkt werden, aber er kann sehr gut vor der abreise versenkt worden sein (wie das die Sn. E. erzählt), damit er nicht in fremde hände gerate.

Daher beweisen $\mathrm{m}$. e. die getrennten nordischen und deutschen zeugnisse, dass schon in der älteren deutschen, dann auch in der altnordischen sage der hort von den Burgunden in den Rhein versenkt worden ist.

\$ 39. Hognis herz, Hjalli.

Warum Atli dem Hoggni das herz ausschneiden lässt, ist in der Akv. klar und einfach gesagt: als von Gunnarr das 
gold verlangt wird, fordert dieser, man solle ihm erst Hognis herz zeigen: dann wird, nach kurzer episode, dem Hogni tatsächlich das herz ausgeschnitten. Sehr merkwürdig ist dagegen die begründung in den Am.: einzig um Guđrún zum weinen zu bringen, soll Hogni das herz ausgeschnitten und Gunnarr den schlangen übergeben werden. Es wäre schon an sich kaum zu bezweifeln, dass die einfache motivierung der Akv. die ältere, die wunderliche der Am. die jüngere ist. Zum überfluss tritt aber die deutsche sage des NL. hinzu und bestätigt, dass die entscheidende bedingung, durch die der eine held den tod des andern veranlasst, in der sage alt ist: str. 2367 - 2371 zeigen, wie schon mehrfach hervorgehoben wurde ${ }^{1}$ ), eine ganz ähnliche situation wie die Akv. 21-29: Kriemhild fragt den gefangenen Hagen, ob er mit dem hort sein leben lösen wolle; er erklärt, ihn nicht herausgeben $\mathbf{z u}$ können, solang noch einer seiner herren (d. h. der allein übrige Gunther) lebe; Kriemhild bringt ihm Gunthers haupt. Der hauptunterschied $\mathrm{zwischen}$ der nordischen und deutschen fassung besteht darin, dass im NL. die frage an Hagen, in der Akv. an Gunnarr gerichtet ist. Nach dem oben s. 243 über das ursprüngliche verhältnis von Hogni und Gunnarr gesagten muss ich hier die fassung des NL. für die ältere halten. Wir werden aber die fassung der Akv. (frage an Gunnarr) auch schon für die ganze altnordische sage in anspruch nehmen dürfen, da wir dieselben todesarten auf dieselben personen verteilt (nur ohne den causalen zusammenhang) auch in den Am. finden. Die hervorhebung und idealisierung Gunnars im gegensatz zur älteren deutschen sage setzte zuerst in der altnordischen offenbar an diesem punkte ein: Gunnarr wurde als der eigentliche herr des schatzes angesehen und daher gefragt; die Akv. gieng dann auf diesem wege weiter.

Charakteristisch für die nordische sage, aber in keiner quelle der deutschen sage belegt, ist das ausschneiden des herzens. Boer (Untersuchungen 1, 166. 167) vermutet, dass die quelle I der ThS., die als einzige viersion der deutschen sage den schlangenturm zeigt, ursprünglich auch das ausschneiden des herzens gekannt habe. Beweisen lässt sich das freilich

1) Wilmanns, Untergang der Nibelunge s. 4 u.a. 
nicht. Ich möchte also zunächst diesen zug als specifisch nordisch ansehen. - Das ausschneiden des herzens erscheint ausserhalb der Atli-lieder noch Gðkv. II, 32, 7.8 (geahnt von Guđrún), ebenda 9,5.6 (angedeutet in einer verwünschung), Odrgr. 26, 5. 6, Ghv. 18, ausserdem Dráp Nifl., Vs. 37 und Sn. E. 42.

Die durch die todbringende forderung des einen helden geschaffene situation hat weiterhin im norden eine gestalt erzeugt, deren hauptbedeutung in beiden Atli-liedern darin besteht, dem andern der beiden helden als folie zu dienen und seinen mut ins hellste licht zu setzen ${ }^{1}$ ): Hjalli den feigen (Akv. 23 ff. Am. 57 ff.). - In der älteren deutschen sage scheint Hagen der mutige eine andere folie gehabt $\mathrm{zu}$ haben, wenngleich nicht bei dieser gelegenheit: Gunther selbst. Dass ursprünglich Gunther selbst der feige war, geht deutlich hervor aus dem Waltharius, besonders 1413-15, aus dem NL. (Gunthers stellung am anfang des Sachsenkrieges 148. 153. 154; gegenüber Brünhild bei den kämpfen und in der brautnacht); aus ThS. 228 (die brautnacht) und vor allem noch aus der eddischen strophe Vs 28 (Symons, Ausg. s. 496, frg. 3), wo Brynhild zu Guđrún sagt:

$\begin{array}{ll}\text { en hlýre pín } & \text { hvárke porpe } \\ \text { eld at rípa né yfer stiga. }\end{array}$

In der speciell nordischen sage, besonders in der Akv., ist dagegen Gunnarr ins heldenhafte gesteigert (s. 242), infolgedessen ist an seine stelle der feigling Hjalli getreten. Akv. nennt diesen nur kurz den feigen (24. 26), sagt aber sonst nichts über seine person. Wenn er dagegen in den Am. der kesselhüter (58), der koch Buđlis, der elende sclave (59) heisst, so brauchen diese züge keineswegs der altnordischen sage zu entstammen, sondern können auf die ausmalung des dichters zurückgehen, der gern gerade nebengestalten ausführte (oben $\S 12 \mathrm{~b} \beta$ ).

Dass dem Hjalli das herz ausgeschnitten wird; hat in der Akv. seine volle begründung: Gunnarr soll durch den anblick des herzens betrogen werden und den schatz ausliefern, ohne

1) Akv. 24, 26 direct die gegenüberstellung: Hjalla ens blauba Hogna ens frékna. 
dass Hognis blut fliesst: der betrug ist das entscheidende. In den Am., wo dieser betrug wegfällt und das herz Hognis nur ausgeschnitten werden soll, um Guđrún zum weinen zu bringen, hat der vorschlag, statt dessen Hjallis herz auszuschneiden, keinen sinn: sein herz nützt niemandem etwas, da eben nur der bruder Guđrúns sterben soll. Höchstens müsste man annehmen, dass Atli sich während der procedur entfernt hätte (und Beiti ihn mit Hjallis herz täuschen wollte): das ist aber ganz unwahrscheinlich. Auch dieser zug wird also von dem dichter der Am. unverstanden übernommen worden sein. Dafür, dass man nicht mehr wusste, was Hjallis tod eigentlich nützen sollte, spricht vor allem, dass Hjalli in den Am. schliesslich gar nicht getötet wird, sondern mit der todesangst davonkommt. Das ist gegenüber seinem tod in der Akv. natürlich als eine degeneration anzusehen.

Dagegen ist die grundbedeutung von Hjallis ganzer gestalt in den Am. noch klar erhalten. Hjalli dient auch hier dem Hogni als folie, aber in feinerer weise. In der Akv. wird schlicht und roh das zitternde herz neben das ruhige gelegt: die Am. charakterisieren den $H_{j a l l i}$ in einer ausgeführten scene durch sein verhalten, seine worte als feigling im gegensatz zu dem unerschrockenen Hogni, der verächtlich erklärt, ihm sei ein solches spiel leichter, und es sei unmöglich, länger ein solches geschrei anzuhören.

Beide Atli-lieder stimmen endlich darin überein, dass Hogni lacht, während ihm das herz ausgeschnitten wird (Akv. 25, Am. 61). Nach dem was schon oben (§ 16) über diese beiden stellen gesagt ist, können wir auch diesen zug schon der altnordischen sage zuweisen.

§ 40. Die schlangengrube.

Dass Gunnarr in eine schlangengrube geworfen wird, findet sich ausdrücklich erwähnt in der Akv. 34 d, dann Odrgr. 26, 7. 8, Sg. sk. 58, 3. 4, im Dráp Nifl., Vs. 37, Sn. E. 42. Ferner wird der ormgarđr Gunnars in dem schon oben s. 247 genannten itinerarium des abtes Nicolaus aus dem 12. jh. erwähnt: einige leute behaupteten, dass er sich bei der stadt Luna in Italien befände (die 857 von den Normannen gestürmt wurde, s. Massmann, Zs. fda. 1, 396 und Grimm, HS. ${ }^{3}$ N. 27). 
Unklar sind dagegen Am. 21 und 55, wonach Gunnarr an einem galgen befestigt werden soll, damit ihn schlangen fressen, und Ghv. 17, wo nur gesagt ist, dass glänzende schlangen Gunnarr auf den leib krochen.

$\mathrm{Da}$ sich die vorstellung von einem schlangengehege, in dem Gunnarr sein leben lässt, auch in der ThS. ${ }^{1}$ ) findet (quelle I, s. Boer, Untersuchungen 1, 167), so muss diese vorstellung. auch schon der älteren deutschen sage geläufig gewesen sein. Der ausdruck ormgarb cap. 383 (den B nicht hat), mag auf eddische beeinflussung zurückgehen: aber añ der tatsache, dass in Niederdeutschland die geschichte von einem schlangenturm Gunthers bekannt gewesen ist, darf man wol nicht zweifeln, da zweimal, cap. 383 und 394, ausdrücklich versichert wird, dass der turm in Susat stehe.

Dass der bericht der Akv. (34) dem interpolator d angehört, beeinträchtigt seine bedeutung nicht. Dieser mit der grössten trockenheit berichtende interpolator, den eine bereits vorliegende lücke im text zur abfassung seiner seltsamen verse veranlasst haben mag (oben s. 203 f.), gab gewiss nichts anderes, als was die herschende sage von Gunnars ende erzählte; von eigner phantasie werden wir bei ihm kaum etwas zu befürchten haben.

Gegenüber der klaren vorstellung vom oringarpr, die wir in der Akv. finden, ist die unklare der Am. als eine degeneration anzusehen. Man wusste in Grönland offenbar nicht mehr, was ein ormgarbr war: so veränderte sich die vorstellung zu der eines galgens, bei dem man sich ausser aasvögeln offenbar auch schlangen hausend dachte, die ja nach der vorstellung jener zeiten nicht nur bissen, sondern geradezu, wie raubtiere, menschliches fleisch frassen (ganz deutlich Saxo IX, 43, s. 143 Holder, vom tode Ragnars, Am. 21, Sn. E. 42). Gunnarr soll demnach am galgenbaum angebunden werden, sodass er den schlangen erreichbar ist.

Specifisch nordisch ist widerum im gegensatz zur ThS. die sage vom harfenspiel Gunnars, die sich in Akv.34, Am.62, Odrgr. 27, Dráp Nifl., Vs. 37, Sn. E. 42 findet, und auf die sich

1) C.383 i ormgarb; nach hs. B: i einn turn, en par eru inni eitrormar; c. 394 ormaturn. 
vielleicht der in Nornagests páttr c. 2 erwähnte Gunnarsslagr bezieht (Bugge, Fornkvæđi, fortale XLIII), ferner das lied von Sigurd svein str. 48 (Landstad s. 122): og Gunnar slagi slóg (als Asgardreiter).

Nun ist zunächst $\mathrm{zu}$ betonen, dass die drei genannten Eddalieder von einer wirkung des harfenspieles auf die schlangen nichts sagen. Akv. 34,10-12 (d) gibt überhaupt keinen zweck des spieles an, sondern sagt nur reflectierend: svá skal golle frołkn hringdrife vip fira halda (ganz im sinne von $A$ und $B$, wo immer das gold im mittelpunkt steht, oben s. 256). - Nach den Am. gibt Gunnarr der herrlichen (Guđrún) kunde, und die dachsparren bersten. - Der Odrgr. lässt Gunnarr durch sein spiel Odrún zu hilfe rufen (sie kommt aber zu spät). Von diesen drei fassungen ist jedenfalls die letztere mit Odrúns gestalt als die jüngste anzusehen.

Warum spielt nun in der Akv. Gunnarr die harfe? Ich glaube, nur um seine todesverachtung zu zeigen. Der commentar von Detter und Heinzel s. 490 führt mehrere beispiele an, nach denen leute in todesqual strophen vortragen oder singen: Ragnar in der Ragnarssaga FAS. I, 282/3, Krákumál 26; sein sohn Eiríkr am spiess FAS. I, 262/3, Sigurd Slembidjákn FMS. VII, 352, der psalmen singt, während er gepeinigt wird. So zeigt auch Gunnarr hier in der Akv., dass sein heldenmut nicht zu erschüttern ist. - Die Am. motivieren das spiel schon anders: str. 62 ríkre ró́b sagpe. Gunnarr will also offenbar Guđrúns hilfe anrufen; in der Akv. war das unmöglich, da Myrkheim von Atlis burg weit entfernt lag (35. 45). - Der Odrgr. hat dieselbe motivierung, mit entsprechender veränderung: Gunnarr will seine geliebte von Hlésey herbeirufen. - Wenn die Am. erzählen, dass Gunnarr mit den zehen die harfe schlägt, so ist das als eine weitere ausführung anzusehen, die logisch aus seiner fesselung hervorgehen musste; Sn. E. 42 und Vs. 37 sind darin den Am. gefolgt.

Im. gegensatz zu den drei liedern reden nur die drei prosaberichte Dráp Nifl., Vs. 37, Sn. E. 42 von einer einschläferung der schlangen; schon das macht die sache verdächtig und lässt an jüngere weiterbildung denken. Dem sammler der lieder (Dráp Nifl.) lagen Akv., Am., Odrgr. vor. Ihm konnte nun leicht Odrgr. den anlass bieten, die sage fortzuspinnen. Odrún, 
die durch den harfenklang über den sund herbeigerufen wird, kommt zu spät, weil Atlis mutter schon in schlangengestalt Gunnarr nach dem herzen gegraben hat, (30). Hier konnte der sammler fragen: warum ist nur von der einen schlange die rede? offenbar, weil die andèren sich ruhig verhielten. Wie kamen sie dazu, sich ruhig zu verhalten? offenbar, weil sie durch eine zauberkraft gebannt waren: als solche aber konnte hier nur der klang der harfe in betracht kommen. Daher nahm der sammler an, Gunnarr habe die anderen schlangen durch sein spiel eingeschläfert. - Sn. E. 42 berichtet wesentlich dasselbe wie Dráp Nifl. - Einen schritt weiter geht der verfasser der Vs.: Guđrún reicht selbst dem bruder die harfe. Die schlange, die Gunnarr tötet, hebt der verfasser, offenbar im blick auf Odrgr. 30, als 'grosse und bösartige natter' hervor; er nennt sie aber nicht Atlis mutter, ebenso wie er auch cap. 5 die mörderische wölfin nur unter vorbehalt als Siggeirs mutter eingeführt hatte.

\$ 41. Atlis und Guđrúns söhne.

Dass Guđiún zwei söhne von Atli hat und sie tötet, berichten Akv. 39. 40 und Am. 74. Auf diese tatsache beziehen sich kurz Hm. 8. 10, 2, Ghv. 5, 4. 12,6; prophezeit wird der tod von Atlis söhnen durch Brynhild Sg. sk. 59,6; geahnt von Guđrún Gðkv. II, 34, 8; im traum gesehen unter bildern von Atli Gðkv. II, 41. 42. 43; ausserdem erzählen es Sn. E. 42 und Vs. 38, während die erzählung des Drạp Nifl. nicht bis dahin reicht. $\left.{ }^{1}\right)$ Für die altnordische sage steht der zug jedenfalls durch die übereinstimmung der beiden Atli-lieder fest.

Dagegen nennen die namen Erpr und Eitill nur Akv. 40 (B), Dráp Nifl. und Hm. 8, welche strophe Ranisch (Hamđismál s. 5 f.), wie schon oben s. 239 bemerkt, für eine alte interpolation hält. Akv. A und Am. nennen keinen namen.

Wenn wir nun unter den namen für Etzels söhne in der deutschen sage umschau halten, so finden wir im NL. 1913 u. ö. Ortliep, in der ThS. c. 360. 379 Aldrian für Eitzels sohn

1) In Dráp findet sich die eigentümlichẹ stelle : en er Gjúkkungar kómu til Atla, bá bap Guprún sonu sína at bokpi Gjükungum lífs, en peir vildu eigi, was Gering (Uebersetzung s. 241) gewiss richtig als einen versuch des liedersammlers ansieht, den kindermord zu motivieren. 
von Kriemhild; ferner im Biterolf 3334 die namen Orte und Erpfe, in der Rabenschlacht 158. 172 u. ö. Orte und Scharpfe, in der ThS. c. 56 Ortvinr und Erpr. Die letzteren sind alle söhne von der Helche bez. Erka: daher gehören diese drei paare nicht in die Nibelungensage, sondern in die Dietrichsage oder genauer in die gotische Attilasage 1), die die historische königin Kreka erhalten hat, aber Kriemhild und die Burgunden nicht kennt. Nun hat ferner Kreka als die erste und ursprüngliche königin und gattin selbstverständlich kinder von Attila; Ildico ist dagegen erst eine später angenommene gattin, mit ihr hat Attila nur eine einzige nacht zugebracht, über die sich bald dunkle gerüchte bildeten: da kann man von vornherein zweifeln, ob Kriemhild nach der ältesten sage überhaupt von Attila kinder hatte.

Wenn nun Kriemhild im NL. ein kind von Etzel hat, das Ortliep, in Akv. und Hm. eines, das Erpr heisst, so liegt der gedanke nahe, dass die namen Ort und Erpf ${ }^{2}$ ) aus der AttilaHelche-sage in die Attila-Kriemhild-sage eingedrungen sind, d. h. in die Burgunden-sage: in Deutschland blieb der name Ort als Ortliep, im norden der name Erpf als Erpr erhalten für je einen sohn Kriemhilds (ähnlich Bugge s.6. 8). ${ }^{3}$ )

Während aber das deutsche NL. eine wirkliche verbindung der gotischen sage mit der Burgundensage zeigt, ist das bei den heldenliedern der Edda bekanntlich noech nicht der fall (auch nicht in Gðkv. III, s. Jiriczek s. 160), es kann also auch in der älteren deutschen sage noch nicht der fall gewesen sein. Wir dürfen also nicht annehmen, dass ein name wie

1). Bugge, der auf die drei paare aufmerksam macht, bringt den namen Erp in zusammenhang mit den Hernac des Jordanes c: 50 (Mommsen s. 127, wo auch ${ }^{5} H \varrho v \alpha \chi$ aus Priscus frg. 36 Muell. citiert wird), Bugge, Erpr og Eitill s. 4 f.

2) Scharpfe ist wol nur eine jüngere volksetymologische umbildung des später nicht mehr verständlichen Erpf.

3) Bleyer leitet freilich (Beitr.31,566 ff.) den namen Ort von dem namen eines Gepidenfürsten Ardarich ab, der in der ungarischen sage zu Kriemhilds und Attilas sohn geworden sei (Aladár). Hier steht wahrscheinlichkeit gegen wahrscheinlichkeit. Ich für meine person möchte mit dieser erklärung nicht rechnen, weil es mir nicht naheliegend erscheint, den. deutschen namensstamm Ort-, der auch in anderen sagen in Ortnît, Ortwîn, Ortrûn auftritt, hier auf diesem wege zu erklären. 
Erpr ${ }^{1}$ ) aus der älteren deutschen sage stamme, sondern müssen hier einmal mit einer späteren, nachträglichen aufnahme eines namens aus deutscher sage rechnen.

Wir sahen, dass die söhne Ortliep und Erpr nicht von jeher der verbindung Kriemhilds mit Attila entstammten. Ebensowenig scheint aber auch der sohn Aldrian von haus aus dieser verbindung $\mathrm{zu}$ entstammen, den ThS. c. 360.379 als Attilas sohn kennt. Denn er trägt einen namen, der sonst in der sage Hagens vater zukommt, ThS. 169 auch Grímhilds vater. Was es mit diesem namen für eine bewantnis hat, werden wir noch unten $(\$ 43) \mathbf{z}$ u erörtern haben.

Nach diesem allen ist es sehr zu bezweifeln, dass die ehe Kriemhilds mit Attila in der ältesten sage überhaupt kinder gezeitigt hat. Wol aber hat in der weiterentwickelten deutschen sage Kriemhild die beiden söhne Helches übernommen, die mehr in den hintergrund trat, obgleich sie und ihre kinder nicht vergessen wurden; den namen des einen sohnes hat das NL. erhalten; der náme des andern ist nach norden gekommen, wo wir ihn in der Akv. B und Hm. finden.

Die sölne Helches hat aber Kriemhild vielleicht erst zu einer zeit übernommen, wo sie in Deutschland nicht mehr die feindin Attilas war, also keinen grund hatte, seine söhne $\mathbf{z u}$ töten. Wir können. jedenfalls nicht behaupten, dass einmal in Deutschland eine sage von einem kindermord Kriemhilds geherscht habe; wir müssen diese sage zunächst als eine specifisch nordische weiterbildung betrachten.

Erst einem jüngern deutschen stadium der sage gehört m. e. die opferung des einen kindes durch Kriemhild an (NL. 1912 dô der. strît niht anders kunde sîn erhaben etc.; ThS. 359; Anh. z. Hb.), durch die der völlig ehrenfeste Etzel zur feindschaft gegen die Nibelungen gedrängt wird. Ich möchte also nicht, wie Wilmanns (a.a.o.s. 8) und Boer (Untersuchungen $1,148)$ vermuten, dass diese opferung des kindes der veränderte überrest einer alten deutschen sage vom kindermord Kriemhilds bedeute, eben weil ich nicht glaube, dass sie in der älteren deutschen sage überhaupt kinder von Etzel hatte.

1) Auf diesen Erpr widerum führt Jiriczek s. 108 den namen des bastards Erpr in der Ermanarichsage (Hampésmól) zurück. 
Ueber die geschichte des mit Erpr alliterierenden zweiten namens Eitill wissen wir gar nichts. - Zu Bugges ableitung s. unten $\S 42$.

Ist nun auch der name Erpr erst nachträglich nach norden gedrungen (s. 270), so werden wir doch annehmen, dass die sage von Guđłúns kindern und ihrem mord im norden älter ist, da wir sie in beiden Atli-liedern (auch den Am., wo der name Erpr fehlt), und Hm. 10 finden. Dann bedeutete also die namengebung der beiden kinder eine neuerung; wahrscheinlich hatten diese frühzeitig getöteten ursprünglich überhaupt noch keine namen: darin mögen die Am. gegenüber der Akv.B das ältere erhalten haben.

$\$$ 42. Die mahlzeit.

Die bewirtung Atlis durch seine gattin findet in der Akv. sofort nach dessen ,rückkehr vom mordplatz statt. In den Am. vergeht bis dahin erst eine zeit (76 svaf ek mjgk sjaldan sípans beir fello), wol deshalb, weil die bewirtung in den Am. als erbmahl (erfi 71. 81, 12) aufgefasst wird (oben s. 219). Die Akv., die diese auffassung nicht hat, mag in der einfacheren form das ältere erhalten haben.

Von der mahlzeit selbst berichtet am einfachsten Akv. 39. Atli hat die herzen seiner söhne mit honig gekaut und davon verteilt; dass er blutgemischten wein getrunken hätte, wird nicht gesagt, ist aber wol mit Gudrúns kelch gemeint, den sie Atli darbringt (36). Ausführlicher berichten die Am. 77 f.: aus den schädeln der kinder hat Guđrún trinkschalen gemacht, blut in den wein gemischt, die herzen am spiess gebraten, als kalbfleisch gereicht. Vs. 38 und Sn. E. 42 geben dasselbe; nur fehlt der zug, dass die herzen als kalbfleisch gegessen werden; ferner werden in Sn. E. die schädelbecher mit gold und silber hergestellt, d. h. überzogen.

Grundtvig (Ausgabe der. Sæm. Edda² s. 248) und Bugge (Erpr og Eitill s. 10) vermuten in dem motiv der schädelbecher einfluss von seiten der Wielandsage." Ich möchte einen solchen für die Am. nicht sicher behaupten, da aus schädelbechern zu trinken bei den Germanen eine verbreitete sitte war (vgl. Alboin und Rosimund, bei den brüdern Grimm, Deutsche sagen s. 278 ff., erzählt nach Paulus Diaconus). Dagegen besteht 
dieser einfluss zweifellos in der Sn. E.42, wo von gold- und silberüberzogenen schädeln die rede ist, ganz wie Vkv. 25. 37.

In der genannten schrift s. 10 vermutet Bugge ferner eine beeinflussung der Am. durch die antike Tereussage, wie sie Ovid, Metam. VI, 636-74 vorliegt. Der name des Itys (des sohnes des Tereus und der Procne) soll ferner quelle des namens Eitill sein. Aber der name Eitill fehlt geeráde in den Am., die Bugge als besonders stark beeinflusst ansieht (er steht in der Akv.B und Hm.); und Ovid spricht auch nur allgemein von dem zubereiteten fleisch des Itỹs, während sich das charakteristische motiv vom verspeisen der herzen schon in der den Am. im alter voranstehenden Akv. A 39 findet.

So halte ich die darstellung der Am. nur für die selbständige ausschmückende weiterbildung einer sage, die in einfacherer gestalt in der Akv. vorliegt.

§ 43. Der Hniflungr der Atlamọ́l.

Am. 83. 84. 86 berichten von einem Niflung, einem sohne Hoggnis, an Atlis hof, der. der Guđrún seinen grimm gegen Atli entdeckt, in ihr die erinnerung an Hǫgnis tötung weckt, von ihr zur rache angespornt wird und sich mit Guđrún in das werk der rache teilt; das letztere berichtet auch Vs. 38 und Sn. E. 42. Woher dieser sohn Hognis kommt, wird mit keinem wort angedeutet.

Einen versuch, diese dunkle gestalt zu erklären, finden wir bei Boer, Arkiv 20,185 ff. Er hält den nachgebornen sohn Hognis in der ThS, 393. 423-27, Aldrian, für einen ursprünglichen sohn der schwester Grímhild von ihrem brüder, den sie vor dessen tod empfangen habe; er erklärt ferner den namen des ersten Aldrian der ThS. (Grimhilds sohn von Attila 360. 379) als eine dunkle erinnerung eben an einen solchen incest, der auf beeinflussung durch die Signýsage deute; endlich dehnt er, allerdings mit vorbehalt (s. 194 f.), diese auffassung auf den Niflung der Am. aus.

Für die jüngeren sagenformen, die in der ThS., dem färöischen Högnilied, der Hìvenschen Chronik, endlich in Grímhilds hævn $\mathrm{C}$ vorliegen, mag diese erklärung von Hognis sohn das richtige treffen. Für die Am. halte ich aber diese erklärung nicht für möglich aus dem grunde, weil wir nicht 
erweisen können, dass in der Am. vor Hognis ende eine nacht vergangen sei, die gelegenheit zur erzeugung geboten hätte. Die str. 63, an die Boer erinnert: doo pbá dýrer, dags vas heldr snimma, legt zwar die annahme einer zwischennacht nahe, aber nach der voranstehenden scene (str. 54-61) müssen wir notwendig doo als plusquamperfect fassen, = 'tot waren sie' (so Gering, übersetzung s. 278). Atli will ja die brüder sofort der todesstrafe ausliefern, um Guđrün zum weinen zu bringen: so müssen wir annehmen, dass Gunnarr sofort zu den schlangen gebracht wird, wenn er auch noch nicht sogleich stirbt, und dass Hogni nach dem kurzen zwischenspiel mit Hjalli sofort das herz ausgeschnitten wird. In str. 61 schliesst sich auch dem entsprechend an Hognis festnahme unmittelbar sein lachen in der todesqual an. Also ist in den Am. für Hoggni zur erzeugung eines rächers im lande Atlis keine gelegenheit. Ich möchte zur erklärung dieses Niflungen überhaupt nicht auf die ThS. und andere jüngere quellen zurückgreifen, sondern eine erklärung desselben aus den Atli-liedern selbst versuchen. Auch in der Akv. wird ein sohn Hognis erwähnt, ein junger erbe $(12,5.6)$, der seinen vater offenbar noch nicht auf die reise begleiten kann. An dieser gestalt, die keineswegs eine blosse zutat des dichters zu sein braucht (s. oben s. 242), wird. die weitere sage angeknüpft haben. Man fragte: was wurde nach dem untergang der Niflunge aus dem überlebenden sohn Họgnis? Für ihn konnte es nur ein amt geben, das des rächers. So liess man Guđ̛ứn die rache aufschieben, bis dieser sohn herangewachsen war: dann kommt er, natürlich heimlich und unerkannt, zum hause Atlis und teilt sich mit Guđrún in das rachewerk: das ist die sage, wie sie in den Am. vorliegt. Ganz ähnlich kommt in der griechischen sage Orest heimlich und unerkannt zum hause Aegisths, um seinen vater zu rächen.

In keinem fall ist diese weiterbildung der sage dem dichter der Am. zuzuschreiben. Er. spricht mit äusserster kürze von dem Niflung, lässt kein wort über dessen vorgeschichte fallen; er setzt also offenbar alles übrige als schon bekannt voraus. Die geschichte gehörte also bereits einer der jüngern nordischen sagenschichten an, ehe der grönländische dichter sie im liede darstellte. 
$\$$ 44. Atlis tod.

Nach Akv. 43. 44 wird Atli, während er sinnlos betrunken (hafpe ópan sik drukket) auf seinem bett liegt, mit dem schwert erstochen. - Nach Am. 84. 85 wird Atli auch im schlaf, aber nicht im rausch, tötlich verwundet. - Dass Atli im bett erstochen werden würde, prophezeit Brynhild Sg. sk. 59; Atli träumt Gðkv. II, 39, von Guđrún erstochen zu werden. — Nach Sn. E. 42 wird Atli nach einem grossen metgelage schlafend getötet; ebenso wird Atli in Vs. 38, nachdem er getrunken hat, schlafend getötet.

Dass Attila in schwerem rausch liegend in beisein eines weibes ums leben kommt, berichtet, wie bekannt, schon Jordanes cap. 49, der sich auf Priscus beruft. Den übergang von geschichtlicher überlieferung zur sage bezeichnen die worte des chronisten Marcellinus Comes, zum jahre 454: Attila rex Hunnorum - - noctu mulieris manu cultroque confoditur; quidam vero sanguinis reiectione necatum perhibent (Monum. Germ. auctores antiquissimi 11 s. 86). Da ausserdem zwei deutsche quellen, Poeta Saxo aus dem 9. jh. und die Quedlinburger Annalen aus dem 11. jh. (Grimm, HS. ${ }^{3}$ s. 10) von Attilas tod durch weibeshand berichten ${ }^{1}$ ), so müssen wir annehmen, dass der in der nordischen sage feststehende blutige tod des königs schon der älteren deutschen sage angehört hat und nicht eine von den geschichtlichen grundlagen unabhängige nordische neubildung ist.

Die Am. haben wider einen alten charakteristischen zug, die trunkenheit, verloren (vgl. Müllenhoff, Zs. fda. 10, 158).

Attilas blutiger tod ist in der deutschen dichtung ganz vergèssen worden; im übrigen gibt es aus deutschen sagen nur einen näheren bericht über Attilas ende: die geschichte vom hungertode Attilas im Sigfridskeller, zu dem Aldrian den könig führt (ThS. 423-426). Auch dem dichter der Klage scheint eine ähnliche sage bekannt gewesen zu sein (2166. 67. 68. 70). Beide züge, die verhungerung Atlis -und der Sigfridskeller, können jedenfalls erst der späteren deutschen sage angehören, da auch in der ältesten deutschen sage Attila

1) Poeta S. (MG. Script. I) lib. II, v. 26-34 (v. 29 vino somnoque gravatum!). - Ann. Quedl. MG. Script. III, s. 32 (Pertz). 
eines blutigen todes stirbt, und der hort in den Rhein versenkt wird. Nachdem in der deutschen sage Etzels tod durch Kriemhild verloren gegangen war, entstand diese sage, die an seine noch von alters her uberlieferte habsucht anknüpfte und den goldgierigen mitten im golde verhungern liess.

§ 45. Guđrúns tod.

Akv. 44 ff. wird erzählt, dass Guđrún nach der ermordung ihres gatten die halle anzündete und alles ausser den hausknechten und hunden verbrannte; über ihr eigenes schicksal wird nichts gesagt. In den Am. findet sich nichts von einem feuer am schluss des gedichts, dagegen wird ausdrücklich gesagt, dass Guđrún weiterlebt (98). Vs. und Sn. E. berichten beide vom hausbrand, zugleich aber vom fortleben Guđrúns, indem sie ausführlich die Ermanarichsage anschliessen. Von Guđrúns fortleben weiss, ausser Ghv. und Hm., noch Sg. sk. 61 ff.

Es ist zunächst zu fragen, wann und wie starb Guđrún in der älteren sage?

Was die deutsche sage in ihrer ältesten form über die art berichtete, wie die mörderin Attilas starb, können wir nicht mehr wissen. Soviel ist aber sicher, dass in den beiden vorliegenden deutschen fassungen Kriemhild da stirbt, wo die Nibelungensage zu ende ist: im NL. durch Hildebrand, in der ThS. durch Dietrich; von einem weiteren fortleben weiss die deutsche sage nichts.

Dafür nun, dass auch in der altnordischen sage Guđrún Atlis tod nicht überlebt habe, spricht zunächst zweierlei: einmal ihr versuch des selbstmords, der nur durch ein naturwunder vereitelt wird: sie stürzt sich ins meer, um sich zu ertränken, aber die wogen tragen sie zum lande Jónakrs (Sg. sk. 61, 5 ff. Ghv. 13. Vs. 39, wo sie noch vorher steine in den busen tut; Sn. E. 42); zweitens die parallelität von Signýs tod Vs. cap. 8; denn wie man auch über das verhältnis der Guđrúnsage zur Signýsage denken mag, eine wechselbeziehung muss man in jedem fall annehmen; s. unten $\S 46$. Auch in der Signýsage wird die halle angezündet, und Signý stirbt freiwillig mit dem gehassten gatten. - In der altnordischen sage war im übrigen nicht der geringste grund gegeben, Guđrún fortleben $\mathrm{zu}$ lassen: vielmehr forderte das gefühl für die 
blutbefleckte und vereinsamte den tod, als sühne wie als erlösung.

Dass nun Guđrún nach der Edda gerettet wird und weiterlebt, hat seinen grund einfach darin, dass ihre tochter Svanhild den Jormunrekkr heiraten soll: dass also die Ermanarichsage angeschlossen worden ist. Dieser anschluss ist specifisch nordisch (genauer norrön) und erst im norden erfolgt: in Deutschland findet sich die sage von Ermenrîch nirgends mit der Nibelungensage verknüpft. Es gab demnach auch im norden zunächst eine zeit, wo dieser anschluss noch nicht erfolgt war: damals wird Gưđrún sogleich nach Atlis ermordung gestorben sein. Und zwar sicher in den von ihr sellbst entzündeten flammen, wie Signý in einem saalbrand (Jiriczek, Deutsche heldensage, sammlung: Göschèn s. 55).

Dann bog man den schluss der sage um: Guđrún musste noch eine dritte ehe eingehen. Und nun liess man Gựirún einen sprung ins wasser (statt in die flammen) tun, damit die wogen sie zu einem neuen strande tragen könnten, während sich bei dem hausbrand keine rettung anknüpfen liess.

Es ist weiter zu fragen: wie verhalten sich Akv. und Am. gegenüber der sage?

Ranisch (Eddalieder, sammlung Göschen s. 138) nimmt an, dass nach Akv. 45 eine strophe weggefallen sei, in der erzählt wurde, wie Guđrún sich selbst in die flammen gestürzt habe. Für diese annahme spricht $\mathrm{m}$. e. deutlich erstens die tatsache, dass Guđrún Akv. 42 ihr gold an die knechte verschenkt, ganz wie eine, die auf der welt nichts mehr zu suchen hat '); man vergleiche die stelle der Sigurparkvipa (48ff.), wo die sterbende Brynhild ihr gold verschenkt. Ferner spricht dafür die ausdrucksweise der schlussstrophe 46

$$
\begin{aligned}
& \text { hón hefr priggja pjópkonunga } \\
& \text { banorp boret bjort, ápr sylte. }
\end{aligned}
$$

Wozu die erwähnung ihres todes, wenn derselbe jetzt noch gar nicht eintritt?

Da.str. 42 der Akv. A, str. 46 der Akv.B angehört, so ist

1) In Am. scheint dieser zug erhalten, aber wegen des veränderten schlusses ümgedeutet und vom schluss weggerückt worden zu sein: Guđrún schleudert aus erregung ihre halskleinode weg, als sie vom ausbruch des kampfes hört (Am. 43). 
anzunehmen, dass in den beiden alten parallelliedern von Guđrúns tod die rede war; welchem die ausgefallene strophe gehörte, können wir nicht wissen. Diese strophe hat wahrscheinlich niemand anders als der sammler der Eddalieder entfernt: der darstellung von Guđrúns tod an dieser stelle der sage widersprach für ihn der inhalt von Ghv. und Hm., wo Guđrún noch lebte: darum mag er sich am text vergriffen haben.

Da Am. 98 ein fortleben Guđrúns ausdrücklich behauptet wird:

fróp vilde Guprún fara sér at spilla, urpo dvęl dógra, dó i sinn annat.

so muss hier die verbindung von Nibelungensage und Ermanarichsage als schon eingetreten vorausgesetzt werden, während sich in der Akv. keine spur davon findet.

Dass sich in dem saalbrand, den Kriemhild in NL. und ThS. entfacht, eine erinnerung an einen abschliessenden brand in der älteren deutschen sage erhalten habe, auf den der nordische zurückgehe, ist mit Wilmanns (Untergang der Nibelunge s. 8) als möglich anzusehen, aber nicht als sicher. Da wir ausserhalb der nordischen sage einen solchen abschliessenden brand nicht finden, werden wir diesen zug zunächst als specifisch nordisch ansehen müssen.

§. 46. Guđrún und Signý.

Anschliessend an Guđrúns tod müssen wir zu der frage stellung nehmen, wie sich die gestalten der Guđrún und Signý zu einander verhalten: da sie bekanntlich in verschiedener hinsicht parallele züge zeigen, so kann man den gedanken an eine beziehung nicht ablehnen.

Rieger (Germania 3, 196 ff.) hielt die gestalt Guđrúns, wie wir sie im norden finden, für stark beeinflusst durch die gestalt Signýs. In der ältesten sage hätte die gattin den gatten rächen müssen: die von der deutschen sage verschiedene stellung der schwester zu ihren brüdern sei der einwirkung der Signý-sage zuzuschreiben. Rieger sah darin eine benachteiligung der sage: alles was bei Signý richtig und angemessen sei, sei bei Guđrún verkehrt und widrig.

Wir können die gestalt Signýs nicht aus dem zusammenhang der sage lösen, wie sie in der Vs. cap. 4-8 erzählt wird. Diese ganze geschichte zeigt nun überhaupt eine so starke 
ähnlichkeit mit der vom untergang der Nibelunge und von Atlis ende, dass man zu dem schluss getrieben wird, eine der beiden geschichten sei von der andern abhängig. Folgende züge sind parallel (z. t. schon von Jiriczek, Deutsche heldensage Göschen s. 79 hervorgehoben):

1) Siggeirr lädt den ihm verschwägerten Volsungr ein und überfällt ihn verräterisch (Vs.4. 5), wie Atli die Niflunge.

2) Signý ahnt unheil, ehe sie in Siggeirs haus kommt (Vs.4), wie Guđrún, ehe sie sich mit Atli vermählt (Gðkv. II, 32).

3) Signý warnt die Wölsunge (Vs.5), wie Guđrún ihre brüder.

4) Siggeirr gibt die überlebenden einem grausamen tod preis (Vs.5), wie Atli die beiden Niflunge.

5) Die mutter Siggeirs mordet als wölfin (Vs.5), die mutter Atlis als schlange (Odrgr. 30).

6) Signý lässt ihre söhne von Siggeirr töten (Vs.6. 8), Guđrún tötet ihre söhne von Atli.

7) Signý betreibt Siggeirs tod (Vs.7), Güđrún den Atlis.

8) Signý stirbt mit dem gehassten gatten im feuer (Vs. 8), Guđrún einst ebenfalls (s. oben s.276).

Welche der beiden geschichten hat auf die andere eingewirkt?

Zunächst wollen wir fragen, welche der beiden sagen, die in Vs. cap. 4-8 erzählte oder der zweite teil der Nibelungensage, die ältere ist.

Die erzählung von der einladung der Nibelunge durch Attila und ihren untergang bei ihm steht als einer der ältesten bestandteile der sage fest. Dasselbe gilt von der erzählung, dass Attila durch weibeshand seinen tod gefunden habe.

Was nun die andere sage betrifft, so sind die gestalten Sigmund und Sinfjotli in der sage alt, wie Beowulf 876.880 und Eiríksmọl 4 zeigen; ausserdem erscheinen sie in beiden liedern von Helgi Hundingsbani. Aber irgendwelche an den zweiten teil der Nibelungensage erinnernde geschichten finden wir vor der Vs. nirgends mit ihrem namen verknüpft. Von Signý findet sich dagegen vor der Vs. nicht einmal der name (während Siggeirs name wenigstens erwähnt wird HHb. I, 43); ebensowenig von Volsungr, dessen name, der sicher erst vom geschlechtsnamen der Volsungar abgeleitet ist, von vorherein keinen anspruch auf alter in der sage hat. 
Nun sind aber ausser Siggeirr gerade Signý und Vqlsungr diejenigen gestalten, auf denen die übereinstimmung der sage mit dem zweiten teil der Nibelungensage heruht. Signý ahnt das unheil voraus, Signý warnt die Wölsunge, Signý opfert ihre söhne der rache, Signý betreibt des gatten tod, Signý stirbt mit dem gatten im feuer; Volsungr ist der schwäher, er wird eingeladen und verräterisch überfallen.

Das führt mich dazu, die Signý-Volsungr-sage als jünger anzusehen als den zweiten teil der Nibelungen-sage.

Nun könnte ja an sich die jüngere sage in einzelnen zügen auf die ältere eingewirkt haben: das anzunehmen haben wir aber keinen grund. Die s. 277 angeführten urteile Riegers kann ich nicht teilen. Der zweite teil der nordischen Nibelungensage ist so scharf vom ersten und von der Sigfrid-sage getrennt, so in sich geschlossen, dass die rolle der Guđrún nicht weniger verständlich ist als die der Signý. Und dass der zweite teil so scharf vom ersten getrennt bleiben konnte, wird verständlich, wenn wir mit Wilmanns (a.a.o.s.3) annehmen, dass in der ältesten sage Kriemhild noch gar nicht die gattin Sigfrids war.

Daher möchte ich die Signý-Volsungr-sage, soweit sie mit der sage vom untergang der Niflunge und von Atlis tod übereinstimmt, geradezu als eine copie der letzteren ansehen, wobei man den Siggeirr nach dem bilde Atlis zeichnete.

Dass die sage trotzdem älter ist als die Vs., ist-über jeden zweifel erhaben. Müllenhoff, Zs. fda. 23, 129 ff. 151 und Symons, Grundriss 32, 653 haben schlagend nachgewiesen, dass dem sagaschreiber auch hier lieder vorgelegen haben, von denen er sogar in cap. 8 ein fragment citiert.

Was speciell die gestalt der Signý betrifft, so vermute ich nach dem oben gesagten, dass sie nach dem bilde Guđrúns gezeichnet worden ist, wie es in der älteren sage stand.

Wenn nun die an Guđrún erinnernden züge Signýs jung sind, so ist damit noch nicht gesagt, dass die ganze gestalt Signýs ebenso jung ist. Ich glaube vielmehr, dass es schon eine ältere sage von einer schwester Sigmunds gab, die von ihrem bruder einen sohn gebar: den incest sehe ich als den alten kernpunkt dieser sage an: welchen sinn und zweck er ursprünglich hatte, können wir nicht wissen. Der dichter von 
HHb. I mag von dem incest gewusst haben: stjuppr vast Siggeirs (45); vielleicht kannte er sogar schon die lieder, die der Vs. cap. 4-8 zu grunde lagen.

Für mich kam es hier nur darauf an festzustellen, dass wir für die gestalt der Guđrún nicht beeinflussung von seiten der Signýsage anzunehmen haben, dass vielmehr das entgegengesetzte verhältnis besteht.

\$ 4\%. Guđrúns stellung zu ihren brüdern.

In bezug auf Guđ̛̣ún müssen wir noch auf eine andere frage eingehen, đie von Wilmanns angeregt worden ist (Untergang der Nibelunge s. 7, § 7). Wilmanns bezweifelt nämlich, ebenso wie Rieger, dass die stellung der schwester zu den brüdern, wie sie die nordische sage zeigt, in jeder hinsicht schon der älteren deutschen sage eigen gewesen sei. Während die nordische sage die schwester nur als die beschütżerin und rächerin ihrer brüder kennt, ist sie in der deutscchen Nibelungensage deren feindin: Wilmanns macht auf die schwierigkeit aufmerksam, wie von einer der nordischen fassung gleichen grundlage die spätere deutsche sage entstanden $\mathrm{zu}$ denken sei. Vielmehr nimmt er an, dass schon in der älteren deutschen sage Kriemhild ihren brüdern feindlich gesinnt gewesen sei und als die eigentlich handelnde Etzel zum mord veranlasst habe: aber nicht um der gattenrache willen, wie Rieger meinte (die verbindung Kriemhilds mit Sigfrid hält Wilmanns nicht für ganz ursprünglich s. $3, \S 2$ ), sondern aus habgier: die tochter des geizigen Nibelungengeschlechts habe den : hort für sich begehrt: daher habe sie Etzels habgier gereizt, der schon ursprünglich eine mehr passive rolle gespielt habe. Für ihre habgier zeugen ihre zwei fragen nach dem schatz im NL., 1739 ff. (dazu ThS. cap. 373) und 2367: am stärksten die. letztere an Hagen, dem sie gegen auslieferung des schatzes das leben verspreche. So habe in der älteren deutschen sage Kriemhild aus habgier die brüder vernichtet. Dạn aber habe sich der harte sinn des weibes gegen Etzel gewendet: sie habe alsdann der pflicht der blutrache an ihm genügt.

Auf die geschichtlichen grundlagen der sãge, die gegen eine solche passivität Etzels sprechen würden, möchte ich mich hier nicht berufen, da Wilmanns diese grundlagen als solche 
bezweifelt, s. 1 f. Dagegen möchte ich betonen, dass auch Wilmanns' auffassung insofern eine beträchtliche schwierigkeit bietet, als sie nicht erklärt, wie der plötzliche umschwung in der sinnesart Kriemhilds zu denken sei. Ausserdem lässt sich aber das, was das NL. über Kriemhilds habgier andeutet, leicht anders erklären. Etzel, ursprünglich der habgierige (s. oben s. 257. 259), trat in der sage unter dem einwirken verschiedener factoren in den hintergrund, sodass er mehr passiv und schliesslich ganz fleckenrein wurde (NL.): auf Kriemhild, die die eigentlich handelnde wurde, gieng mit der mordlust zugleich etwas von Etzels habsucht über, die ja in einer sage, wo der Nibelungenhort eine rolle spielte, nie ganz in vergessenheit geraten konnte. Insofern erkennt Wilmanns mit recht an den stellen, wo Kriemhild nach dem schatz fragt, einen alten zug: nur gehörte dieser ursprünglich nicht Kriemhild, sondern Etzel an.

Daher halte ich die stellung der schwester $\mathrm{zu}$ ihren brüdern, wie die nordische sage sie zeigt, für schon aus der älteren deutschèn sage überkommen.

\$ 48. Zusammenstellung der ergebnisse.

Nach unseren bisherigen untersuchungen müssen wir zunächst für die altnordische sage vom untergang der Niflunge folgende züge ansetzen i):

Gjúki, könig der Borgunden am Rhein (Akv.), aus dem geschlecht der Niflunge, hat drei kinder hinterlassen: Hoqgni, Gunnarr, Guđrún. - Hogni nimmt eine gewisse hervorragende stellung ein (Am.) und hat nachkommenschaft. - König Atli von Húnmork (Akv.), aus dem geschlecht der Buđlunge, dessen reich südlich von dem Gunnars liegt (Akv.), hat Guđrún zur gattin, - die früher Sigurđr besessen hatte (Am.). - Atli begehrt der Gjúkunge gold, das erbe der Niflunge (Akv.) und lädt diese ein, ihn zu besuchen, indem er hoffnung auf geschenke erweckt. - Vor der abreise haben frauen unheilverkündende träume (Am.). - Die grenze gegen Atlis reich bildet wasser (Am.). - Auf der fahrt begegnen schlimme vorzeichen (Am.). - Nach der landung befestigt man das

1) Wo in dieser zusammenstellung der altnordischen sagenzüge keine quelle genannt wird, sind beide Atli-lieder als übereinstimmend gemeint. 
schiff nicht (Am.). - In Atlis halle angelangt, werden die brüder von der schwester gewarnt (Akv.A). - Atli fordert in güte den schatz von ihnen; ablehnung (für Akv. zu ergänzen aus Vs. 36). - Kurzer kampf im saal, wobei Hogni sich auszeichnet (Akv.). - Gefangennahme beider brüder. Zweite frage an Gunnarr, ob er den schatz herausgeben wolle, um sein leben zu lösen (Akv.). - Er will erst Hognis herz sehen (Akv.). - Man schneidet einem Hjalli das herz aus und bringt es Gunnarr, er erkennt es als das herz eines feigen (Akv.). - Man schneidet Hogni das herz aus; er lacht. Gunnarr weiss den schatz im Rhein verborgen; gibt seinen ort nicht an (Akv.). Der schatz stammt von den asen (Akv.). Gunnarr wird in einer grube (Akv.) schlangen übergeben, spielt harfe, stirbt als letzter. - Guđrún tötet ihre und Atlis söhne und bewirtet diesen mit den herzen derselben. - Sie sagt Atli, was er gegessen hat. - Guđrún verschenkt kostbarkeiten (Akv.). - Sie ersticht den schlafenden Atli, - wie er im schweren rausch liegt (Akv.). - Guđrún zündet die halle an (Akv.) und stirbt in den flammen (für Akv. zu ergänzen aus verschiedenen anzeichen).

Dem seien nụ im folgenden die bedeutenderen abweichungen der einzelnen Atli-lieder entgegengestellt:

Akv. Gunnarr ist ganz zur hauptperson gesteigert 'gegenübẹr Hogni. Es fehlen die träume der frauen, denn die reise beginnt anscheinend gleich nach der einladung. Nicht wasser als grenze gegen Atlis reich, sondern der Myrkviđr, demnach keine wasserfahrt.

Die söhne Atlis heissen Erpr und Eitill (B).

Die brüder werden nicht mehr persönlich von der schwester, sondern durch ein symbol (wolfshaar) gewarnt (c).

Am. Es fehlt der Burgundenname, der Rhein (die Niflunge sitzen am Limafjord, dem grenzwasser gegen Atli), der Hunnenname in verbindung mit Atli (während Sigurðr der hunnische heisst); das Niflungengold. Runenstäbe werden übersant zur warnung, der bote fälscht sie eigenmächtig. Bei Atlis gehöft verhöhnt der bote die Niflunge, wird getötet: äusserer anstoss zum kampf. Der kampf findet ausserhalb des saales statt, lang ausgedehnt; Guđrún ist beteiligt. Atlis begierde nach dem gold und fragen nach dem gold fehlen, ebenso das gold selbst. Der grund von Atlis verräterischer einladung ist ganz dunkel. Atli hat Guđrúns mutter und schwestertochter getötet. Mit der frage Atlis fällt auch die bedingung Gunnars weg, die Hjalli und Hǫgni das leben kostete. Die grausame tötung der brüder ist wesentlich unmotiviert; ebenso unmotiviert, wozu Hjalli zuerst das herz ausgeschnitten werden soll. Hjalli kommt mit dem leben 
davon. Die schlangen befinden sich am galgen, die schlangengrube fehlt. Es verstreicht eine zeit bis zum erbmahl, dann wider bis zum heranwachsen des rächers. Ein Niflung, HQ̣gnis sohn, erscheint: mit ihm zusammen führt Guđrún das rachewerk aus; von seinem rausch ist nichts gesagt. Der hausbrand fehlt. Guđrun lebt weiter.

Wie wir sehen, sind die abweichungen der Akv. von der altnordischen sagenform gering, die der Am. beträchtlich. Wie viel von allen abweichungen der einzelnen lieder den dichtern, wie viel einer ihnen schon vorliegenden jüngeren sagenform zufällt, ist unmöglich zu entscheiden. Darum sind hier nur die bedeutenderen abweichungen zusammengestellt worden, bei denen doch eine möglichkeit besteht, dass sie schon einer jüngeren sagenform angehörten.

Da wir die grenze zwischen der jüngsten tradition und der subjectiven erfindung der dichter nicht bestimmen können, so müssen wir im weitern auf den versuch verzichten, ihr literarisches eigentum festzustellen.

Trotzdem zeigen die angeführten abweichungen der Am., namentlich die beträchtlichen verluste gegenüber der altnordischen sage, dass in den Am. mehr vorliegt als subjective umbildung der sagenzüge durch einen dichter: dass vielmehr die sage selbst stark in verwirrung, verdunkelung geraten war, ehe sie der dichter ergriff; dass man sich namentlich über die motive und zusammenhänge der handlungen in Grönland nicht mehr klar war.

Hätte der dichter der Am. die Akv. gekannt, so wären für ihn mit einem schlage alle unklarheiten aufgehellt gewesen, die bei ihm zu tage treten. Gerade diese verworrenheit und dunkelheit der zusammenhänge ist für mich der stärkste grund dafür, anzunehmen, dass der dichter der Am. die Akv. nicht gekannt hat. (vgl. s. 231).

Anhangsweise sei noch kurz das verhältnis der altnordischen sage $\mathrm{zu}$ der älteren deutschen sage dargelegt.

Von den zügen der altnordischen sage gehörten schon der älteren deutschen sage folgende: .

Gibich ${ }^{1}$ ) (W'altharius u. ö.), könig der Burgunden (NL.) am Rhein, hinterlässt einen sohn Gunther (an dessen hof Hagen), und eine tochter.

1) Im folgenden ist nicht der versuch gemacht, die althochdentschen oder altniederdeutschen formen $\mathrm{zu}$ reconstruieren. 
- Hagen ist eine hervorragende persönlichkeit. - Etzel, könig eines südlichen Hunnenreiches (Waltharius), aus dem geschlecht der *Botelunge (Botelunc heisst sein vater NL. 1314. 1372) hat die schwester zur gattin, die früher Sigfrid besessen hatte (NL. ThS.). - Gunther besitzt einen schatz, der Nibelunges hort heisst (NL.). - Etżel begehrt nach dem schatz und lädt Gunther und Hagen zu sich ein. - Vor der abreise träumt eine frau von unheil (NL. ThS.). - Die Burgunden ziehen über ein wasser (NL. ThS.). - Auf der fahrt begegnen schlimme vorzeichen (NL. ThS.). - Nach der landung machên sie sich die rückkehr unmöglich (NL.). Bei Etzel angelangt, werden die helden von Günthers schwester gewarnt. - Etzel fordert in güte den schatz von ihnen; ablehnung. - Kampf in einem saal (NL. ThS. II), wobei Hagen sich auszeichnet (NL. ThS.). Gefangennahme der helden (NL. ThS.). - Frage an den einen der beiden, ob er den schatz herausgeben wolle; er weigert sich es zu tun, solang der andere lebt; man tötet diesen; der überlebende gibt den schatz nicht heraus; der schatz ist im Rhein versenkt worden; der überlebende wird getötet (NL.) - Einer der beiden endet in einem schlangengehege (ThS.). - Nach einem gelage wird Etzel von seinem weib erstochen, während er im rausch schlafend liegt.

Von diesen sagenzügen sind in deutscher sage nicht erhalten, aber aus nordischer zu reconstruieren folgende:

Etzel begehrt den schatz ( $A \mathrm{kv}$.), die schwester warnt den bruder (Atli-lieder), Etzel fordert den schatz (Ak (Atli-lieder), im rausch (Akv.).

Gegenüber dieser älteren deutschen sagenform sind folgende züge der altnordischen sage specifisch nordisch:

Niflungar als geschlechtsname für die Gjúkunge. Guđrún als name für die schwester. HQ̨gni ist der bruder Gunnars ${ }^{1}$ ), hat nachkommenschaft. Atli lockt durch aussicht auf geschenke. Die entscheidende frage nach dem schatz richtet sich an Gunnarr. Der schatz stammt von den asen. Hogni wird das herz ausgeschnitten; er lacht. Hjalli. Gunnar spielt harfe und stirbt als letzter. Guđrún hat söhne von Atli, tötet sie und bewirtet Atli mit ihren herzen, enthüllt ihm darauf, was er gegessen hat. Sie verschenkt kostbarkeiten, zündet die balle an und stirbt in den flammen.

1) Da im Sigfridslied (175. 177. 179) und Anh. z. Hb. Gunther und Hagen brüder und söhne Gibichs sind, so könnte man annehmen, dass dieser zug schon der älteren deutschen sage angehört hätte, wenn nicht der Waltharius (27 ff. 629 ff.) diese annahme unmöglich machte. 


\section{Inhalt.}

I. Literarischer teil . . . . . . . . . . . . . .

1. Vorfrage s. 193 (§ 1. Winheitlichkeit der Atlamól. § 2. Das alte fornyrðislag in der Atlakvipa (B). § 3 . Die interpolation c. $\S 4$. Das junge fornyroislag (d). \$ 5 . Zusammensetzung der Atlakripa).

2. Stilistische eigentümlichkeiten s. 205. (§ 6. Eigentümlichkeiten im wortschatz. \$ 7. Adjectivische epitheta, variationen. § 8. Epische und prosaische sprache. § 9. Schlussbemerkung).

3. Poetische eigentümlichkeiten s. 217. (§ 10. Darstellung im allgemeinen. $\S 11$. Zeit und ort. $\$ 12$. Charakterzeichnung. § 13 . Lyrisches und rhetorisches element. $\S 14$. Hervortreten des dichters. § 15. Schlussbemerkung).

4. Einige literaturgeschichtliche fragen s. 230. (§ 16. Beziehungen der lieder zu einander. § 17. Das relative alter der lieder. $\$ 18$. Die bezeichnung en grónlenzka, grónlenzko. \$19. Heidnische und christliche urheberschaft. $\S 20$. Beziehungen $z$ wischen den Atli-liedern und anderen heldenliedern der Edda).

II. Sagengeschichtlicher teil . . . . . . . . . . . .

(§ 21. Vorbemerkung. § 22. Das gemeinsame im inhalt. § 23. Gunnarr und Hegni. § 24. Burgunden und Goten. $\S 25$. Hunnen und Húnmork. § 26. Atlis boten. \$ 27. Gnitaheide. § 28. Der Myrkviđr und die grenze gegen Atlis reich. § 29. Warnung und begrüssung durch die schwester. $\S 30$. Die träume der frauen. $\$ 31$. Unheilvolle zeichen auf der fahrt. \$ 32 . gorbot far festa. $\S 33$. Der kampf. § 34 . Atlis fragen nach dem gold. $\S 35$. Der tod der schwester Atlis. $\S 36$. Abschliessendes über Atlis motiv. § 37. Die herkunft des goldes. $\$ 38$. Die versenkung des goldes in den Rhein. \& 39. Hognis herz, Hjalli. \$ 40. Die schlangengrube. \$ 41. Atlis und Guđrúns söhne. § 42 . Die mahlzeit. § 43 . Der Hniflungr der Atlamọl. § 44. Atlịs tod. § 45 . Guđrúns tod. § 46. Guđrún und Signý. § 47. Guđrúns stellung zu ihren brüdern. \$ 48 . Zusammenstellung der ergebnisse). 